TA 7

C6
CER $72 / 73-27$
CODY 2

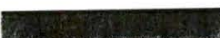

\title{
LAYERED BEAM SYSTEMS WITH INTERLAYER SLIP
}

M. F. Ko

J. R. Goodman

M. D. Vanderbilt

M. E. Criswell

J. Bodig

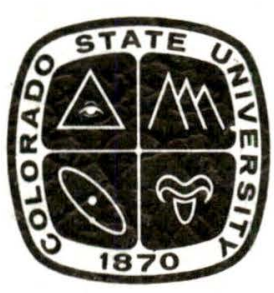

Structural Research Report No. 8 Civil Engineering Department

Colorado State University

Fort Collins, Colorado 80521

December, 1972 
M. F. Ko

J. R. Goodman

M. D. Vanderbilt

M. E. Criswell

J. Bodig

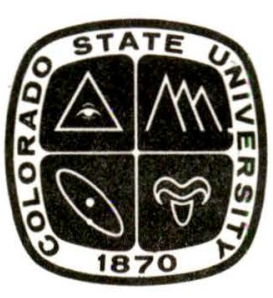

Structural Research Report No. 8 Civil Engineering Department Colorado State University Fort Collins, Colorado 80521

December, 1972 
ABSTRACT

LAYERED BEAM SYSTEMS

WITH INTER LAYER SLIP

This report describes a portion of a study on wood joist floor systems. The objective of this portion of the study is to develop a general theory for the analysis of the layered beams within the system including the effects of interlayer slip.

The development leads to the governing equations for beams having a single axis of symmetry and an arbitrary number of layers and fastened together with mechanical connectors. Solutions to the governing equations are presented in closed form and in finite difference approximation. These solutions show the effect of interlayer connection on the deflection. In all cases, consideration is given to variation of properties along the beam length.

The results of some tests are presented. The proposed theory is shown to agree favorably with the results obtained in the tests.

Meng-Fang Ko

Civil Engineering Department Colorado State University

Fort Collins, Colorado 80521

December, 1972 
TABLE OF CONTENTS

Chapter

$\underline{\text { Page }}$

1 INTRODUCTION AND LITERATURE

REVIEW . . . . . . . . . . . . 1

1. 1 Introduction . . . . . . . . . . . 1

1. 2 Literature Review . . . . . . . . . 3

1. 3 Notation ............ 13

2 THEORETICAL DEVELOPMENT . . . . . 14

2. 1 Introduction ............ 14

2. 2 Theoretical Development ....... . 14

2. 3 The General Equations for $m$

Layered Systems with Uniform Load . . 27

3 TWO LAYERED SYSTEMS . . . . . . . 30

3. 1 Introduction ............ 30

3. 2 Closed Form Solution for Beam with Uniform Load . . . . . . 30

3. 3 Finite Difference Approach for Beam with Uniform Load . . . . . . 38

3. 4 Example Problem for Beam with Uniform Load . . . . . . . . . . 44

3. 5 Closed Form Solution for Beam with Concentrated Load . . . . . . . 52

3.6 Finite Difference Approach for Beam with Concentrated Load . . . . 57

3. 7 Example Problem for Beam with Concentrated Load . . . . . . . . 61

4 THREE LAYERED SYSTEMS . . . . . . 71

4. 1 Introduction ............. . 71

4. 2 Closed Form Solution for Beam with Uniform Load . . . . . . . . 71

4. 3 Finite Difference Approach for Beam with Uniform Load ........ 
4. 4 Example Problem for Beam with Uniform Load . . . . . . . . . 88

4. 5 Closed Form Solution for Beams with Concentrated Load . . . . . . 88

4.6 Example Problem for Beam with Concentrated Load . . . . . . . . 98

5 RESULTS OF BEAM TESTS ........

5. 1 Introduction ............

5.2 Connector Modulus . . . . . . .

5. 3 Test Results ...........

6 CONCLUSIONS . . . . . . . . . . .

APPENDICES .....................

APPENDIX I REFERENCES .......

APPENDIX III- 1 EXPRESSION OF HIGH

ORDER DIFFERENTIAL

TERM DERIVED FROM

TAYLOR SERIES EXPANSION .

APPENDIX III-2 BOUNDARY CONDITIONS FOR THREE LAYERED BEAM WITH UNIFORM LOAD .... 


\section{LIS T OF TABLES}

Table

Page

3. 1 Deflections with Uniform Load vs

Connector Modulus . . . . . . . . . . 50

3. 2 Deflections with a Load at Midspan

vs Connector Modulus .......... . 65

3. 3 Deflections with a Load at $L / 3$

vs Connector Modulus ........... 66

4. 1 Deflections with Uniform Load

vs Connector Modulus . . . . . . . . . . 90

4.2 Deflections, Axial Forces and

Deflection Ratio vs Connector

Modulus for Load Applied at Midspan . . . . . . 99 


\section{LIST OF FIGURES}

Figure

Page

1. 1 Layered Beam with Interlayer Slip

According to Granholm . . . . . . . . . 4

1.2 Two Equal Layered System .......... 8

2. 1 Five Layered Example of $\mathrm{m}$

Layered System . . . . . . . . . . 15

2. 2 Matrix Operator for an $m$ Layered System . . . 28

3.1 Two Layered System ............ 31

3.2 Boundary Conditions ............. 40

3. 3 Matrix Formulation for Finite

Difference Solution for F . . . . . . . 43

3. 4 Matrix Formulation for Finite

Difference Solution for $\mathrm{y}_{\mathrm{s}}$. . . . . . . . 45

3. 5 Two Layered System with Uniform Load . . . . 46

3.6 Deflection Ratio vs Connector Modulus

with Uniform Load . . . . . . . . . . 51

3. 7 Axial Force and Deflection Shape ....... 53

3. 8 Two Layered System with Con-

centrated Load. . . . . . . . . . . . 54

3.9 Matrix Form of $F$ for Finite Difference

Solution by Concentrated Load . . . . . . 60

3. 10 Matrix Form of $\mathrm{y}_{\mathrm{s}}$ for Finite Difference

Solution by Concentrated Load . . . . . . . 62

3. 11 Deflection Ratio Curve for Varying

$\mathrm{k}$ Values with Concentrated Load........ 67

viii 
3.12 Axial Force and Deflection Shape . . . . . . 68

3. 13 Deflection Ratio vs Effective Con-

nection for Any Point Loaded Simply

Supported Beam ............. 70

4.1 Three Layered System ........... . . 72

4. $2 \mathrm{H}$ Matrix............... 87

4. 3 Three Layered System with

Uniform Load . . . . . . . . . . . . . .

4.4 Deflection Ratio Curve for Varying

k Values with Concentrated Load . . . . . . 100

5. 1 Force-Slip Curve for Connectors . . . . . . 102

5.2 T-Beam Test Tl-8D16-1 .......... 104

5.3 Test Results of Tl-8Dl6-1 ......... 106

5.4 T-Beam Test T2-8D48-1 .......... 107

5.5 Test Results of $\mathrm{T} 2-8 \mathrm{D} 48-1$.......... 108

5.6 T-Beam Test T4-8D16-1 .......... 109

5.7 Test Results of T4-8D16-1 ......... . 111

5.8 T-Beam Test T5-8Dl6-1 .......... 112

5.9 Test Results of T5-8D16-1 ......... 113 


\section{CHAPTER 1}

\section{INTRODUCTION AND LITERATURE REVIEW}

\section{1 Introduction}

Layered systems have become an important structural component in modern engineering construction. Well known examples of this construction system include "sandwich" structures, which combine high-strength facings with a light weight core, constructed of various materials and composites. An important application of this concept in wood constructions is where laminated beams and wood joists are commonly used. These layered structures are fastened together by nailing, gluing or by the combination of these two. Layered plate and shell systems have also been constructed by these techniques.

The procedures presently used to analyze this type of construction are generally based on the assumption of rigid connections between layers or on neglecting the composite action. If the layers are fastened together with very stiff adhesives, the rigid interconnection assumption is reasonable. This fact was borne out by such diverse studies as Calcote (3)*, Abel (4), Hoff and Mautner (5),

*Numbers in the parentheses correspond to references listed in Appendix I. 
Raville, Ueng and Lei (6) and Ross, Ungar and Kerwin (7). But for some widely used systems such as nailed wood construction, the as sumption of either rigid connections or no connections is not reasonable. Interlayer movements have been shown to produce significant effects on the overall deflection of structures using nails for connection of the layers (1), (2), (13), (14), (15), (16), (17).

The objective of this study is to develop a general theory for the analysis of layered beam systems including the effect of interlayer slip. The governing equations are developed for various cases of interest. A numerical solution technique is presented to give approximate answers which include the effect of variation of beam and connector properties along the beam length. Closed form solutions for beams with constant properties along their length are also presented.

Experimental verification of the theoretical developments was sought to confirm the proposed methods of analysis. Results of tests on several beam systems are presented and show satisfactory agreement between experiments and theory. This work is particularly applicable to wood systems but is also applicable to other types of layered or composite construction utilizing mechanical connections. 


\section{2 Literature Review}

In this section a brief review of the previous developments related to this study is presented. Additional comments concerning some of these works are treated in more detail in later sections.

The behavior of layered beam systems has been treated by several authors. These works were developed separately but have been shown to be generally equivalent.

Granholm (8) developed a theory for layered beam systems including the effect of interlayer slip. His theory is based on the following assumptions:

1. The connector spacing is constant.

2. The effect of the connectors can be uniformly distributed along the length of the beam.

3. Linear variation exists between the force on a connector and its deformation.

The second assumption implies a smoothing out of the discrete connection effects along the entire length of the beam. These assumptions lead to the following governing equations for a twolayered system shown in Figure 1.1 where each layer has the same cross-sectional properties.

$$
\frac{d^{2} \Phi}{d x^{2}}-\frac{2 b k^{\prime}}{E A} \Phi=r \frac{d^{3} y}{d x^{3}}
$$




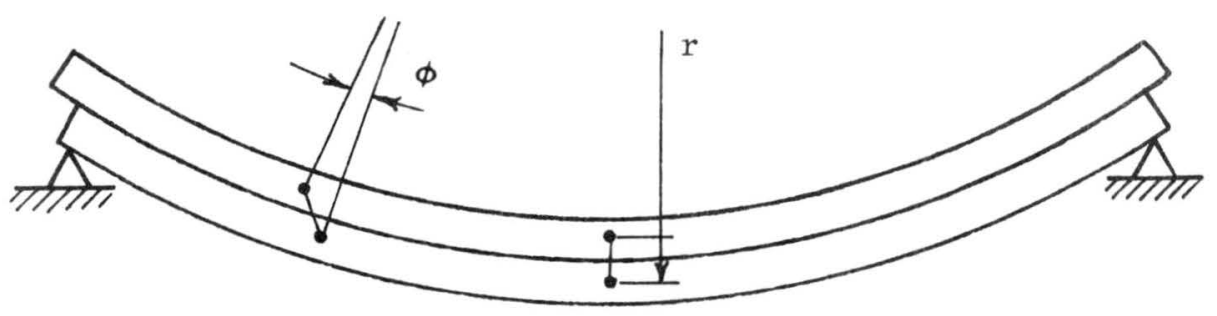

(a) Side view

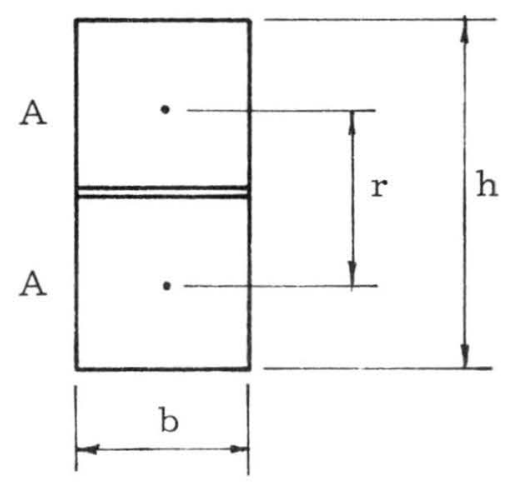

(b) Cross-section

Figure 1. 1. Layered Beam with Interlayer Slip According to Granholm 


$$
\frac{d^{2} y}{d x^{2}}-\frac{E A r}{2 E I} \frac{d \Phi}{d x}=-\frac{M}{E I_{s}}
$$

where

$$
\begin{aligned}
\Phi= & \text { relative longitudinal displacement between the } \\
& \text { layers (in.), } \\
\mathrm{b}= & \text { the width of each layer (in.), } \\
\mathrm{k}^{\prime}= & \text { displacement modulus (lb./in. }{ }^{2} \text { ), related to } \Phi \text { by the } \\
& \text { relation } \mathrm{k}^{\prime}=\tau / \Phi, \\
\mathrm{r}= & \text { distance between the centroids of the two layers (in.) } \\
\mathrm{E}= & \text { the modulus of elasticity of the material of the layers } \\
& \left(\text { lb. /in. }{ }^{2}\right. \text { ), } \\
\mathrm{I}_{\mathrm{S}}= & \text { moment of inertia of an equivalent rigidly connected } \\
\mathrm{A}= & \text { cross section area of each layer (in. }{ }^{2} \text { ), and } \\
\mathrm{M}= & \text { external moment at the section (in. }-1 \mathrm{~b} \text { ). }
\end{aligned}
$$

Equations (1.1) and (1.2) can be solved simultaneously for the system deflection $y$. The theory can be extended to include the case of $\mathrm{n}$ layers.

Pleshkov (9) also developed a theory for layered beam systems with interlayer slip. Again the assumptions of continuous shear connection, constant connector spacing and a linear connector force 
versus connector displacement relationship were made. Generalization was also made to a system of $n$ layers. Pleshkov's theory led to the following governing equation:

$$
\sum_{k=1}^{n} E_{k} \frac{d^{4} y}{d x^{4}}-\frac{4 G}{E \Omega}\left(E I \frac{d^{2} y}{d x^{2}}+M\right)=-\frac{d^{2} M}{d x^{2}}
$$

where

$$
\begin{aligned}
& \mathrm{n}=\text { number of layers in the system, } \\
& E=\text { the modulus of elasticity of the material (lb./in. }{ }^{2} \text { ), } \\
& \mathrm{I}_{\mathrm{k}}=\text { the moment of inertia of the } \mathrm{k}^{\text {th }} \text { layer about its own } \\
& \text { neutral axis (in. } \left.{ }^{4}\right) \text {, } \\
& I_{S}=\text { the moment of inertia of the rigidly connected section } \\
& \text { (in. }{ }^{4} \text { ), } \\
& M=\text { the external moment (lb. - in.), } \\
& \mathrm{G}=\text { average connector modulus }=\left(\mathrm{G}_{1}+\mathrm{G}_{2}+\ldots\right. \\
& \left.+G_{n}\right) / n \\
& \mathrm{G}_{\mathrm{k}}=\text { connector modulus for the joint between the } \mathrm{k}^{\text {th }} \text { and } \\
& (\mathrm{k}+1)^{\mathrm{st}} \text { layers (lb. /in.), } \\
& y=\text { deflection (in.), } \\
& \Omega=\frac{4}{\mathrm{n}}\left(\frac{\mathrm{A}_{1} \mathrm{Z}_{1}}{\mathrm{r}_{1}}+\frac{\mathrm{A}_{1} \mathrm{Z}_{1}+\mathrm{A}_{2} \mathrm{Z}_{2}}{\mathrm{r}_{2}}+\cdots+\frac{\mathrm{A}_{1} \mathrm{Z}_{1}+\cdots+\mathrm{A}_{\mathrm{n}} \mathrm{Z}_{\mathrm{n}}}{\mathrm{r}_{\mathrm{n}}}\right), \\
& r_{k}=\text { the distance from centroid of the } k^{\text {th }} \text { layer to that of } \\
& \text { the }(k+1)^{\text {st }} \text { layer, }
\end{aligned}
$$




$$
\begin{aligned}
Z_{k}= & \text { the distance from the centroid of the } k^{\text {th }} \text { element to the } \\
& \text { centroid of the entire section, and } \\
A_{k}= & \text { area of the } \left.k^{\text {th }} \text { element (in. }{ }^{2}\right) .
\end{aligned}
$$

Examples of the application of this governing equation to several types of problems are given in (9).

Newmark, Seiss and Viest (10), (11) have studied the problem of incomplete interaction between the steel girder and concrete slab of a composite $\mathrm{T}$-beam. Interaction between girder and slab is essentially the same as the slip between beam layers. Again the assumptions of continuous shear connection and linear connector load versus connector deflection were used. For a beam constructed of two equal layers, shown in Figure 1.2, a final form of the governing equation derived by Newmark, Seiss and Viest is

$$
\frac{d^{2} F}{d x^{2}}-\frac{k n}{S} F\left(\frac{2}{E A}+\frac{h^{2}}{2 E I}\right)=-\frac{k n}{S} \frac{M h}{2 E I}
$$

where

$$
\begin{aligned}
& \mathrm{h}=\text { depth of each layer } \\
& \mathrm{n}=\text { number of nails per row, } \\
& \mathrm{I}=\text { moment of inertia for each layer, } \\
& \mathrm{F}=\text { axial force in each layer, } \\
& \mathrm{k}=\text { connector modulus per connector, } \\
& \mathrm{M}=\text { the external moment, }
\end{aligned}
$$




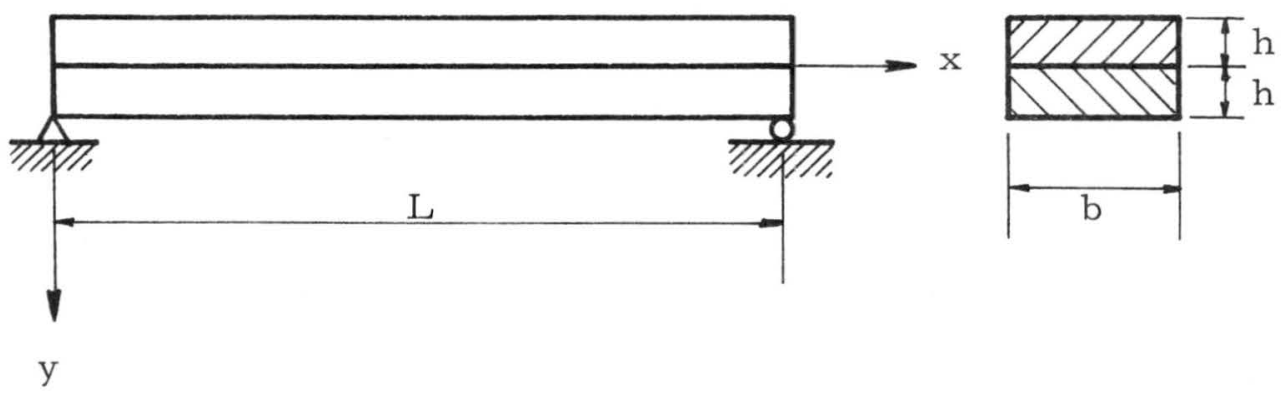

(a) Longitudinal view and cross-section
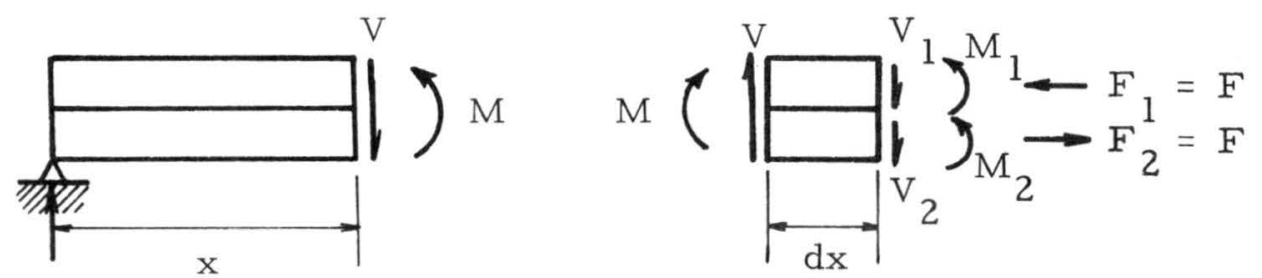

$\mathrm{R}$

(b) Element and internal forces

Figure 1.2. Two Equal Layered Systems 
$\mathrm{E}=$ the modulus of elasticity,

$A=$ area of each layer, and

$\mathrm{S}=$ the spacing of connectors.

Solution of this equation gives the variation in axial force along the beam length.

Deflection of the beam may be obtained by solving for $y$ from the expression:

$$
\frac{d^{2} y}{d x^{2}}=-\frac{M}{2 E I}+\frac{F h}{2 E I}
$$

Another approach to the problem of layered beams was developed by Norris, Ericksen and Kommers (18) and extended by Kuenzi and Wilkinson (19). This method assumes that a layer of low shear rigidity exists between the layers. In this method interlayer slip is assumed to be approximated by the action of the layer of low shear rigidity and thus the approach is not the same as that by most other authors.

The governing equation for a two layered simply supported beam subjected to a concentrated load, as reported by Kuenzi and Wilkinson (19), is:

$$
\Delta=J_{\Delta} \frac{P^{3}}{48 E I}
$$


where

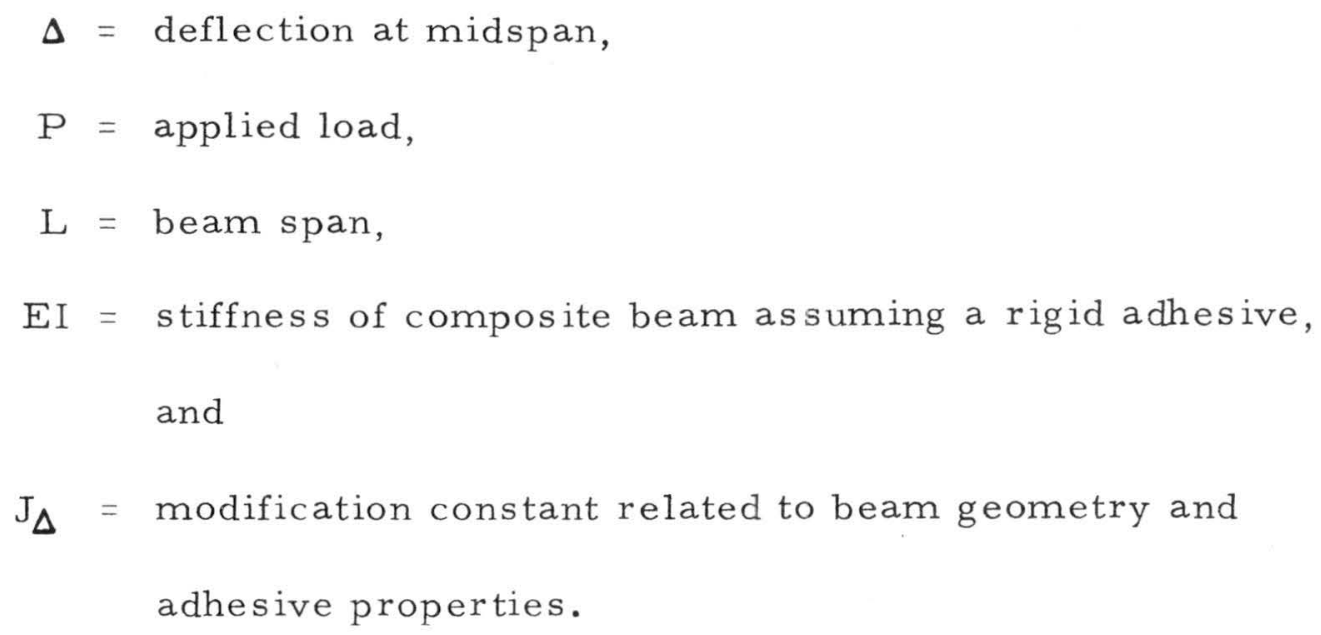

For a simply supported beam with midspan load:

$$
J_{\Delta}=1+3\left(\frac{E I}{E I_{u}}-1\right)\left(\frac{2}{a L}\right)^{2}\left(1-\frac{\tanh \frac{a L}{2}}{\frac{a L}{2}}\right)
$$

where

$$
\begin{aligned}
\mathrm{EI}_{\mathrm{u}}= & \text { stiffness of composite beam assuming an adhesive } \\
& \text { with zero rigidity, } \\
\mathrm{a}^{2}= & \frac{h^{2} \mathrm{~S}}{(\mathrm{EI})-\left(\mathrm{EI}_{\mathrm{u}}\right)}\left(\frac{\mathrm{EI}}{\mathrm{EI}}\right), \\
\mathrm{h}= & \text { distance between centroids of laminations, and } \\
\mathrm{S}= & \text { shear load per unit span to cause unit slip between } \\
& \text { laminations. }
\end{aligned}
$$

Clark (12) has developed a theory for layered systems fastened by rigid connectors such as rivets or spot welds. In his work, he 
assumed that slip occurred between connectors but that the connectors themselves were perfectly rigid. Clark's method considered the connectors to be discrete instead of assuming a uniformly distributed connector effect. Clark's theory actually provides an upper bound for beam stiffness.

A general treatment of the interlayer slip problem was made by Goodman (1), (2). He developed a comprehensive theory for beam, plate and shell systems consisting of three equal layers. Experimental results for wooden beam and plate systems showed excellent agreement with the predicted values. Nonlinearities in the connector force versus connector deflection relationship were treated using a step-wise linear numerical procedure. Again, this study assumed continuous shear connection. The close agreement between theory and experiments indicates that frictional effects are negligible for static bending.

For a beam with three equal layers, Goodman reported the following governing equation:

$$
3 E I \frac{d^{4} y}{d x^{4}}-\frac{k n}{S E A}\left(E I s \frac{d^{2} y}{d x^{2}}+M\right)=-\frac{d^{2} M}{d x^{2}}
$$

where

$S=$ the spacing between connector rows along the beam length, 
$\mathrm{n}=$ the number of connectors per row, and

k, I, Is, M, A and E are the same definitions as before.

For a system of two equal layers, Goodman was also able to show that the theories of Granholm (8), Pleshkov (9) and Newmark, Seiss and Viest (10) all provided identical governing equations as follows:

a) Granholm's final equations are given previously as (1.1) and (1.2). The variable $\Phi$ can be eliminated from the two equations. After additional algebraic manipulation the following equation is obtained:

$$
\sum_{1}^{2} E I \frac{d^{4} y}{d x^{4}}-\frac{2 k^{\prime} b}{E A}\left(E I \frac{d^{2} y}{d x^{2}}+M\right)=-\frac{d^{2} M}{d x^{2}}
$$

b) Pleshkov's final equation, (1.3), is reduced to the following form:

$$
\sum_{1}^{2} E I \frac{d^{4} y}{d x^{4}}-\frac{2 G}{E A}\left(E I \frac{d^{2} y}{d x^{2}}+M\right)=-\frac{d^{2} M}{d x^{2}}
$$

c) The final equations of Newmark, Seiss and Viest were given as (1.4) and (1.5). Again, the variable $F$ is eliminated and after algebraic manipulation the following equation is obtained: 


$$
\sum_{1}^{2} E I \frac{d^{4} y}{d x^{4}}-2 \frac{k n}{S} \frac{1}{E A}\left(E I \frac{d^{2} y}{d x^{2}}+M\right)=-\frac{d^{2} M}{d x^{2}}
$$

Comparing (1.9), (1.10) and (1.11) it is noted that except for the constants, $\mathrm{k}^{\prime} \mathrm{b}, \mathrm{G}$ and $\mathrm{kn} / \mathrm{S}$, the three equations are identical. These three forms for the constants are equivalent as may be seen by reference to each author's definitions for the constants.

Henghold (13), (16) developed a theory for dynamics problems for two and three layered systems. His work, though for the vibration problem, is based on the same basic concepts of interlayer slip behavior. Important generalizations of the theory of layered systems were made in his work including the extension of the theory to n layered systems.

Rassam (14), (15), (17) studied the behavior of layered columns with interlayer slip. His study included columns with cross-sections having both single and double symmetry and his theory allowed for variation in column properties along the column length. Experimental verification of the developed theory was sought and in general showed good agreement between experiment and theory.

\section{3 Notation}

Symbols used in the development of the governing theory for two and three layered systems are described first introduced and in addition are summarized in Appendix II. 
CHAPTER 2

THEORETICAL DEVELOPMEN T

\section{1 Introduction}

The theories described in Chapter 1 are generally inadequate to handle all the various problems posed in the current investigation. Extension to the case of several unequal layers was necessary. Special boundary conditions had to be satisfied to handle the variety of situations which arose during the testing program of the overall study of which this investigation was a part. These requirements lead to the theoretical developments of the study presented in the following sections.

\section{2 Theoretical Development}

General and basic theoretical developments are made in the following sections and are then extended to the special problem of the study. A typical $m$ layered system with one axis of symmetry is considered. Layers with different material properties may be treated by using the principle of transformed cross-section.

Figure 2.1 depicts a five layered system which serves as an aid in generalizing to $\mathrm{m}$ layers. The nomenclature for Figure 2.1 is 


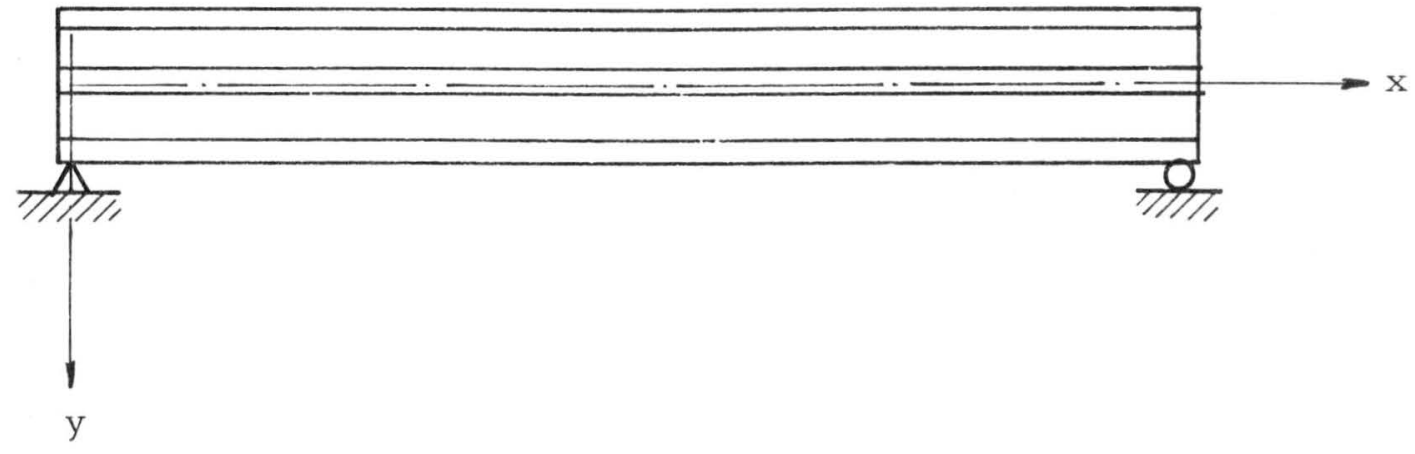

(a) Beam with sign convention

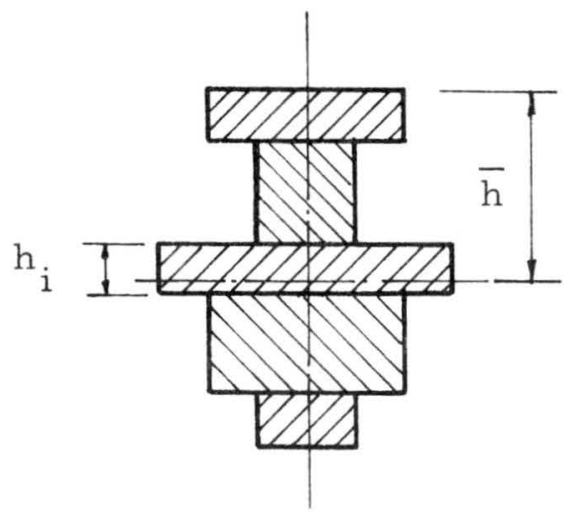

(b) Cross-section

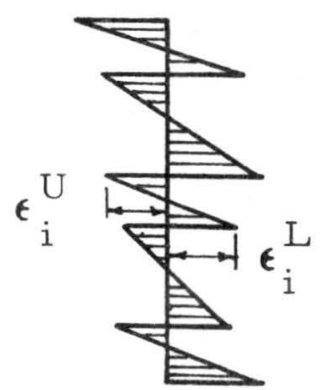

(c) Strain distribution

Figure 2.1. Five Layered Example of $m$ Layered System 


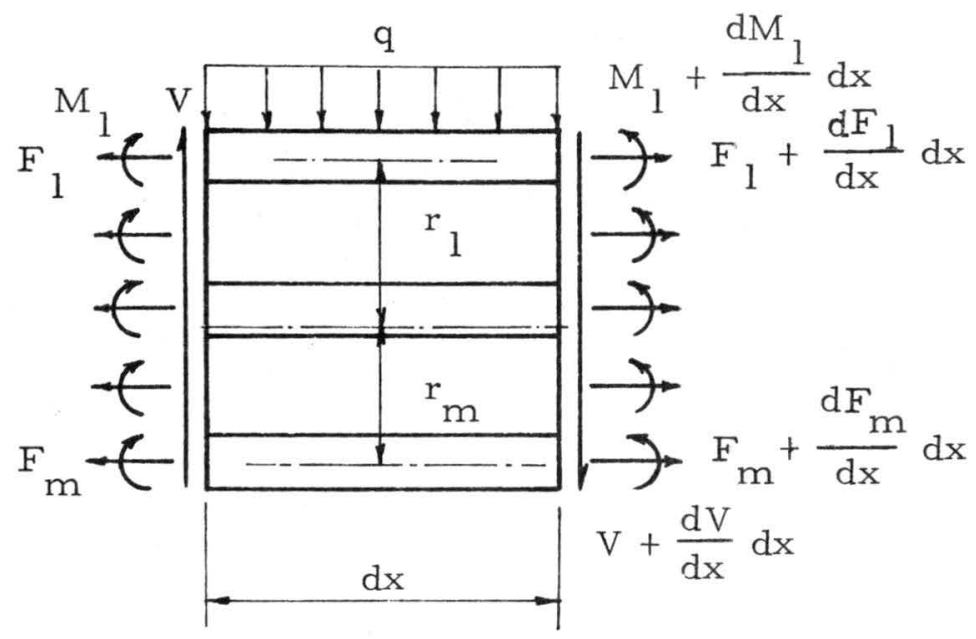

(d) Beam element

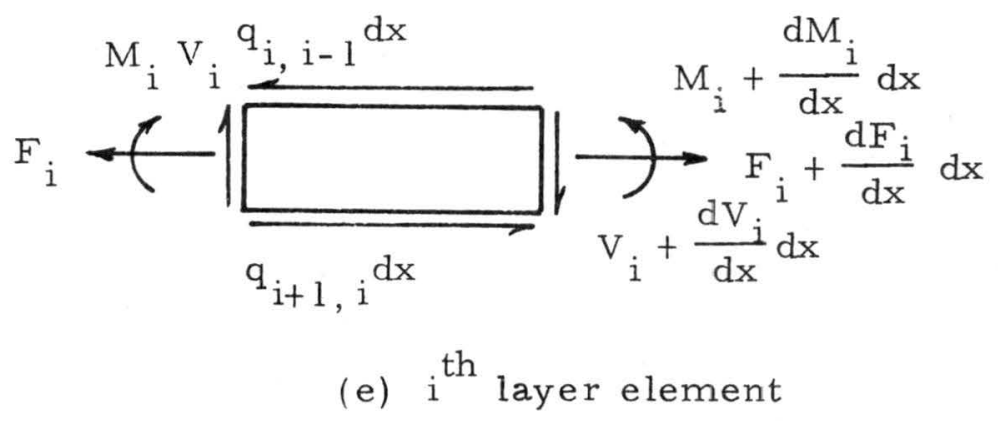

Figure 2. 1.--Continued 
$\overline{\mathrm{h}}=$ the distance from the top of the beam to the centroid of the transformed cross-section (in.),

$r_{i}=$ the distance from the centroid of the transformed crosssection to the centroid of the $i^{\text {th }}$ layer.

For the analysis of this $m$ layered system, the following assumptions are introduced:

1. The shear connection between layers is continuous along the length; i.e., discrete deformable connections are assumed to be replaced by a continuous shear connection.

2. The amount of slip at a connector is directly proportional to the load.

3. The distribution of strain through the depth of a given individual layer is linear.

4. At every section of a beam, each layer deflects the same amount and no buckling of the layers occurs.

5. Friction between the layers is negligible.

Applying the static equilibrium law to the free body diagram in Figure 2.1(d) yields

$$
\text { from } \sum F_{x}=0 \quad \sum_{l}^{m} \frac{d F_{i}}{d x}=0
$$




$$
\begin{aligned}
& \operatorname{from~} \sum F_{y}=0 \quad \sum_{1}^{m} d v_{i}=-q d x \text { for uniform loading } \\
& \sum_{1}^{m} d v_{i}=0 \quad \text { for concentrated loading }
\end{aligned}
$$

The assumption that each layer deflects the same amount and has the same curvature requires

$$
\frac{d^{2} y}{d x^{2}}=\frac{d^{2} y}{d x^{2}}
$$

and

$$
M_{i}=-E I_{i} \frac{d^{2} y}{d x^{2}}
$$

For a uniformly loaded beam, (2.2) through (2.5) may now be combined to yield

$$
\sum_{1}^{m} E_{i} \frac{d^{4} y}{d x^{4}}-\sum_{1}^{m} r_{i} \frac{d^{2} F_{i}}{d x^{2}}=q
$$

For an $m$ layered system there are $\mathrm{m}+1$ unknowns ( $\mathrm{m} F$ values and one value of $y)$ and therefore $m+l$ equations are needed to find these unknown quantities. Equations (2.1) and (2.6) provide two of these equations. The additional $\mathrm{m}-1$ equations must come 
from slip relationships. Applying assumption 2, the slip permitted by a connector is directly proportional to the load transmitted by the connector. Thus,

$$
\Delta S=\frac{\mathrm{Q}}{\mathrm{k}}
$$

where

$$
\begin{aligned}
\Delta S= & \text { the relative interlayer slip difference between layers (in.), } \\
\mathrm{k}= & \text { the connector modulus per connector (lb./in.), } \\
Q= & \frac{S q_{i, j}}{n}=\text { shear force transmitted by a row of con- } \\
& \text { nectors / number of connectors per row (lb.), } \\
q_{i, j}= & \text { the force transmitted between the } i^{\text {th }} \text { and } j \text { th layers of } \\
& \text { the beam per unit length of the beam (lb. /in.) and is } \\
n= & \text { number of connectors per row, and } \\
S= & \text { the spacing of connectors (in.). }
\end{aligned}
$$

Thus,

$$
\Delta S=\frac{S}{k n} q_{i, j}
$$

or for any two adjacent layers

$$
\Delta S_{i, i+1}=\left(\frac{S}{k n}\right)_{i, i+1} q_{i, i+1}=-\left(\frac{S}{k n}\right)_{i, i+1} \frac{d F_{i}}{d x} .
$$

By differentiating with respect to $x,(2.9)$ becomes 


$$
\frac{d}{d x}\left(\Delta S_{i, i+1}\right)=\left(\frac{S}{k n}\right)_{i, i+1} \frac{d}{d x}\left(q_{i, i+1}\right)=-\left(\frac{S}{k n}\right) i, i+1 \frac{d^{2} F_{i}}{d x^{2}} .
$$

Equations (2.9) and (2.10) are general and allow for variation of $S$, $\mathrm{k}$ and $\mathrm{n}$ between layers.

The displacement difference between the $i^{\text {th }}$ and $(i+1)^{\text {th }}$ layers may also be found by integrating the strains as

$$
\Delta S_{i, i+1}=\int_{0}^{\mathrm{x}} \epsilon_{i+1}^{\mathrm{U}} \mathrm{dx}-\int_{0}^{\mathrm{x}} \epsilon_{i}^{\mathrm{L}} \mathrm{dx}
$$

where

$$
\begin{aligned}
\epsilon_{i+1}^{U}= & \text { the strain in the }(i+1)^{\text {th }} \text { layer evaluated at its upper } \\
& \text { boundary, and } \\
\epsilon_{i}^{L}= & \text { the strain in the } i^{\text {th }} \text { layer evaluated at its lower } \\
& \text { boundary. }
\end{aligned}
$$

Equation (2.11) is differentiated to change the form to a differential equation. This yields

$$
\begin{aligned}
\epsilon_{S} & =\frac{d}{d x}\left(\Delta S_{i, i+1}\right) \\
& =\epsilon_{i+1}^{U}-\epsilon_{i}^{L} \\
& =\frac{\sigma_{i+1}^{U}}{E}-\frac{\sigma_{i}^{L}}{E}
\end{aligned}
$$




$$
\begin{aligned}
& =\left(\frac{F_{i+1}}{E A_{i+1}^{*}}-\frac{M_{i+1}}{E I_{i+1}} \frac{h_{i+1}}{2}\right)-\left(\frac{F_{i}}{E A_{i}^{*}}+\frac{M_{i}}{E I_{i}} \frac{h_{i}}{2}\right) \\
& =\frac{F_{i+1}}{E A_{i+1}^{*}}-\frac{F_{i}}{E A_{i}^{*}}+\frac{1}{2}\left(h_{i+1}+h_{i}\right) \frac{d^{2} y}{d x^{2}}
\end{aligned}
$$

where

$\epsilon_{\mathrm{S}}=$ relative strain between layers, and

$A_{i}^{*}=$ transformed area of the $i^{\text {th }}$ layer.

Finally, combining (2.10) and (2.12) gives

$$
-\left(\frac{S}{k n}\right)_{i, i+1} \frac{d^{2} F i}{d x^{2}}=\frac{F_{i+1}}{E A_{i+1}^{*}}-\frac{F_{i}}{E A_{i}^{* k}}+C_{i, i+1} \frac{d^{2} y}{d x^{2}}
$$

where

$$
C_{i, i+1}=\frac{1}{2}\left(h_{i}+h_{i+1}\right)
$$

Equation (2.13) provides the needed $\mathrm{m}-1$ slip relationships since in an $m$ layered system there are m-l sets of adjacent layers.

Equations (2.1), (2.6) and (2.13) provide a system of $\mathrm{m}+\mathrm{l}$ equations for the $\mathrm{m}+\mathrm{l}$ unknowns and represent the governing set of equations for an $\mathrm{m}$ layered system. The horizontal equilibrium equation may be used immediately to eliminate one of the $F_{i}$ terms, say $F_{m}$ This gives 


$$
\sum_{1}^{m} E_{i} \frac{d^{4} y}{d x^{4}}+\sum_{1}^{m-1}\left(r_{m}-r_{i}\right) \frac{d^{2} F_{i}}{d x^{2}}=q
$$

and

$$
\begin{aligned}
& -\left(\frac{S}{k n}\right)_{1,2} \frac{d^{2} F_{1}}{d x^{2}}=\frac{F_{2}}{E A_{2}^{*}}-\frac{F_{1}}{E A_{1}^{*}}+C_{12} \frac{d^{2} y}{d x^{2}} \\
& -\left(\frac{S}{k n}\right)_{2,3} \frac{d^{2} F_{2}}{d x^{2}}=\frac{F_{3}}{E A_{3}^{*}}-\frac{F_{2}}{E A_{2}^{*}}+C_{23} \frac{d^{2} y}{d x^{2}}
\end{aligned}
$$$$
\left.-\left(\frac{S}{k n}\right)_{m-1, m} \frac{d^{2} F_{m}}{d x^{2}}=\frac{\sum_{l}^{m-1} F_{i}}{E A_{m}^{*}}-\frac{F_{m-1}}{E A_{m-1}^{*}}+C_{m-1, m} \frac{d^{2} y}{d x^{2}}\right)
$$

where

$$
\begin{aligned}
& -\sum_{1}^{m-1} \frac{d^{2} F}{d x^{2}}=\frac{d^{2} F}{d x^{2}} \text {, and } \\
& -\sum_{1}^{m-1} F_{i}=F_{m} .
\end{aligned}
$$

Equations (2.14) and (2.15) provide a system of $m$ equations with $\mathrm{m}$ unknowns, $\mathrm{y}, \mathrm{F}_{1}, \ldots \mathrm{F}_{\mathrm{m}-1} \cdot$ From an inspection of

Figure 2.1(d), the total moment at any section may be expressed as 


$$
M_{T}=\sum_{l}^{m} M_{i}-\sum_{i=1}^{m}\left(\sum_{j=i+1}^{m} h_{j}+\frac{h_{i}}{2}\right) F_{i}
$$

which may be rewritten as

$$
M_{T}=-\sum_{1}^{m} E_{i} \frac{d^{2} y}{d x^{2}}-\sum_{i=1}^{m-1}\left(\frac{h}{2}+\sum_{j=i+1}^{m-1} h_{j}+\frac{h_{i}}{2}\right) \frac{d F_{i}}{d x} .
$$

similarly

$$
V_{T}=\sum_{1}^{m} E_{i} \frac{d^{3} y}{d x^{3}}-\sum_{i=1}^{m-1}\left(\frac{h^{m}}{2}+\sum_{j=i+1}^{m-1} h_{j}+\frac{h_{i}}{2}\right) \frac{d F_{i}}{d x} .
$$

Boundary conditions are needed to obtain a complete solution to the equations developed. Consider first the conditions associated with a simply supported end. The deflection and total moment at the end of the beam must be zero. In the absence of applied axial force and support friction the axial forces must go to zero at the end. The boundary conditions at a simply supported end thus become

and

$$
\begin{aligned}
y & =0, \\
\frac{d^{2} y}{d x^{2}} & =0
\end{aligned}
$$

$$
F_{i}=0 \text {. }
$$


At a free end, there can be no axial force and the total moment and shearing force must be zero. The boundary conditions become

and

$$
\begin{aligned}
& \mathrm{V}_{\mathrm{T}}=0, \\
& \mathrm{~F}_{\mathrm{i}}=0
\end{aligned}
$$

$$
\frac{d^{2} y}{d x^{2}}=0 \text {. }
$$

Next, consider a fixed end. The displacement and slope of the end must be zero by the definition of fixed. However, the axial force will not necessarily be zero if the end of the beam is fixed against slip displacement. From (2.9) this condition on slip displacement indicates that

$$
q_{i, j}=0
$$

Horizontal equilibrium and (2.9) in turn imply

$$
\frac{d F_{i}}{d x}=0 .
$$

The boundary conditions may be summarized as 


$$
\begin{aligned}
\mathrm{y} & =0, \\
\frac{\mathrm{dy}}{\mathrm{dx}} & =0
\end{aligned}
$$

and

$$
\frac{d F_{i}}{d x}=0 .
$$

When the above conditions are expanded the boundary condi-

tions may be written

at a pinned end:

$$
\begin{aligned}
\mathrm{y} & =0 \\
\frac{\mathrm{d}^{2} \mathrm{y}}{\mathrm{dx}^{2}} & =0 \\
\mathrm{~F}_{1} & =0 \\
& \cdot \\
& \cdot \\
\mathrm{F}_{\mathrm{m}-1} & =0
\end{aligned}
$$

at a free end:

$$
\frac{d^{2} y}{d x^{2}}=0
$$




$$
\begin{aligned}
\mathrm{F}_{1} & =0 \\
\cdot & \\
\cdot & \cdot \\
\mathrm{F}_{\mathrm{m}-1} & =0 \\
\mathrm{~V}_{\mathrm{T}} & =0
\end{aligned}
$$

and at a fixed end:

$$
\begin{aligned}
\mathrm{y} & =0 \\
\frac{\mathrm{dy}}{\mathrm{dx}} & =0 \\
\frac{\mathrm{dF}}{\mathrm{dx}} & =0 \\
& \cdot \\
\frac{\mathrm{dF}-1}{\mathrm{dx}} & =0 .
\end{aligned}
$$

Equations (2.22) through (2.24) indicate that for any end conditions there are $\mathrm{m}+\mathrm{l}$ boundary conditions. 
2. 3 The General Equations for $m$ Layered Systems with Uniform Load

The governing equations (2.14) and (2.15) form a set of $\mathrm{m}$ coupled linear differential equations with constant coefficients. The equations may be expressed in linear operator form as

$$
[\mathrm{L}]\left\{\begin{array}{c}
\mathrm{y} \\
\mathrm{F}_{1} \\
\mathrm{~F}_{2} \\
\cdot \\
\cdot \\
\mathrm{F}_{\mathrm{m}-1}
\end{array}\right\}=\left\{\begin{array}{c}
\mathrm{q} \\
0 \\
\cdot \\
\cdot \\
0
\end{array}\right\}
$$

where [L] is as shown in Figure 2.2 where

$$
D^{p}=\frac{d^{p}}{d x^{p}} .
$$

The closed form solutions depend on the assumption that the section properties, connector modulus and spacing remain constant along the length of the beam. Once these restrictions are lifted, the resulting equations are best solved numerically.

Many approximation techniques, each with strong and weak points, abound in the literature. In this study, the finite difference method is used. Several examples of the application of the 
$[L]=$

\begin{tabular}{|c|c|c|c|c|c|c|c|c|}
\hline$\sum_{1}^{m} \mathrm{EI}_{i} \mathrm{D}^{4}$ & $\left(\mathrm{r}_{\mathrm{m}}-\mathrm{r}_{1}\right)$ & & $\left(\mathrm{r}_{\mathrm{m}}-\mathrm{r}_{2}\right) \mathrm{I}$ & & $\left(r_{m}-r_{3}\right) D^{2}$ & $\cdots$ & $\left(\mathrm{r}_{\mathrm{m}}\right.$ & $\left.r_{m-1}\right) D^{2}$ \\
\hline $\mathrm{C}_{12} \mathrm{D}^{2}$ & $\left(\frac{S}{k n}\right)_{1,2} D^{2}-$ & $\frac{1}{\mathrm{EA}_{1}^{* *}}$ & $\frac{1}{\mathrm{EA}_{2}^{*}}$ & & 0 & $\cdots$ & & 0 \\
\hline $\mathrm{C}_{23} \mathrm{D}^{2}$ & 0 & & $\left(\frac{\mathrm{S}}{\mathrm{kn}}\right)_{2,3} \mathrm{D}^{2}-$ & $\frac{1}{\mathrm{EA}_{2}^{*}}$ & $\frac{1}{\mathrm{EA}_{3}^{*}}$ & . . & & 0 \\
\hline$\cdots$ & $\cdots$ & & $\cdots$ & & $\cdots$ & . & & $\cdots$ \\
\hline$\cdots$ & $\cdots$ & & $\cdots$ & & $\cdots$ & $\cdots$ & & . . \\
\hline $\mathrm{C}_{\mathrm{m}-1, \mathrm{~m}} \mathrm{D}^{2}$ & $-\frac{1}{\mathrm{EA}_{\mathrm{m}}^{*}}$ & & $-\frac{1}{\mathrm{EA}_{\mathrm{m}}^{*}}$ & & $-\frac{1}{\mathrm{EA}_{\mathrm{m}}^{*}}$ & $\cdots$ & $\left(\frac{\mathrm{S}}{\mathrm{kn}}\right)_{\mathrm{m}-1, \mathrm{~m}}$ & $-\frac{1}{\mathrm{EA}_{\mathrm{m}-1}^{* *}}$ \\
\hline
\end{tabular}

Figure 2.2. Matrix Operator for an $m$ Layered System 
finite difference technique applied to two and three layered systems are included in later chapters of this thesis. 


\section{CHAPTER 3}

\section{TWO LAYERED SYSTEMS}

\section{1 Introduction}

In this chapter the general equations are developed for the particular case of a two layered beam system. The equations for a two layered system is directly applicable to a T-beam. The case where the two layers have different moduli of elasticity can be handled by using the transformed cross-section where a single modulus of elasticity is used with transformed widths.

\section{2 Closed Form Solution for Beam with Uniform Load}

Figure 3.1 shows a $\mathrm{T}$-beam with a transformed cross-section which is representative of a general two layered system.

For the two layered system, the axial force of the top and bottom layers must be equal in magnitude but opposite in direction. Thus

$$
F_{1}=-F_{2}=F
$$

as shown in Figure 3.1(e).

The equilibrium equations for the $m$ layered case simplify to

$$
\frac{d V}{d x}=-q
$$




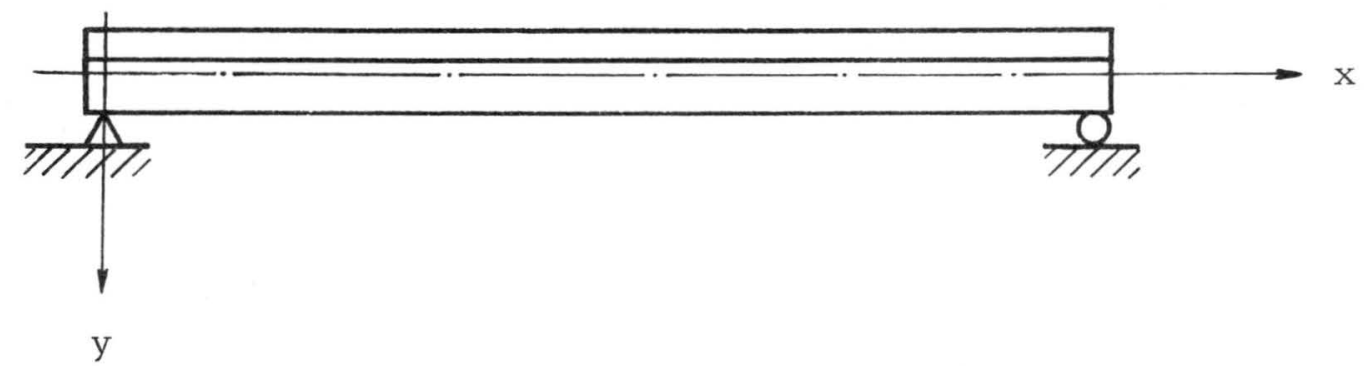

(a) Beam with sign convention

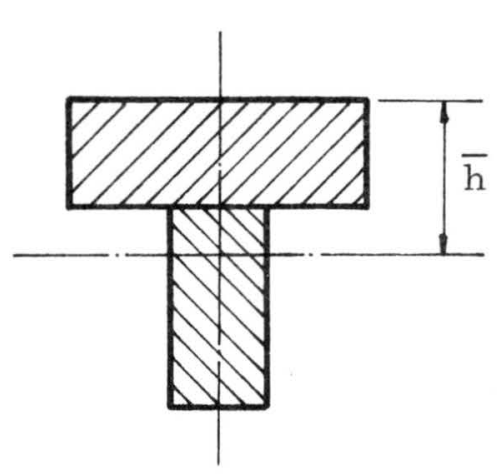

(b) Cross-section

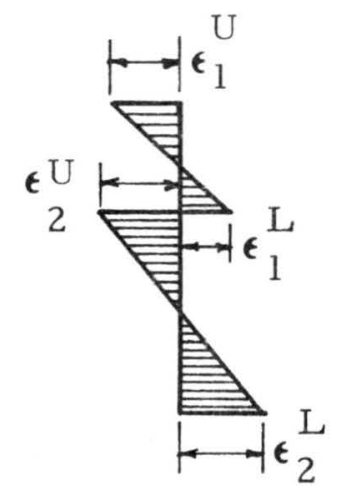

(c) Strain distribution

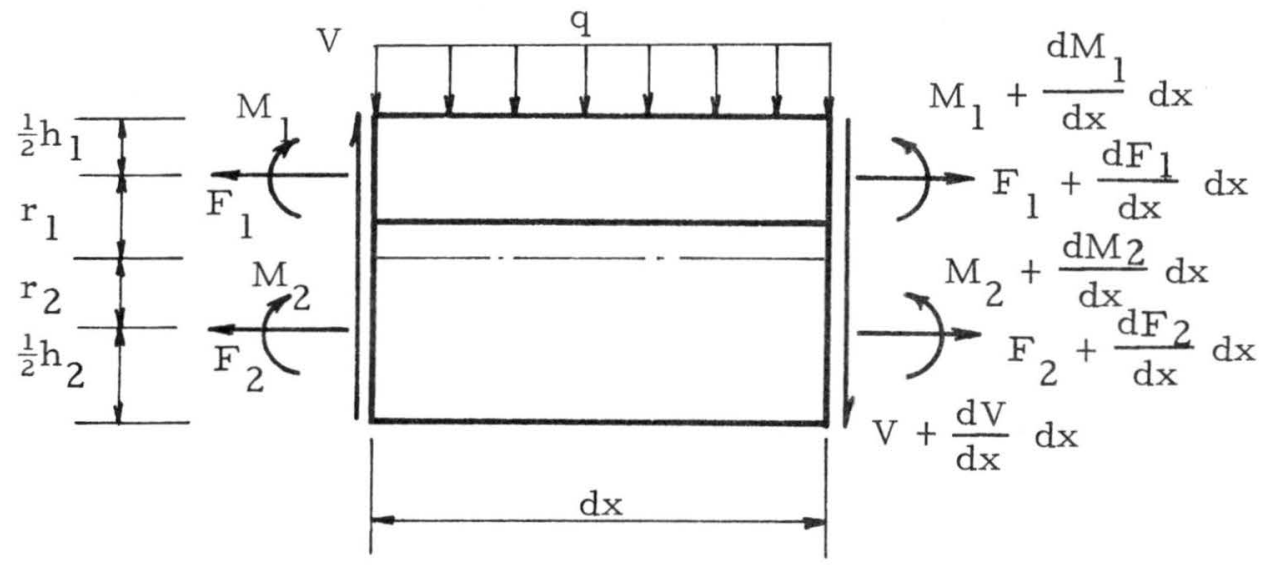

(d) Beam element

Figure 3.1. Two Layered System 


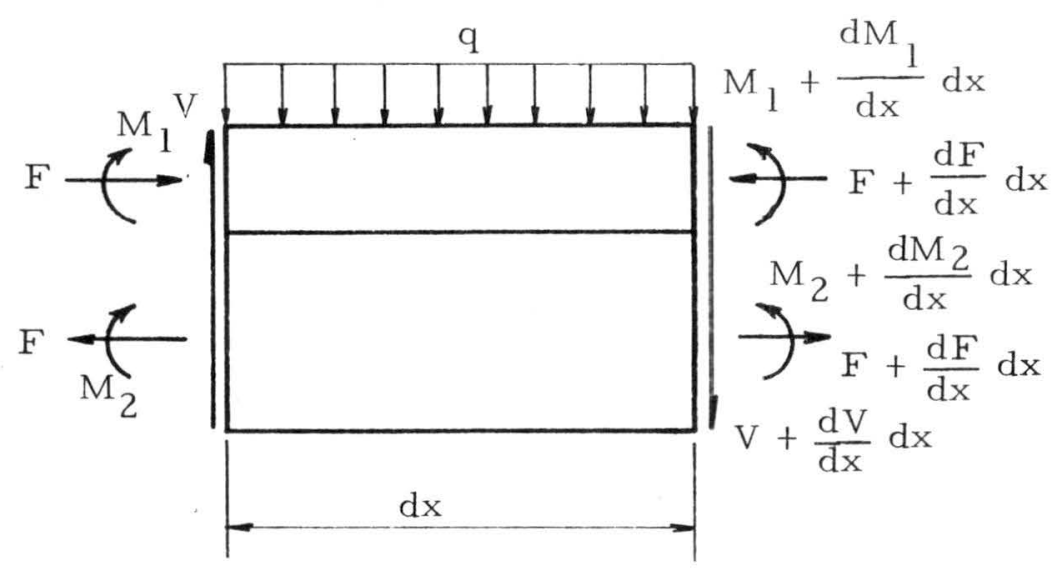

(e) Beam element

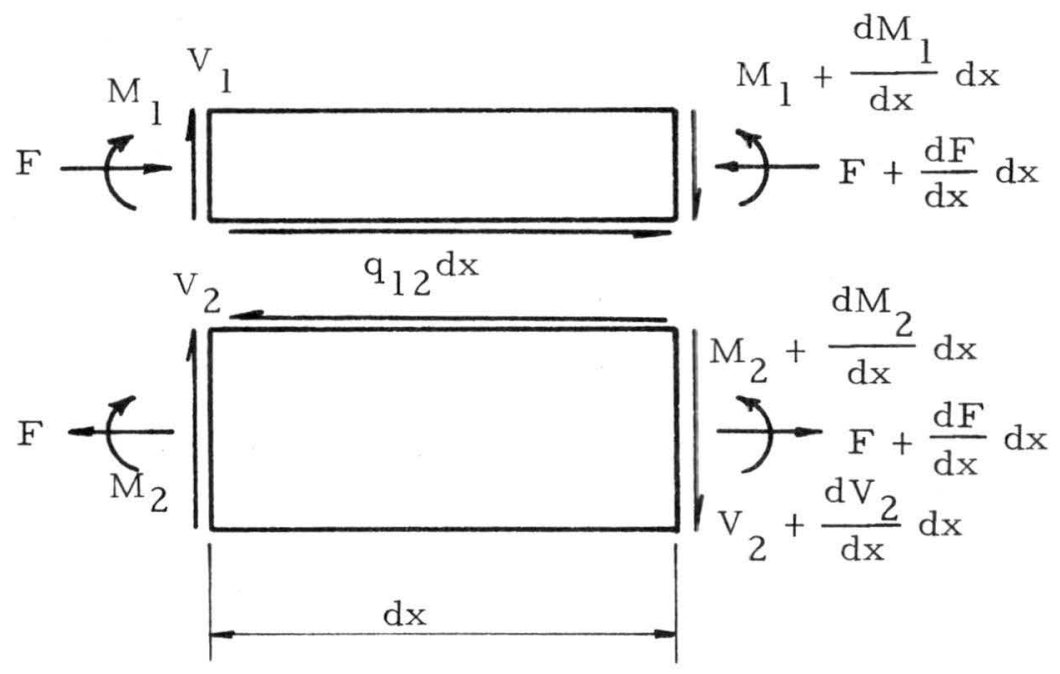

(f) Layer elements

Figure 3.1.--Continued 
After substitution of the equation for shear and integration, (3.2)

becomes

$$
\begin{aligned}
\mathrm{V} & =\sum_{1}^{2}\left(\frac{\mathrm{dM_{i }}}{\mathrm{dx}}+\mathrm{r}_{i} \frac{\mathrm{dF}}{\mathrm{dx}}\right)+\mathrm{q} \frac{(\mathrm{dx})^{2}}{2} \\
& \doteq \sum_{1}^{2} \frac{\mathrm{dM}}{\mathrm{dx}}+\frac{\mathrm{h}_{1}+\mathrm{h}_{2}}{2} \frac{\mathrm{dF}}{\mathrm{dx}} \\
& \doteq \sum_{1}^{2} \frac{\mathrm{dM}}{\mathrm{dx}}+\mathrm{C}_{12} \frac{\mathrm{dF}}{\mathrm{dx}} \\
\text { or } & \doteq \frac{\mathrm{dM} T}{\mathrm{dx}}
\end{aligned}
$$

where

$$
C_{12}=\frac{\mathrm{h}_{1}+\mathrm{h}_{2}}{2} .
$$

If it is now assumed that each layer deflects the same amount and therefore has the same curvature, then

$$
M_{i}=-E I_{i} \frac{d^{2} y}{d x^{2}} .
$$

With this substitution (3.3) will yield, for properties constant along the beam length,

$$
\frac{d^{2} y}{d x^{2}}=\frac{-M_{T}+C_{12} F}{\sum_{1}^{2} E I_{i}}
$$

It is now necessary to relate the $F_{i}$ terms to $y$. Proceeding as with the m-layer case, the displacement difference between the first 
and second layers is

$$
\Delta S_{12}=\frac{S}{k n} q_{12}=\frac{S}{k n} \frac{d F}{d x}
$$

which can be related to the layer strains shown in Figure 3.1 (c) as

$$
\Delta S_{12}=\int_{0}^{x} e_{2}^{U} d x-\int_{0}^{x} e_{1}^{L} d x
$$

where assuming tension taken as positive,

$\epsilon_{2}^{U}=$ the strain at the upper surface of the second layer,

or

$$
\varepsilon_{2}^{U}=\frac{F}{E A_{2}^{*}}+\frac{h_{2}}{2} \frac{d^{2} y}{d x^{2}}
$$

and

$$
\epsilon_{1}^{L}=\text { the strain at the lower surface of the first layer, }
$$

or

$$
\epsilon_{1}^{L}=-\frac{F}{E A_{1}^{*}}-\frac{h}{2} \frac{d^{2} y}{d x^{2}}
$$

where

$A_{1}^{*}=$ the transformed area of the first layer. 
Equations (3.6) and (3.7) are now combined and differentiated once to give

$$
\begin{aligned}
\frac{\mathrm{S}}{\mathrm{kn}} \frac{\mathrm{d}^{2} \mathrm{~F}}{\mathrm{dx}^{2}} & =\left(\frac{1}{E \mathrm{~A}_{1}^{*}}+\frac{1}{\mathrm{EA}_{2}^{*}}\right) \mathrm{F}-\frac{\mathrm{M}_{1}}{\mathrm{EI}} \frac{\mathrm{h}_{1}}{2}-\frac{\mathrm{M}_{2}}{\mathrm{EI}_{2}} \frac{\mathrm{h}_{2}}{2} \\
& =\left(\frac{1}{\mathrm{EA}_{1}^{*}}+\frac{1}{\mathrm{EA}_{2}^{*}}\right) \mathrm{F}+\frac{\mathrm{h}_{1}+\mathrm{h}_{2}}{2} \frac{\mathrm{d}^{2} \mathrm{y}}{\mathrm{dx}^{2}}
\end{aligned}
$$

Equations (3.5) and (3.8) represent a system of two equations in two unknowns, $F$ and $y$, and they are the governing equations for the general two layered system.

By substituting (3.5) into (3.8) the governing equation for $F$ can be rewritten as

$$
\frac{d^{2} F}{d x^{2}}-C_{1} F=-C_{2} M_{T}(x)
$$

where

$$
\begin{aligned}
& C_{1}=\frac{\mathrm{kn}}{\mathrm{SE}}\left(\frac{1}{\mathrm{~A}_{1}^{*}}+\frac{\mathrm{l}}{\mathrm{A}_{2}^{*}}\right)(\mathrm{T} . \mathrm{C} .), \\
& \mathrm{C}_{2}=\frac{\mathrm{kn}}{\mathrm{SE}} \frac{\mathrm{C}_{12}}{\sum_{1} I_{i}} \\
& C_{12}=\frac{\mathrm{h}_{1}+\mathrm{h}_{2}}{2}
\end{aligned}
$$




$$
\begin{aligned}
T . C . & =\frac{I_{s}}{\sum_{1}^{2} L_{i}}=1+\frac{C_{12}^{2}}{\sum_{1}^{2} I_{i}\left(\frac{1}{A_{1}^{*}}+\frac{1}{A_{2}^{*}}\right)}, \\
M_{T}(x) & =\frac{q x}{2}(L-x), \text { and } \\
L & =\text { the span length of the beam. }
\end{aligned}
$$

The parameter, T.C., is introduced to generalize the solution for all types of cross-sections. This parameter allows an easy evaluation of the effect of section properties on the behavior of the system.

The solution of (3.9) for a beam with uniform load can be stated as

$$
\begin{aligned}
F= & A \cosh \left(\sqrt{C_{1}} x\right)+B i \sinh \left(\sqrt{C_{1}} x\right)-\frac{C_{2}}{C_{1}} \frac{q}{2} x^{2} \\
& +\frac{C_{2}}{C_{1}} \frac{q L}{2} x-\frac{C_{2}}{\left(C_{1}\right)^{2}} q
\end{aligned}
$$

where $\mathrm{A}$ and $\mathrm{B}$ are unknown constants. The boundary conditions at the supports for the nailed beams if the ends are simply supported is

$$
\begin{aligned}
& F(0)=0 \\
& F(L)=0
\end{aligned}
$$


A matrix form for the determination of constants $A$ and $B$ may be expressed as

$$
\left[\begin{array}{cc}
1 & 0 \\
\cosh \left(\sqrt{C}_{1} L\right) & i \sinh \left(\sqrt{C}_{1} L\right)
\end{array}\right\}=\left\{\begin{array}{l}
A \\
\left(C_{1}\right)^{2} \\
\end{array}\right\}
$$

The solution of the above for $A$ and $B$ yields

$$
\begin{aligned}
& A=\frac{C_{2}}{\left(C_{1}\right)^{2}} q, \\
& B=\frac{C_{2}}{\left(C_{1}\right)^{2}} \frac{q\left[1-\cosh \left(\sqrt{C_{1}} L\right)\right]}{i \sinh \left(\sqrt{C_{1}} L\right)} .
\end{aligned}
$$

The function for axial force $F$ then becomes

$$
\begin{aligned}
F= & \frac{C_{2}}{\left(C_{1}\right)^{2}} q \cosh \left(\sqrt{C_{1}} x\right)+\frac{C_{2}}{\left(C_{1}\right)^{2}} q \frac{\left[1-\cosh \left(\sqrt{C_{1}} L\right)\right]}{\sinh \left(\sqrt{C_{1} L}\right)} \sinh \left(\sqrt{C_{1}} x\right) \\
& -\frac{C_{2}}{C_{1}} \frac{q}{2} x^{2}+\frac{C_{2}}{C_{1}} \frac{q L}{2} x-\frac{C_{2}}{\left(C_{1}\right)^{2}} q .
\end{aligned}
$$

From (3.5) and (3.9), the deflection equation may be re- 


$$
\frac{d^{2} y}{d x^{2}}=\frac{d^{2} y}{d x^{2}}+\frac{1}{C} \frac{C_{12}}{\sum_{1}^{2} E I_{i}} \frac{d^{2} F}{d x^{2}}
$$

Integ rating (3.12) twice, yields

$$
y=y_{s}+\frac{1}{C_{1}} \frac{C_{12}}{\sum_{1}^{2} E I_{i}} F
$$

This is the final deflection equation for the two layered system.

3. 3 Finite Difference Approach for Beam with Uniform Load

For the reasons stated in Section 2.3, the finite difference method will be used for the numerical solution of the two layered system with uniformly distributed load. The solution starts from (3.9) rewrite below

$$
\frac{d^{2} F}{d x^{2}}-C_{1} F=-C_{2} M
$$

Now the boundary conditions for the simply supported condition are imposed, namely the moments and axial forces at the ends are zero. Thus, from (3.9) the second derivatives of axial forces are also zero. 


$$
\begin{array}{ll}
F_{0}=\frac{d^{2} F_{0}}{d x^{2}}=0 & \text { at } x=0 \\
F_{n}=\frac{d^{2} F_{n}}{d x^{2}}=0 & \text { at } x=L
\end{array}
$$

Based on a three-term expansion for the second derivative in finite difference form, the first boundary condition of (3.14) implies (see Figure 3.2 in which the beam is divided into $\mathrm{n}$ equal divisions)

$$
\frac{d^{2} F_{0}}{d x^{2}}=\frac{1}{h^{2}}\left(F_{-1}-2 F_{0}+F_{1}\right)=0
$$

and since $F_{0}$ is zero,

$$
F_{-1}=-F_{1}
$$

The second boundary condition implies

$$
\frac{d^{2} F n}{d x^{2}}=\frac{1}{h^{2}}\left(F_{n-1}-2 F_{n}+F_{n+1}\right)=0
$$

from which

$$
F_{n+1}=-F_{n-1} \text {, }
$$




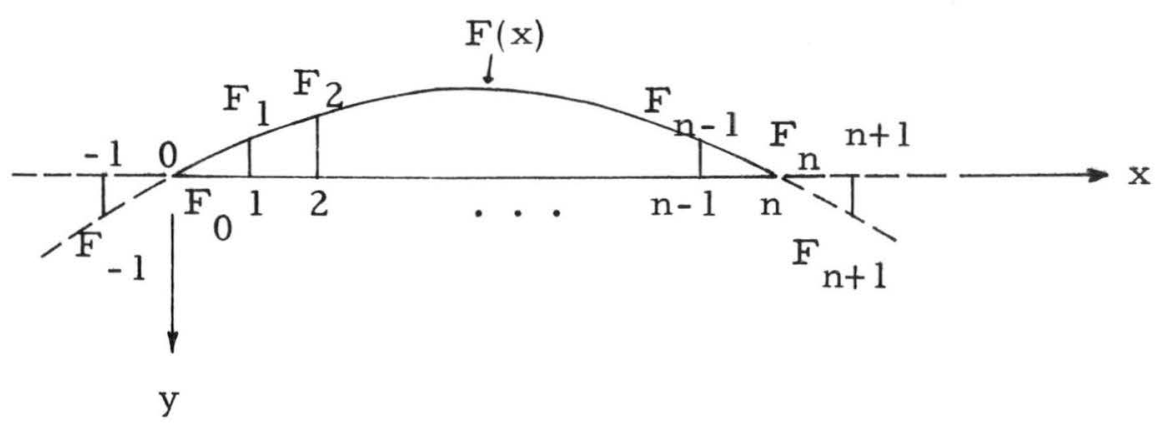

Figure 3.2. Boundary Conditions

For convenience, a symbol $\mathrm{z}$ is used as follows:

$$
\begin{gathered}
\mathrm{z}=\frac{\mathrm{x}}{\mathrm{L}}, \quad 0 \leq \mathrm{z} \leq 1 \\
\frac{\mathrm{d}}{\mathrm{dx}}=\frac{1}{\mathrm{~L}} \frac{\mathrm{d}}{\mathrm{dz}} \text { and } \frac{\mathrm{d}^{2}}{\mathrm{dx} \mathrm{x}^{2}}=\frac{1}{\mathrm{~L}^{2}} \frac{\mathrm{d}^{2}}{\mathrm{dz}^{2}} .
\end{gathered}
$$

The boundary conditions in terms of $z$ become

$$
\begin{aligned}
& F_{0}=0 \text { at } z=0,(x=0) \\
& F_{n}=0 \text { at } z=1,(x=L)
\end{aligned}
$$

Then, using a five point control operator for $\frac{d^{2} F}{d x^{2}}$, the following operators are obtained (see Appendix III-1)

$$
\frac{\mathrm{d}^{2} \mathrm{~F}}{\mathrm{dx} \mathrm{x}^{2}}=\frac{\mathrm{l}}{\mathrm{L}^{2}} \frac{\mathrm{d}^{2} \mathrm{~F}}{\mathrm{d \textrm {z } ^ { 2 }}}=\frac{\mathrm{l}}{12 \mathrm{~h}^{2}}[-1 \text { (16) }
$$


where the error of the finite difference operator is of order $h^{4}$.

Substituting (3.18) into (3.9) for the $i^{\text {th }}$ nodal point yields

$$
\frac{d^{2} F_{i}}{d z^{2}}-C_{1} L^{2} F_{i}=-C_{2} L^{2} M
$$

where

$$
M=\frac{q x}{2}(L-x)-\frac{q(z L)}{2}(L-z L)=\frac{q L^{2}}{2}(1-z) z
$$

and the derivatives are now taken with respect to $\mathrm{z}$.

Substituting (3.20) into (3.21) after some algebraic manipulation the final form of (3.21) will be

$$
\begin{gathered}
-F_{i-2}+16 F_{i-1}-30 F_{i}+16 F_{i+1}-F_{i+2}-12 C_{1} \frac{L^{2}}{n^{2}} F_{i} \\
=-6 C_{2} \frac{q L^{4}}{4}(1-z) z
\end{gathered}
$$

or in the operator form as

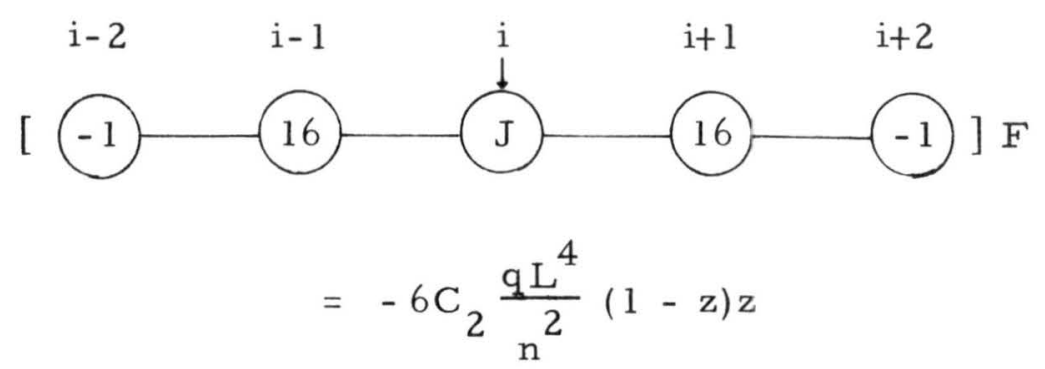


where

$$
J=-30-12 C_{1} \frac{L^{2}}{n^{2}}
$$

Writing (3.24) $(\mathrm{n}-1)$ times for $\mathrm{F}_{1}$ through $\mathrm{F}_{\mathrm{n}-1}$ and using (3.15) and (3.16) gives $(n-1)$ simultaneous linear equations which can be written in matrix form as

$$
[\mathrm{H}]\{\mathrm{F}\}=\left\{\mathrm{C}_{2} \mathrm{~L}^{2} \mathrm{M}\right\} \text {. }
$$

The expanded form of this equation is shown in Figure 3. 3.

The next step is to solve for the deflections of a rigidly connected beam by the same procedure.

$\frac{\mathrm{d}^{2} \mathrm{y} s}{\mathrm{dx} \mathrm{x}^{2}}=\frac{\mathrm{l}}{\mathrm{L}^{2}} \frac{\mathrm{d}^{2} \mathrm{y} s}{\mathrm{dz^{2 }}}=\frac{\mathrm{l}}{\mathrm{h}^{2}}[$ (1) (1)

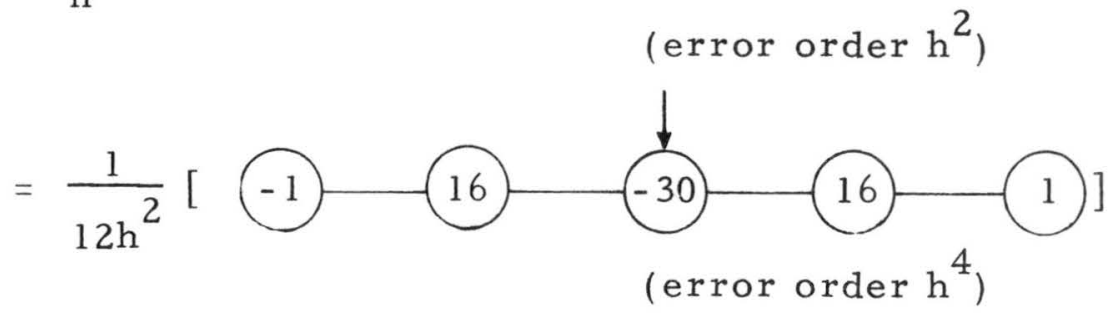

$=0$ at the supports

Thus,

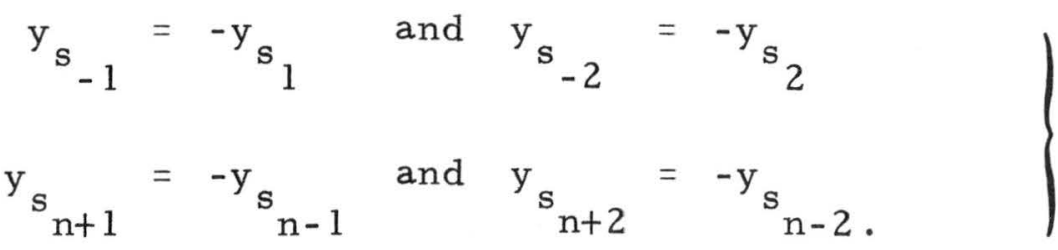




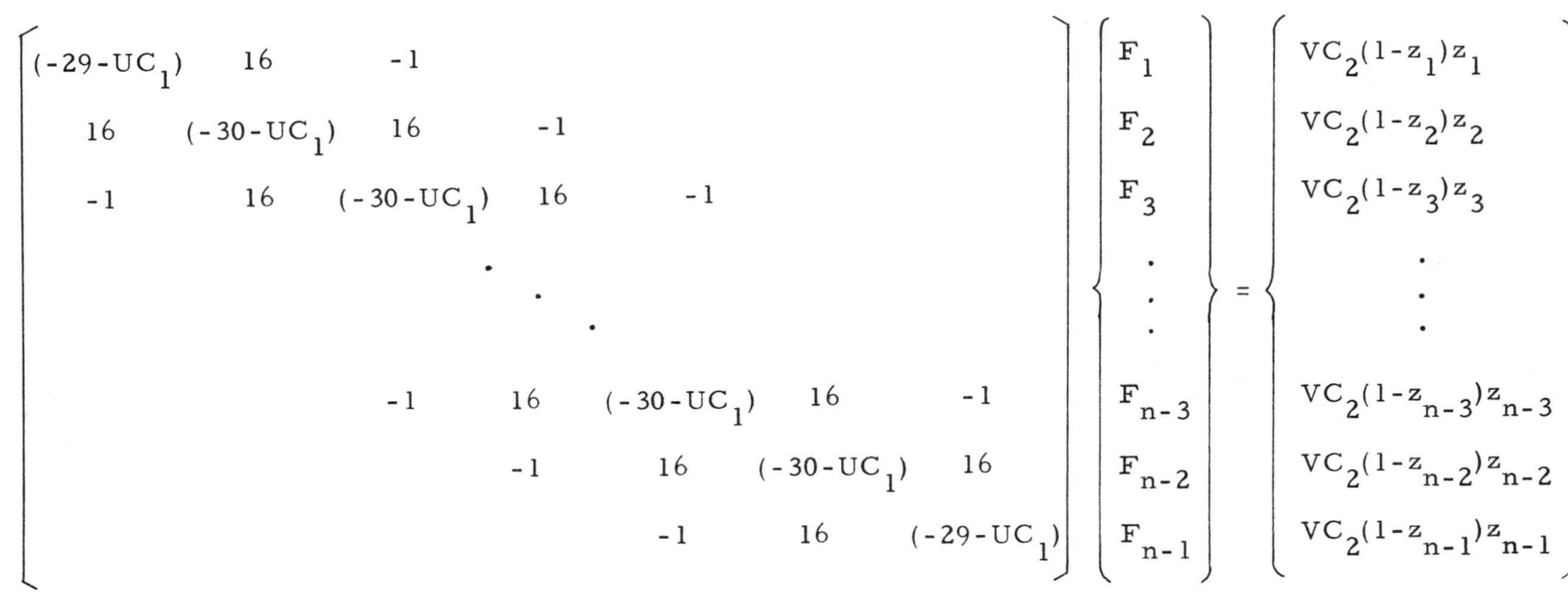

where $U=12 \frac{L^{2}}{n^{2}}, \quad V=-6 \frac{q L^{4}}{n^{4}}, \quad C_{1}$ and $C_{2}$ can vary along the beam length.

Figure 3.3. Matrix Formulation for Finite Difference Solution for F 
Governing equation (3.4) for y becomes

$$
\frac{d^{2} y}{d z^{2}}=-L^{2} \frac{M}{E I s} .
$$

Substituting (3.22) and (3.26) into (3.28) and collecting terms gives

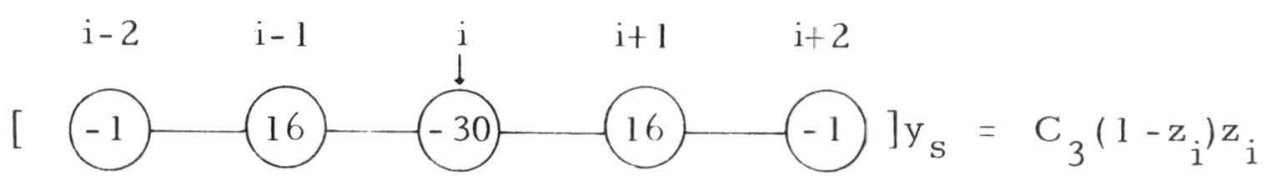

where

$$
C_{3}=-6 \frac{q L^{4}}{n^{2} E I_{s}}
$$

The simultaneous equations for $y_{s}$ written in matrix form is

$$
[R]\left\{y_{s}\right\}=\left\{C_{3}(1-z) z\right\} \text {. }
$$

The expanded form of these equations is shown in Figure 3.4.

Once $F$ and $y_{S}$ are solved by (3.25) and (3.30), the deflection $y$ of this two layered system including interlayer slip can be easily solved by (3.13).

3. 4 Example Problem for Beam with Uniform Load Consider a simply supported beam as a $12 \mathrm{ft}$. span and loaded by a uniformly distributed vertical load $q$ as shown in Figure 3.5. Before testing the equations developed in the previous section, the 


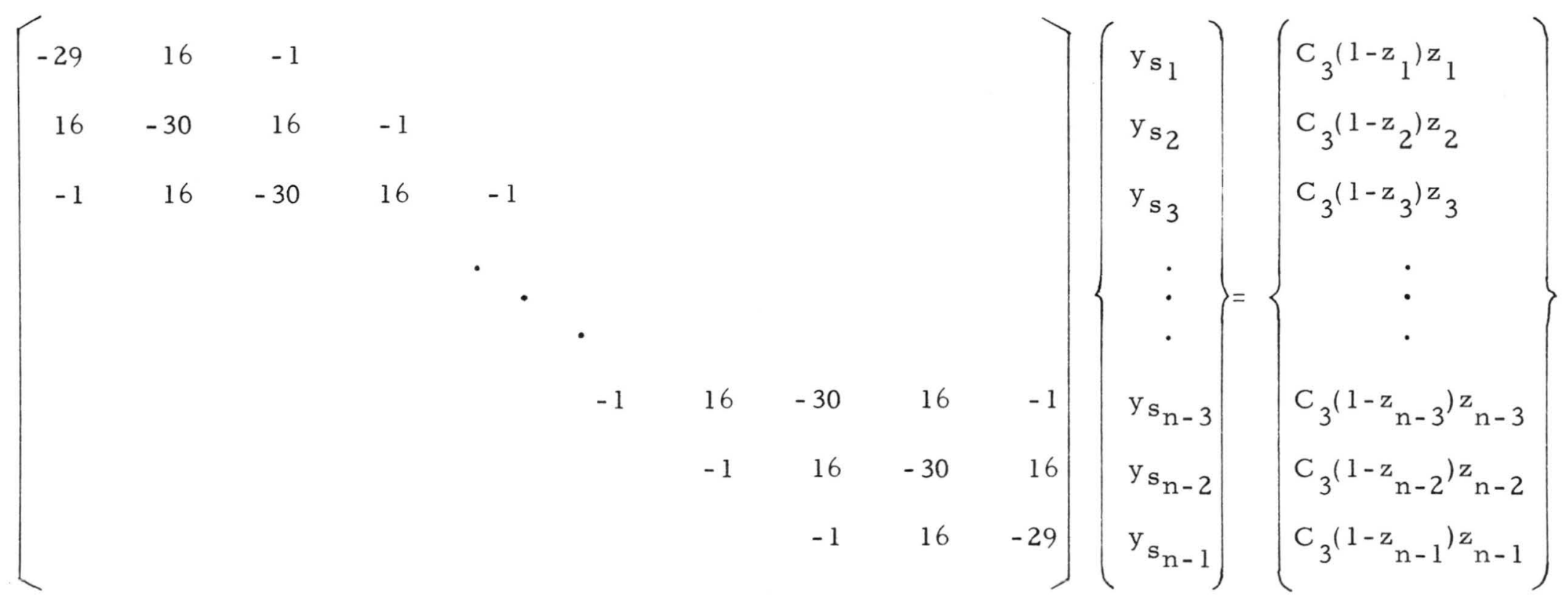

where $\mathrm{C}_{3}$ may vary along the beam length

Figure 3.4. Matrix Formulation for Finite Difference Solution for $\mathrm{y}_{\mathrm{s}}$ 


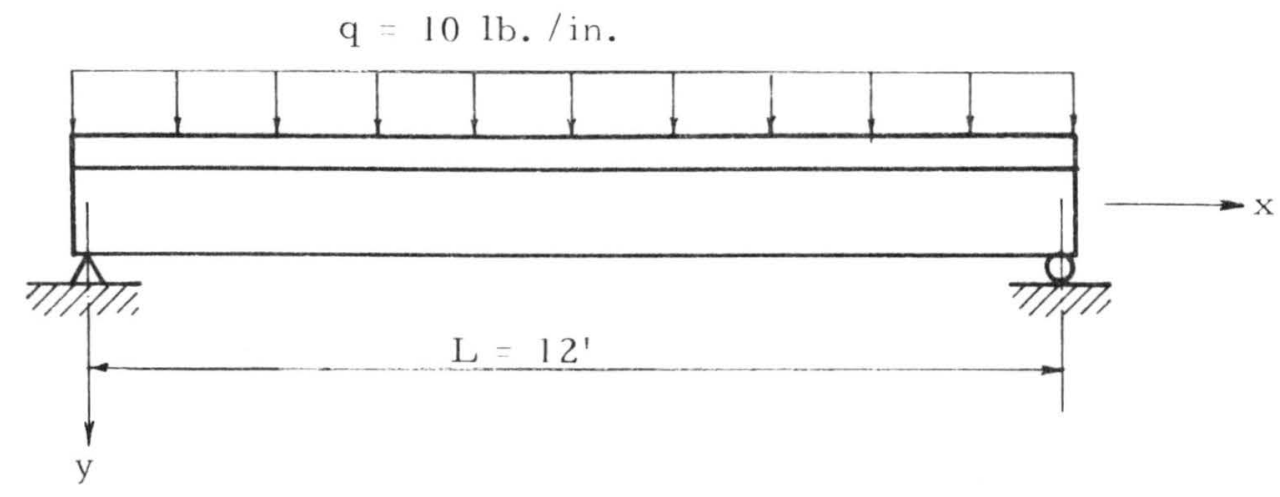

(a) Beam with sign convention and applied loading

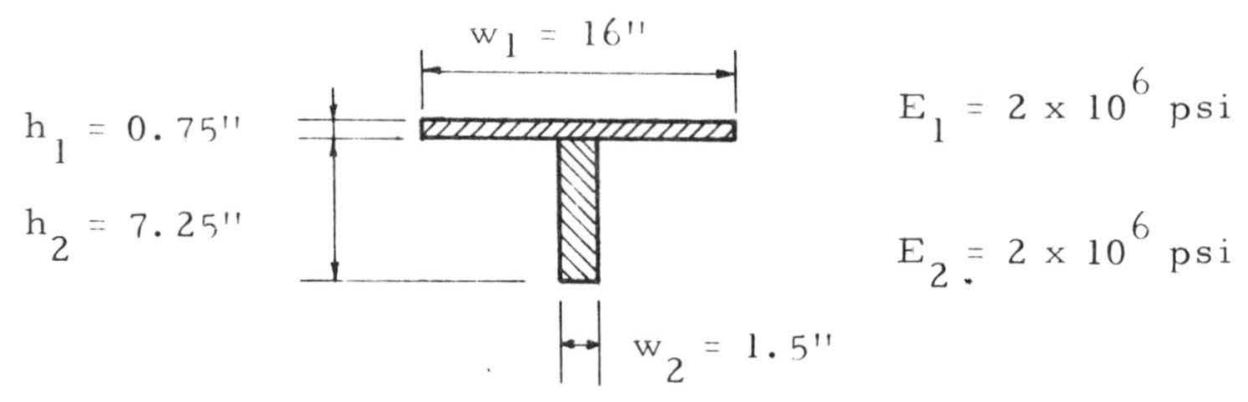

(b) Cross section with one axis of symmetry

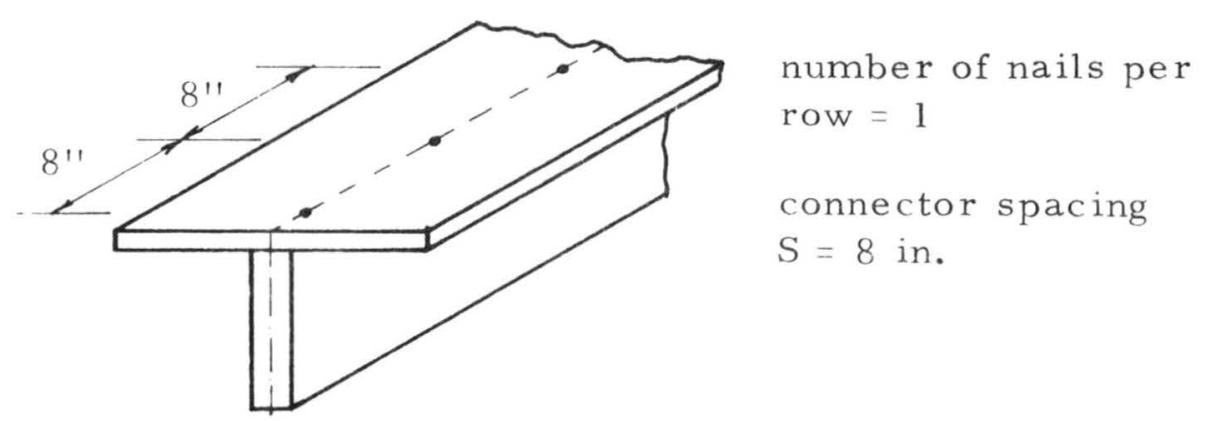

(c) Connector spacing and number of nails

Figure 3.5. Two Layered System with Uniform Load 


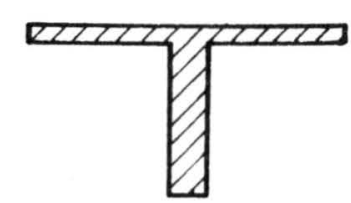

(d) Rigidly connected beam cross section
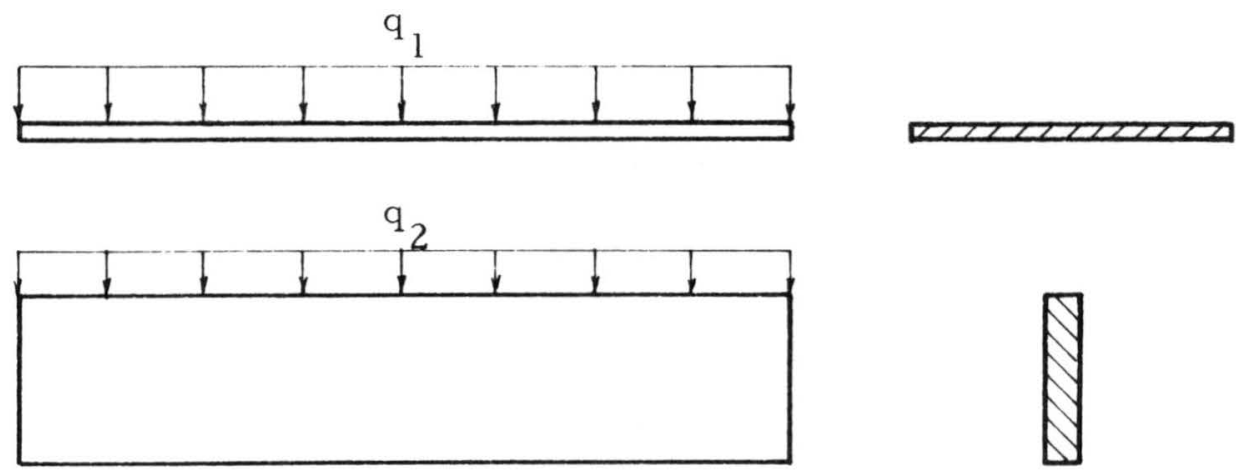

\&

(e) Two separate beams

Figure 3.5.--Continued 
upper and lower bounds can be calculated. The upper bound corresponds to a solution for an equivalent rigidly connected beam as shown in Figure 3. 5(d) and the lower bound is the solution for a beam with no connector between the layers.

(1) Upper bound on beam stiffness:

For rigidly connected beam, no slip occurs and the connector modulus $\mathrm{k}$ will be considered as infinite. Thus at midspan, deflection $\mathrm{y}_{\mathrm{s}}=\frac{5}{384} \frac{\mathrm{qL}^{4}}{\mathrm{EI}}$

$$
\begin{aligned}
& =\frac{5}{384} \frac{(10)(144)^{4}}{\left(2 \times 10^{6}\right)(139.48)} \\
& =0.20070 \mathrm{in} .
\end{aligned}
$$

(2) Lower bound on beam stiffness:

Consider two separate beams with a connector modulus $k$ of zero. Thus,

$$
q_{1}+q_{2}=q
$$

where

$q_{1}=$ the load applied to the top layer, and

$\mathrm{q}_{2}=$ the load applied to the bottom layer.

The load applied to each layer will be proportional to the moment of inertia of that layer. Thus, 


$$
\frac{\mathrm{q}_{1}}{\mathrm{I}_{1}}=\frac{\mathrm{q}_{2}}{\mathrm{I}_{2}},
$$

therefore

$$
q_{1}=q_{2} \frac{I_{1}}{I_{2}} .
$$

With this substitution, (3.31) yields

$$
\mathrm{q}_{2}=\frac{\mathrm{q}}{\left(1+\frac{\mathrm{I}_{1}}{\mathrm{I}_{2}}\right)}=\frac{10}{\left(1+\frac{0.5625}{47.6348}\right)}=9.883293 \mathrm{lb} . / \mathrm{in} .
$$

Thus, at midspan

$$
\begin{aligned}
\text { deflection } y & =\frac{5}{384} \frac{\mathrm{qL}^{4}}{\mathrm{EI}_{2}} \\
& =\frac{5}{384} \frac{(9.883293)(144)^{4}}{\left(2 \times 10^{6}\right)(47.6348)} \\
& =0.58082 \mathrm{in} .
\end{aligned}
$$

The axial force $F$ and deflection $y$ of the theoretical results at every node along the beam can be calculated. The computed deflection at the center point of the beam versus a series of different connector modulus are listed in Table 3. 1 and Figure 3.6. The axial force values and the deflection shape for a $k$ value of 
Table 3. 1. Deflections with Uniform Load vs Connector Modulus

\begin{tabular}{|c|c|c|c|}
\hline \multirow{2}{*}{$\begin{array}{l}\text { connector } \\
\text { modulus } \mathrm{k} \\
(\mathrm{lb} . / \mathrm{in} .)\end{array}$} & \multicolumn{2}{|c|}{ deflection y (in.) at midspan } & \multirow{2}{*}{$\begin{array}{c}y / y s \\
\text { by closed form }\end{array}$} \\
\hline & by closed form & by finite diff. & \\
\hline \multicolumn{4}{|l|}{ (upper bound) } \\
\hline$(\infty)$ & $(0.20070)$ & & $(1.0000)$ \\
\hline $10,000,000$ & 0.20127 & 0.20127 & 1.0028 \\
\hline $1,000,000$ & 0.20619 & 0.20619 & 1.0274 \\
\hline 100,000 & 0.24969 & 0.24969 & 1. 2441 \\
\hline 50,000 & 0.28776 & 0.28776 & 1.4338 \\
\hline 20,000 & 0.36305 & 0.36305 & 1.8090 \\
\hline 15,000 & 0.39026 & 0.39027 & 1.9446 \\
\hline 12,000 & 0.41143 & 0.41144 & 2.0501 \\
\hline 10,000 & 0.42836 & 0.42837 & 2.1344 \\
\hline 9,000 & 0.43789 & 0.43790 & 2.1819 \\
\hline 8,000 & 0.44824 & 0.44825 & 2.2334 \\
\hline 6,000 & 0.47192 & 0.47193 & 2.3514 \\
\hline 3,000 & 0.51730 & 0.51731 & 2.5776 \\
\hline 1,000 & 0.55700 & 0.55701 & 2.7754 \\
\hline 100 & 0.57829 & 0.57830 & 2.8815 \\
\hline 10 & 0.58056 & 0.58057 & 2.8928 \\
\hline 1 & 0.58079 & 0.58080 & 2.8939 \\
\hline \multicolumn{4}{|l|}{ (lower bound) } \\
\hline (0) & $(0.58082)$ & & $(2.8940)$ \\
\hline
\end{tabular}




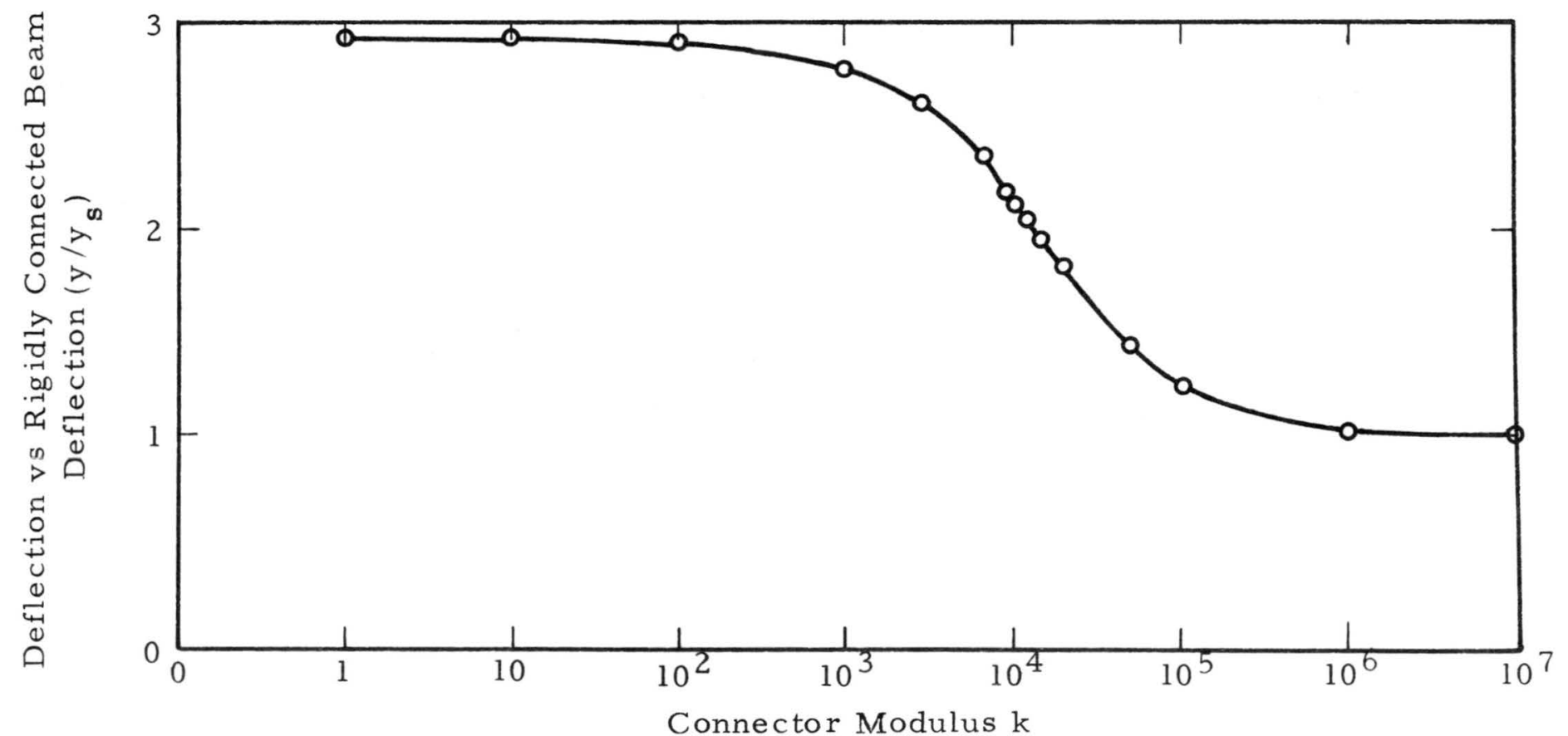

Figure 3.6. Deflection Ratio vs Connector Modulus with Uniform Load 
12, $000 \mathrm{lb}$. /in. / connector are shown in Figure 3.7 for each foot interval along the beam.

3. 5 Closed Form Solution for Beam with Concentrated Load

The two layered system shown in Figure 3.8 is discussed in this section. Using the same procedure stated in (3.1) through (3.9) the final governing equation for $F$ can be written as

$$
\frac{d^{2} F}{d x^{2}}-C_{1} F=-C_{2} M_{x}
$$

where $\mathrm{C}_{1}$ and $\mathrm{C}_{2}$ are the same as (3.9), but

$$
\begin{array}{ll}
M_{x}=M_{L}=P(1-a / L) x=P b x / L, & 0 \leq x \leq a \\
M_{x}=M_{R}=P a(1-x / L) & , a \leq x \leq L
\end{array}
$$

The general solution of (3.32) is stated as

$$
\begin{aligned}
& F_{L}(x)=A_{1} \cosh \left(\sqrt{C_{1}} x\right)+A_{2} i \sinh \left(\sqrt{C_{1}} x\right) \\
& +\frac{C_{2}}{C_{1}} P\left(1-\frac{a}{L}\right) x \quad 0 \leq x \leq a
\end{aligned}
$$

and

$$
\begin{aligned}
& F_{R}(x)=B_{1} \cosh \left(\sqrt{C_{1}} x\right)+B_{2} i \sinh \left(\sqrt{C_{1}} x\right) \\
& +\frac{C_{2}}{C_{1}} \mathrm{~Pa}(1-\mathrm{x} / \mathrm{L}) \quad \mathrm{a} \leq \mathrm{x} \leq \mathrm{L}
\end{aligned}
$$



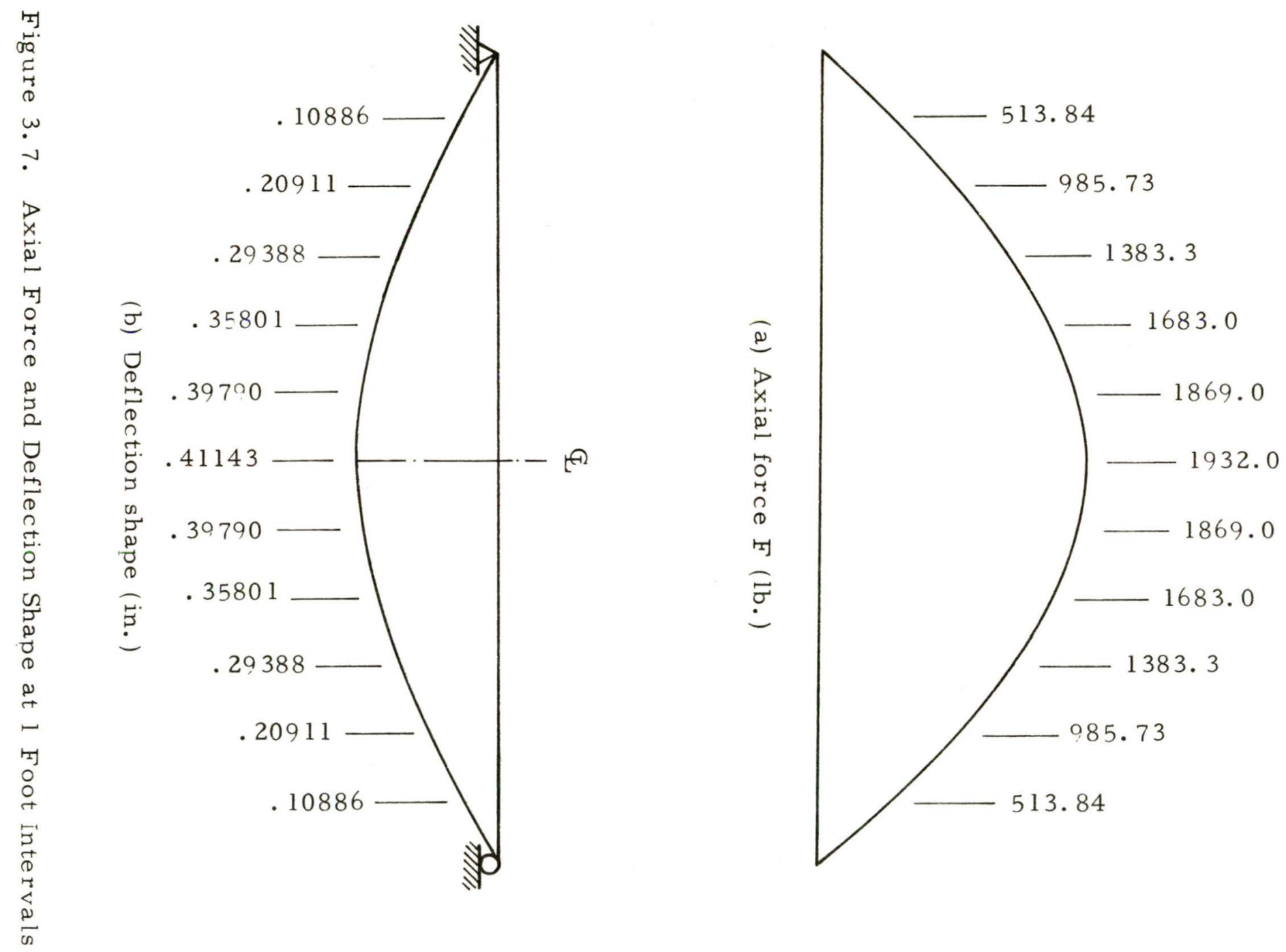


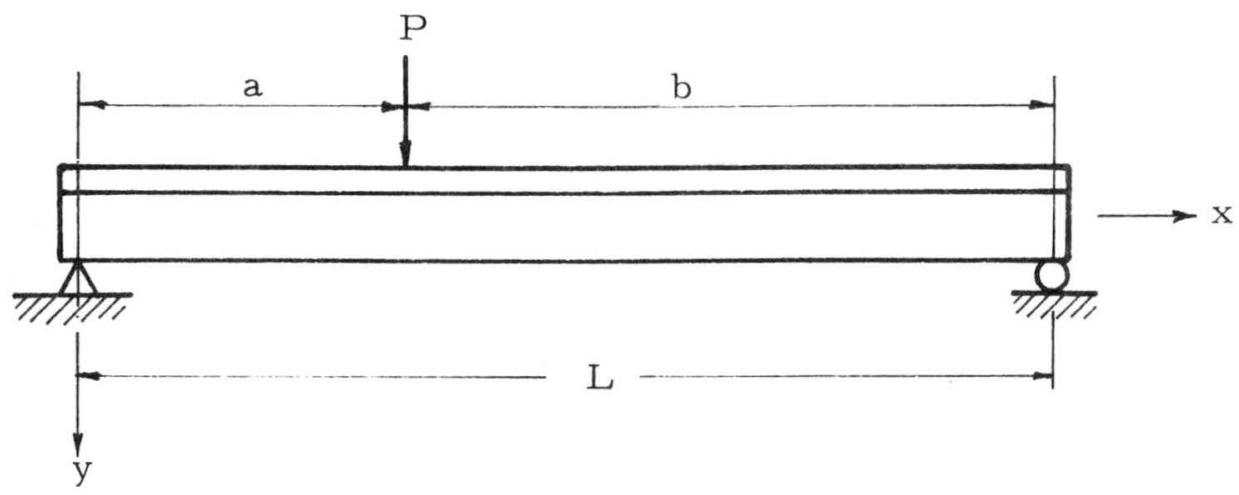

(a) Beam sign concention and applied load P

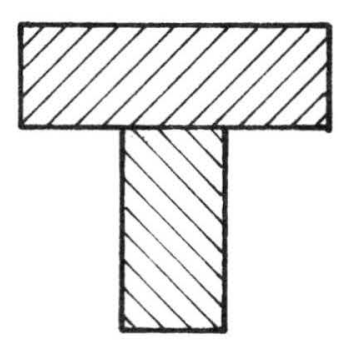

(b) Cross-section

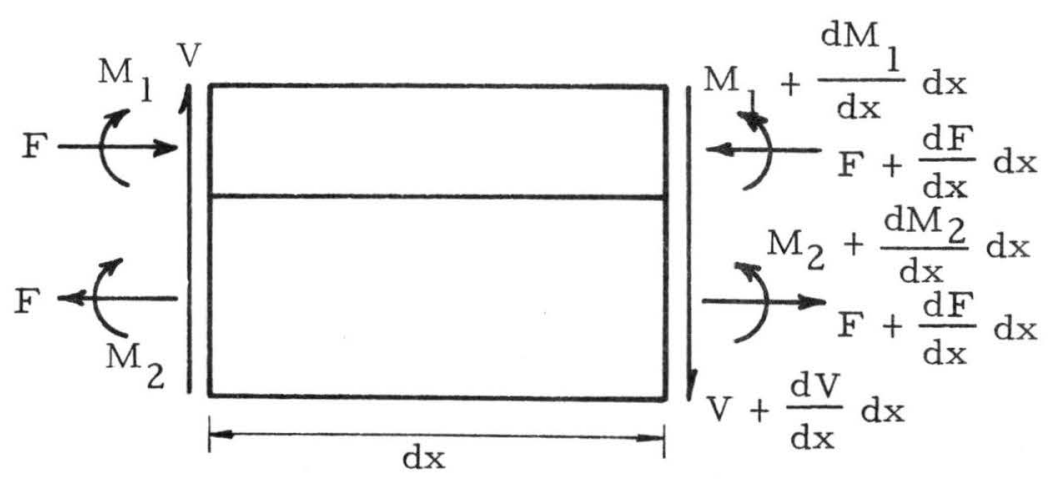

(c) Beam element

Figure 3.8. Two Layered System with Concentrated Load 
where $A_{1}, A_{2}, B_{1}$ and $B_{2}$ are unknown and can be determined from the following boundary conditions:

$$
\begin{aligned}
F_{L}(0) & =0 \\
F_{R}(L) & =0 \\
F_{L}(a) & =F_{R}(a) \\
\frac{d F_{L}(a)}{d x} & =\frac{d F_{R}(a)}{d x}
\end{aligned}
$$

The first boundary condition in (3.34) requires $A_{1}$ to be zero. Equations for the remaining coefficients are on the following page.

Solving these unknown coefficients by Cramer's method or any other simultaneous equations technique gives

$$
\begin{aligned}
& A_{2}=\frac{C_{2}}{C_{1}} \frac{i}{\sqrt{C_{1}}} \frac{\sinh \left[{\sqrt{C_{1}}}_{1}(L-a)\right]}{\sinh \left(\sqrt{\left.C_{1} L\right)} P,\right.} \\
& B_{1}=-\frac{C_{2}}{C_{1}} \frac{\sinh \left(\sqrt{C}_{1} a\right)}{\sqrt{C_{1}} P,} \\
& B_{2}=-\frac{C_{2}}{C_{1}} \frac{i}{\sqrt{C_{1}}} \frac{\sinh \left(\sqrt{C}_{1} a\right)}{\tanh \left(\sqrt{C}_{1} L\right)} P .
\end{aligned}
$$

Thus, the final results for $F_{L}$ and $F_{R}$ are 


$$
\begin{aligned}
F_{L}(x)= & -\frac{C_{2}}{C_{1}} \frac{P}{\sqrt{C_{1}}} \frac{\sinh \left[\sqrt{C_{1}}(L-a)\right]}{\sinh \left(\sqrt{C_{1} L}\right)} \sinh \left(\sqrt{\left.C_{1} x\right)}\right. \\
& +\frac{C_{2}}{C_{1}} P\left(1-\frac{a}{L}\right) x \quad 0 \leq x \leq a \\
F_{R}(x)= & -\frac{C_{2}}{C_{1}} \frac{P}{\sqrt{C_{1}}} \sinh \left(\sqrt{C_{1}} a\right) \cosh \left(\sqrt{C_{1}} x\right) \\
& +\frac{C_{2}}{C_{1}} \frac{P}{\sqrt{C_{1}}} \frac{\sinh \left(\sqrt{C_{1}} a\right)}{\tanh \left(\sqrt{C_{1}} L\right)} \sinh \left(\sqrt{C_{1}} x\right) \\
& +\frac{C_{2}}{C_{1}} \frac{P_{a}(1-x / L)}{1} \quad a \leq x \leq L
\end{aligned}
$$

Equations similar to (3.13) can now be written as

$$
\begin{aligned}
& y_{L}=\left(y_{s}\right)_{L}+\frac{C_{12}}{\sum_{1}^{2} E_{i}} \frac{1}{C_{1}} F_{L}, \\
& y_{R}=\left(y_{s}\right)_{R}+\frac{C_{12}}{\sum_{1}^{2} E I_{i}} \frac{1}{C_{1}} F_{R} .
\end{aligned}
$$

Or, using the alterative forms

$$
y_{L}=\left(y_{s_{L}}\right)+P\left(\frac{1}{C_{1}}\right) \frac{1}{E I_{S}}(T \cdot C \cdot-1) A_{3}
$$


and

$$
y_{R}=\left(y_{s_{R}}\right)+P\left(\frac{1}{C_{1}}\right) \frac{1}{E I_{S}}(T \cdot C \cdot-1) B_{3}
$$

where

$$
\begin{gathered}
A_{3}=\left(1-\frac{a}{L}\right) x-\frac{1}{\sqrt{C_{1}}} \frac{\sinh \left[\sqrt{C_{1}}(L-a)\right] \sinh \left(\sqrt{C_{1}} x\right)}{\sinh \left(\sqrt{C_{1} L}\right)}, \\
B_{3}=a(1-x / L)-\frac{1}{\sqrt{C_{1}}} \sinh \left(\sqrt{C_{1}} a\right) \cosh \left(\sqrt{C_{1}} a\right) \\
+\frac{1}{\sqrt{C_{1}}} \frac{\sinh \left(\sqrt{C_{1}} a\right)}{\tanh \left(\sqrt{C_{1} L}\right)} \sinh \left(\sqrt{C_{1}} x\right), \\
\text { C. C. }=\frac{I_{S}}{2} \\
\sum_{1} I
\end{gathered}
$$

and with other notation corresponding to that given in (3.9).

3.6 Finite Difference Approach for Beam with Concentrated Load Following the same procedure used in Section 3. 3, (3. 32) may be changed to

$$
\frac{d^{2} F}{d z^{2}}-C_{1} L^{2} F=-C_{2} L^{2} M
$$




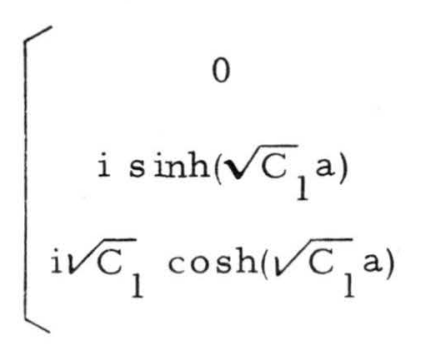

$$
\begin{gathered}
\cosh \left(\sqrt{\mathrm{C}_{1} L}\right) \\
-\cosh \left(\sqrt{\mathrm{C}_{1}} a\right) \\
-\sqrt{\mathrm{C}_{1}} \sinh \left(\sqrt{\mathrm{C}_{1}} a\right)
\end{gathered}
$$

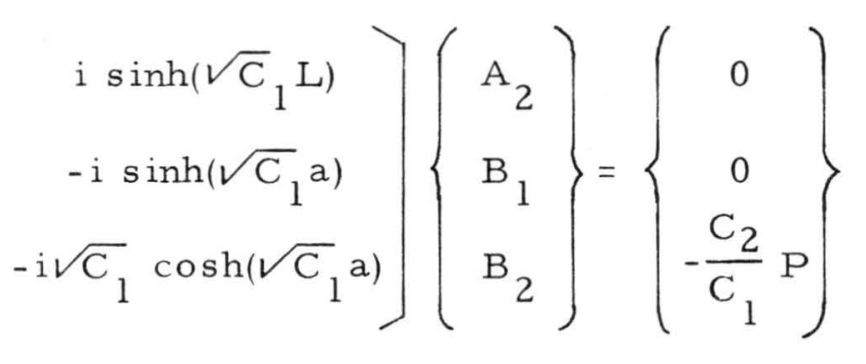


where

$$
\begin{array}{ll}
M=M_{L}=P b z & 0 \leq z \leq a / L \\
M=M_{R}=P a(1-z) & a / L \leq z \leq 1
\end{array}
$$

and the derivatives of this equation are taken with respect to $z$. A final matrix form for the axial forces is similar to (3.25) and is

$$
[\mathrm{H}]\{\mathrm{F}\}=\left\{\mathrm{C}_{2} \mathrm{~L}^{2} \mathrm{M}\right\}
$$

where $M_{L}$ and $M_{R}$ are given in (3.41). The expanded form of (3.42) is shown in Figure 3.9. The load is applied at the $i^{\text {th }}$ nodal point and the following notation is used:

$$
\begin{aligned}
& U=12 \frac{L^{2}}{n^{2}}, \\
& C_{1}=\frac{k n}{E S}\left[\frac{1}{A_{1}^{\cdot \cdot}}+\frac{1}{A_{2}^{\cdot \cdot}}\right](T . C .), \\
& C_{2}=\frac{k n}{E S} \frac{C_{2}}{\sum_{1}^{2} I}, \\
& \text { T.C. }=\frac{I_{S}}{\sum_{1}^{2}}
\end{aligned}
$$

and 


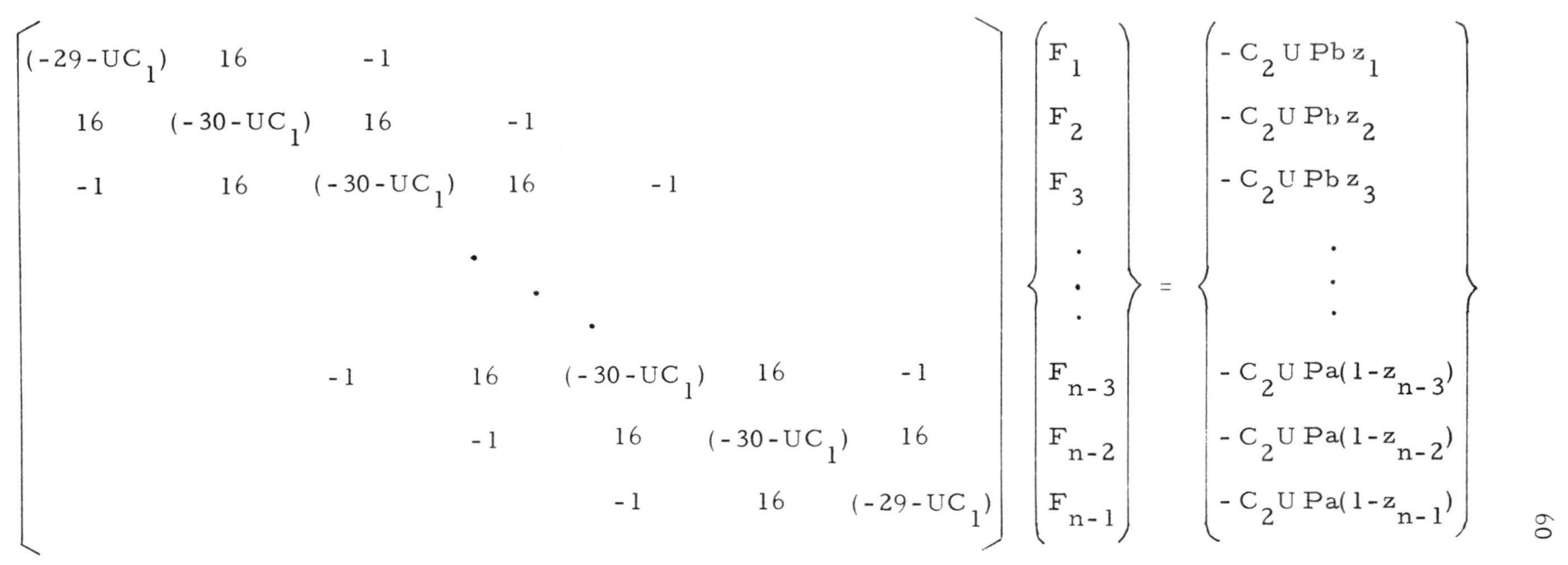

Figure 3.9. Matrix Form of F for Finite Difference Solution by Concentrated Load P Applied at $i^{\text {th }}$ Nodal Point 


$$
\mathrm{C}_{12}=\frac{\mathrm{h}_{1}+\mathrm{h}_{2}}{2} \text {. }
$$

$\mathrm{C}_{1}$ and $\mathrm{C}_{2}$ may vary along the beam length.

The deflection of rigidly connected beam, however, will still be the same as (3.26) through (3.30) except the moment will change to correspond to the concentrated loading. The final matrix form for the rigidly connected beam deflection may be written as

$$
\left.\begin{array}{rl}
{[\mathrm{R}]\left\{\mathrm{y}_{\mathrm{s}}\right\}} & =\left\{\mathrm{C}_{3} \mathrm{M}_{L}\right\} \\
\text { or }=\left\{\mathrm{C}_{3} \mathrm{M}_{\mathrm{R}}\right\} & 0 \leq \mathrm{x} \leq \mathrm{a} \\
& \mathrm{a} \leq \mathrm{x} \leq \mathrm{L}
\end{array}\right\}
$$

or as shown in Figure 3.10,

where

$C_{3}=-12 \frac{L^{2}}{E I_{S}{ }^{2}}$, and may vary along the beam length.

Once $F$ and $y_{s}$ are solved, (3.37) and (3.38) will be used to solve for the actual deflection $y$ including the effects of interlayer s lip.

3. 7 Example Problem for Beam with Concentrated Load

The same example used in Section 3.4 but with concentrated load, P, of $100 \mathrm{lbs}$. will be examined. Upper and lower bounds can 


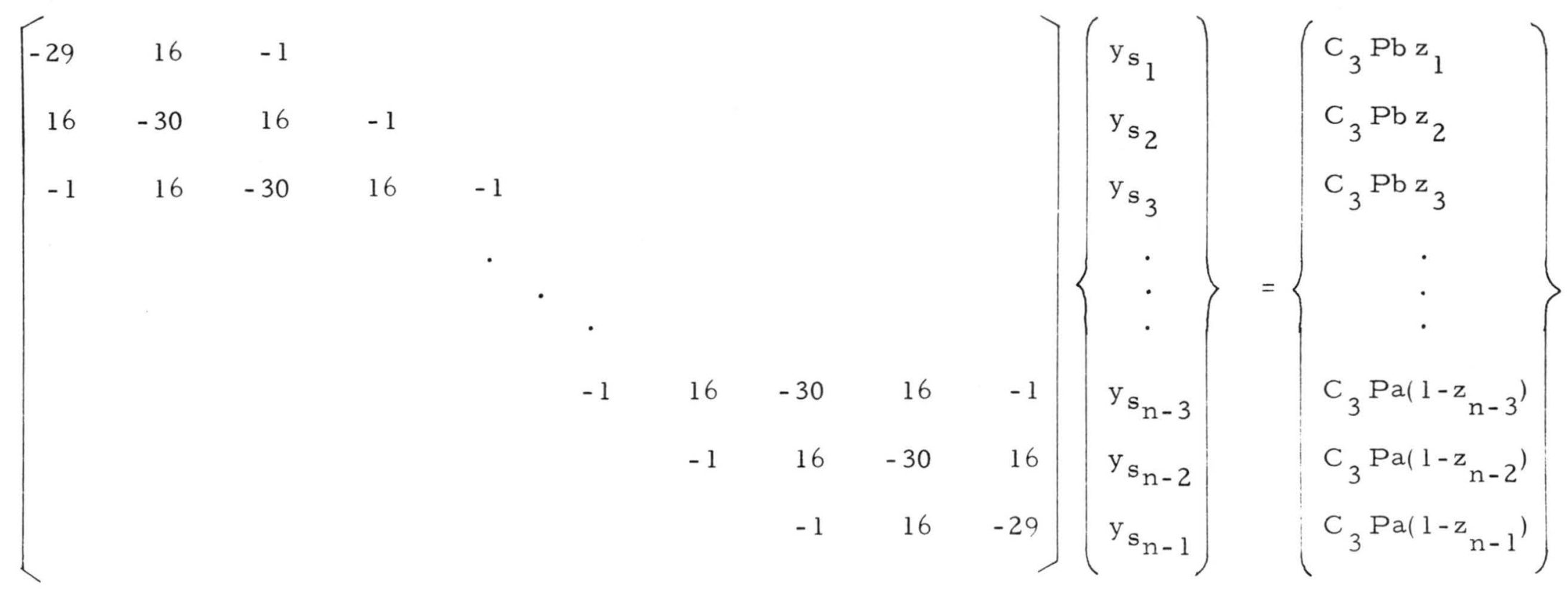

Figure 3.10. Matrix Form of $y_{s}$ for Finite Difference Solution by Concentrated Load $\mathrm{P}$ Applied at $\mathrm{i}^{\text {th }}$ Nodal Point 
be established by computing the deflection corresponding to the rigidly connected beam and the unconnected beams.

(1) Upper bound on beam stiffness:

a) load at midspan,

$$
\begin{aligned}
& \text { deflection } y_{s} \text { at midspan } \\
& =\frac{\mathrm{PL}^{3}}{48 \mathrm{EI}_{\mathrm{S}}}=\frac{(100)(144)^{3}}{48\left(2 \times 10^{6}\right)(139.48)}- \\
& =0.022459 \mathrm{in} .
\end{aligned}
$$

b) load at L/3 from left support,

$$
\begin{aligned}
& \text { deflection } y_{s} \text { at point of load } \\
& =\frac{\mathrm{Pa}^{2} \mathrm{~b}^{2}}{3 \mathrm{EI} \mathrm{s}^{\mathrm{L}}} \\
& =\frac{(100)(48)^{2}(96)^{2}}{3\left(2 \times 10^{6}\right)(139.48)(144)} \\
& =0.017762 \mathrm{in} .
\end{aligned}
$$

(2) Lower bound on beam stiffness:

From calculations in Section 3.4 (2),

$\mathrm{P}_{1}=1.16707 \mathrm{lb}$.

$P_{2}=98.83293 \mathrm{lb}$. 
a) load at midspan,

$$
\begin{aligned}
& \text { deflection } y \text { at midspan } \\
& =\frac{P_{1} L^{3}}{48 \mathrm{EI}_{1}}=\frac{(1.16707)(144)^{3}}{(48)\left(2 \times 10^{6}\right)(0.5625)} \\
& =0.064534 \mathrm{in} .
\end{aligned}
$$

b) load at $L / 3$ from left support, deflection $y$ at point of load

$$
\begin{aligned}
& =\frac{P_{1} a^{2} b^{2}}{3 E I_{1} L} \\
& =0.050990 \mathrm{in} .
\end{aligned}
$$

The final results for this example are listed in Tables 3.2 and 3.3. The axial force value and the deflection shape for $\mathrm{k}=15,000 \mathrm{lb}$ / in. / connector are shown in Figure 3.12. The deflection ratio for both loading conditions are almost the same and the continuous curve is plotted in Figure 3.11. For the design purpose, a plot of $y / y_{s}$ versus $k$ for various value of T.C., a transfer constant relating $I_{S}$ and $\sum I_{i}$, is very useful and is shown in Figure 3.13. 
Table 3.2. Deflections with a Load at Midspan vs Connector Modulus

\begin{tabular}{l|c|c|c}
\hline \multirow{2}{*}{$\begin{array}{c}\text { connector } \\
\text { modulus } k \\
\text { (lb./in.) }\end{array}$} & \multicolumn{2}{|c|}{$\begin{array}{c}\text { load at midspan } \\
\text { deflection at midspan (in.) }\end{array}$} & $\begin{array}{c}\text { y/ys } \\
\text { by closed form }\end{array}$ \\
\cline { 2 - 3 } & by closed form & by finite diff. & \\
\hline
\end{tabular}

(upper bound)

\begin{tabular}{|c|c|c|c|}
\hline$(\infty)$ & $(0.022459)$ & & $(1.000000)$ \\
\hline $1,000,000$ & 0.023011 & 0.023185 & 1.023478 \\
\hline 100,000 & 0.028109 & 0.028340 & 1.251569 \\
\hline 50,000 & 0.032375 & 0.032637 & 1.441515 \\
\hline 15,000 & 0.043678 & 0.044012 & 1. 944788 \\
\hline 10,000 & 0.047857 & 0.048216 & 2.130860 \\
\hline 9,000 & 0.048901 & 0.049266 & 2.177345 \\
\hline 6,000 & 0.052627 & 0.053015 & 2. 343247 \\
\hline 3,000 & 0.057591 & 0.058009 & 2.564272 \\
\hline 1,000 & 0.061932 & 0.062375 & 2.757558 \\
\hline 100 & 0.064259 & 0.064716 & 2.861169 \\
\hline 10 & 0.064507 & 0.064966 & 2.872211 \\
\hline 1 & 0.064532 & & 2.873324 \\
\hline$(0)$ & $(0.064534)$ & & $(2.873413)$ \\
\hline
\end{tabular}


Table 3. 3. Deflections with a Load at L/3 vs Connector Modulus

\begin{tabular}{l|c|c|c}
\hline \multirow{2}{*}{$\begin{array}{c}\text { connector } \\
\text { modulus } k \\
\text { (lb./in.) }\end{array}$} & \multicolumn{2}{|c|}{$\begin{array}{c}\text { load at L/3 } \\
\text { deflection at point of load }\end{array}$} & \multirow{2}{*}{$\begin{array}{c}y / y_{\mathrm{S}} \\
\text { by closed form }\end{array}$} \\
\cline { 2 - 3 } & by closed form & by finite diff. & \\
\hline
\end{tabular}

(upper bound)

$\begin{array}{cccc}(\infty) & (0.017763) & & (1.000000) \\ 1,000,000 & 0.018245 & 0.018402 & 1.027192 \\ 100,000 & 0.022580 & 0.022793 & 1.271253 \\ 50,000 & 0.026067 & 0.026310 & 1.467571 \\ 15,000 & 0.034989 & 0.035296 & 1.969879 \\ 10,000 & 0.038225 & 0.038554 & 2.152066 \\ 9,000 & 0.039030 & 0.039364 & 2.197387 \\ 6,000 & 0.041896 & 0.042248 & 2.358743 \\ 3,000 & 0.045697 & 0.046073 & 2.572739 \\ 1,000 & 0.049008 & 0.049405 & 2.759148 \\ 100 & 0.050781 & 0.051188 & 2.858968 \\ 10 & 0.050969 & 0.051378 & 2.869552 \\ 1 & 0.050988 & 0.051378 & 2.870622 \\ (0) & (0.050990) & & (2.870735)\end{array}$

(lower bound) 


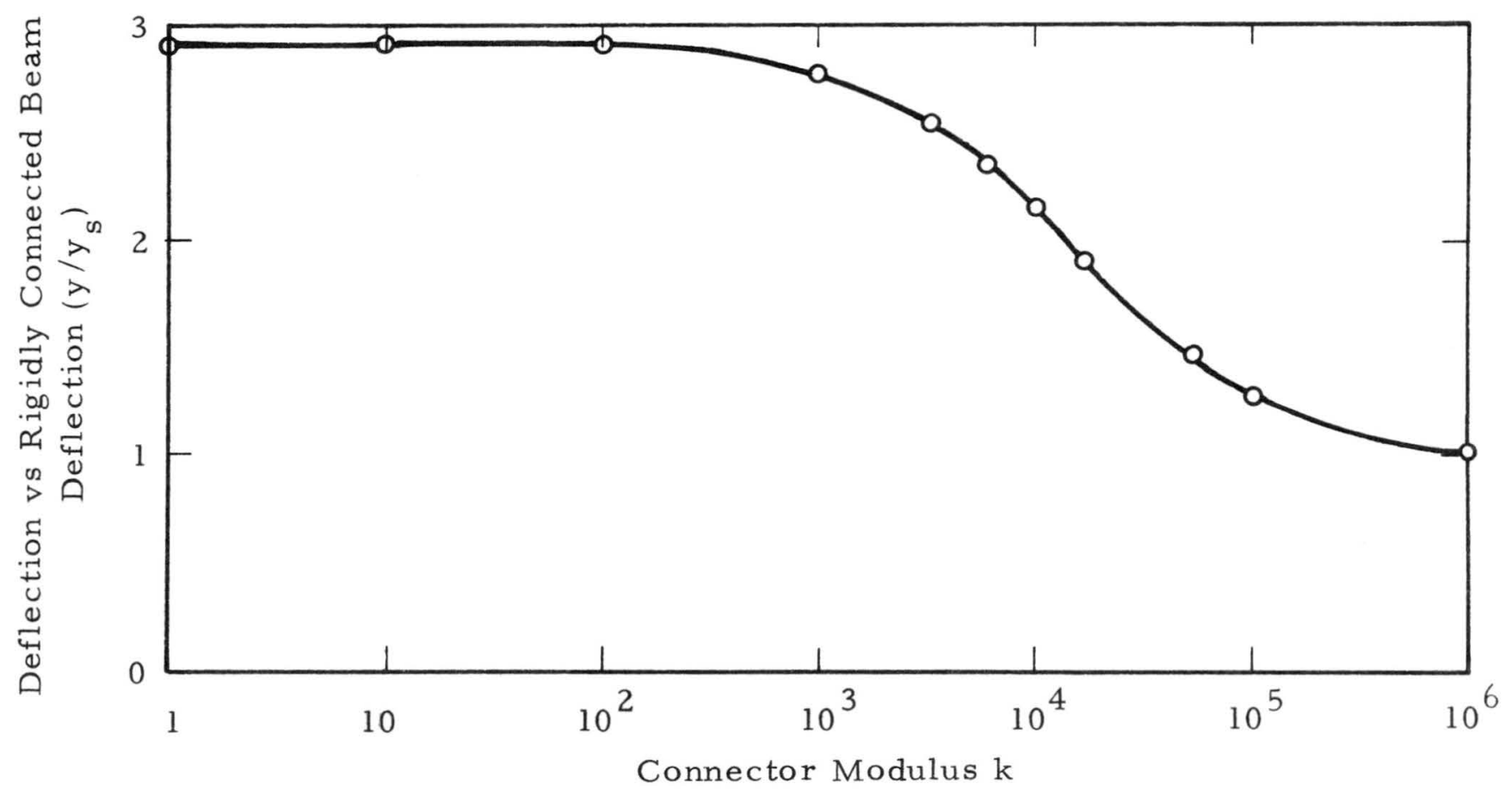

Figure 3.11. Deflection Ratio Curve for Varying k Values with Concentrated Load Applied at Any Point Along the Beam Length 


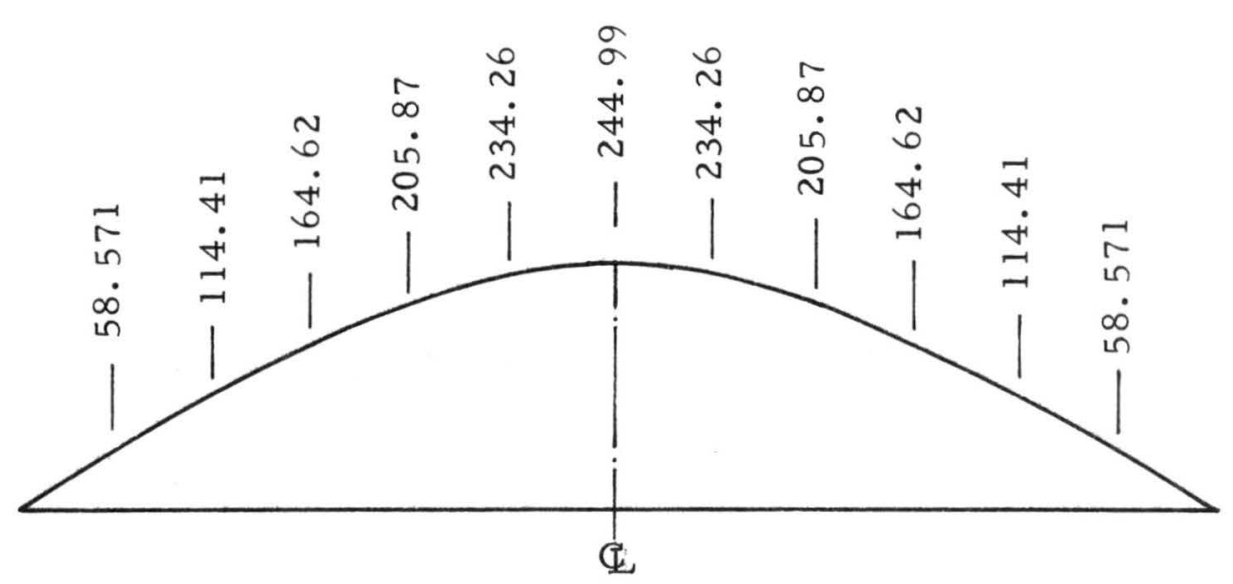

(a) Axial force F (lb.) with concentrated load at center line

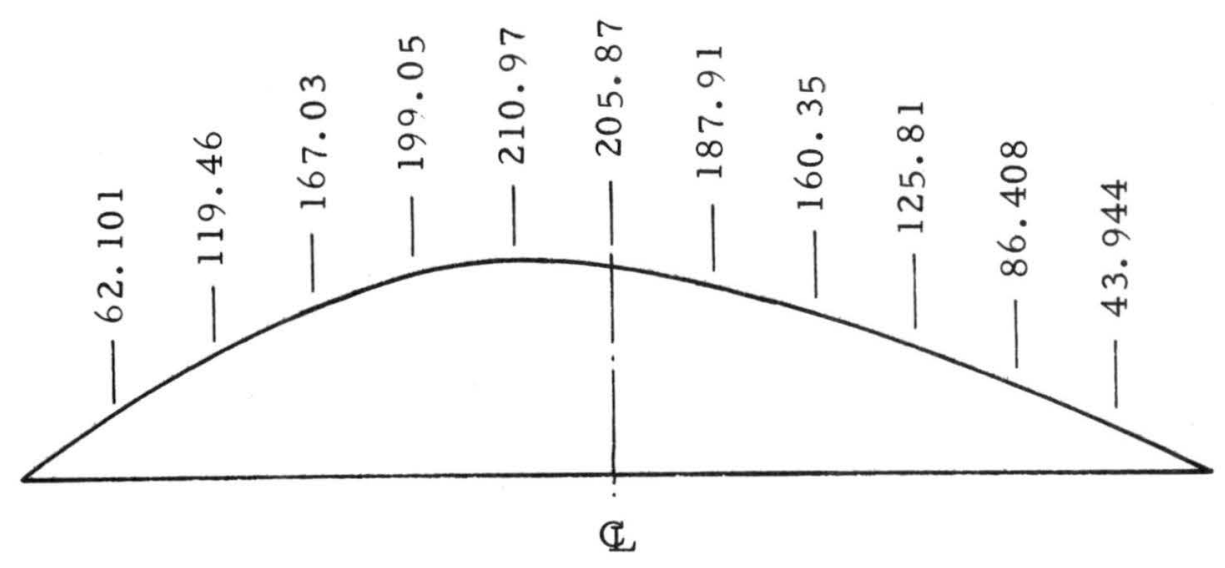

(b) Axial force F (lb.) with concentrated load at left one third point

Figure 3. 12. Axial Force and Deflection Shape at 1 Foot Intervals 

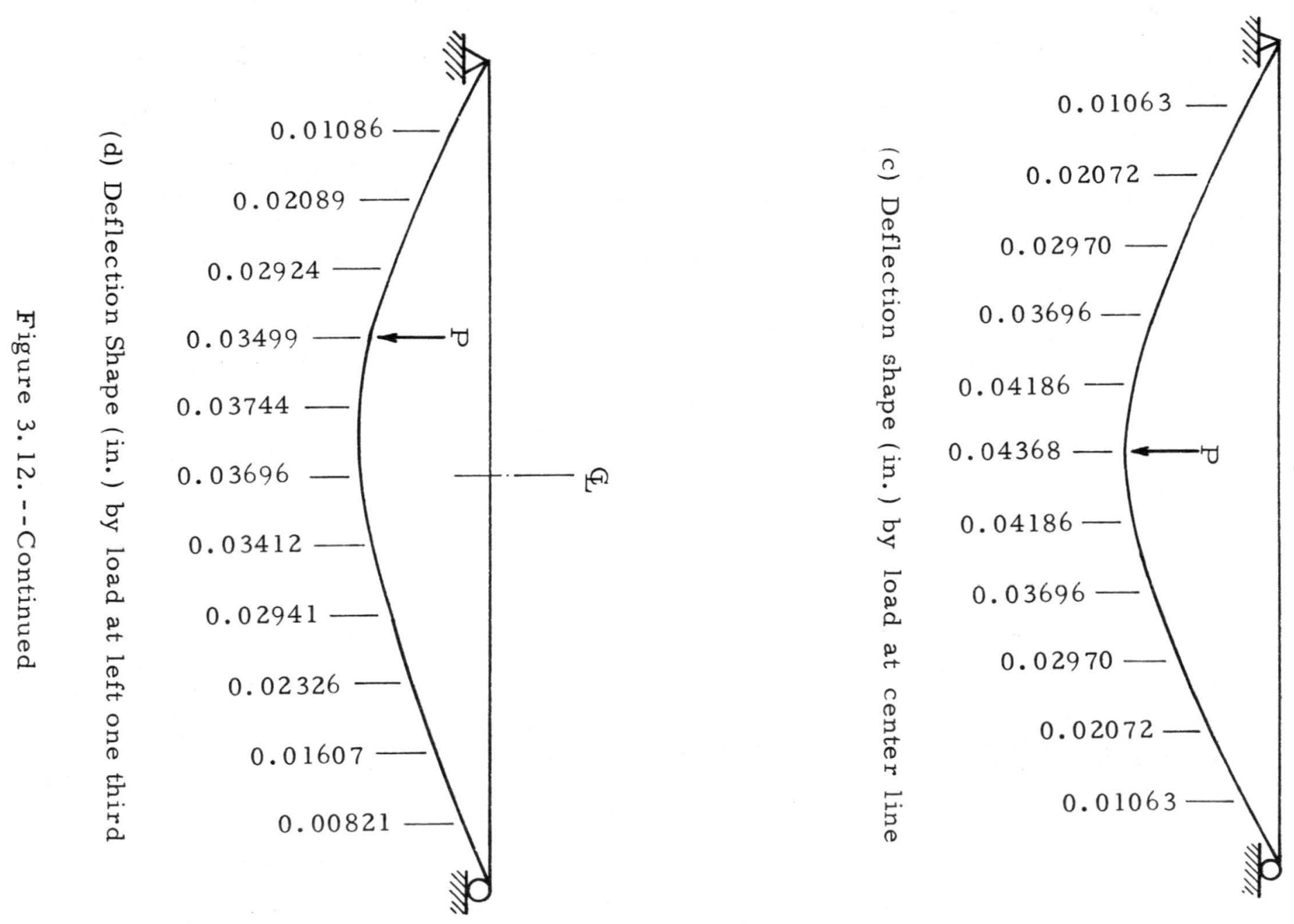


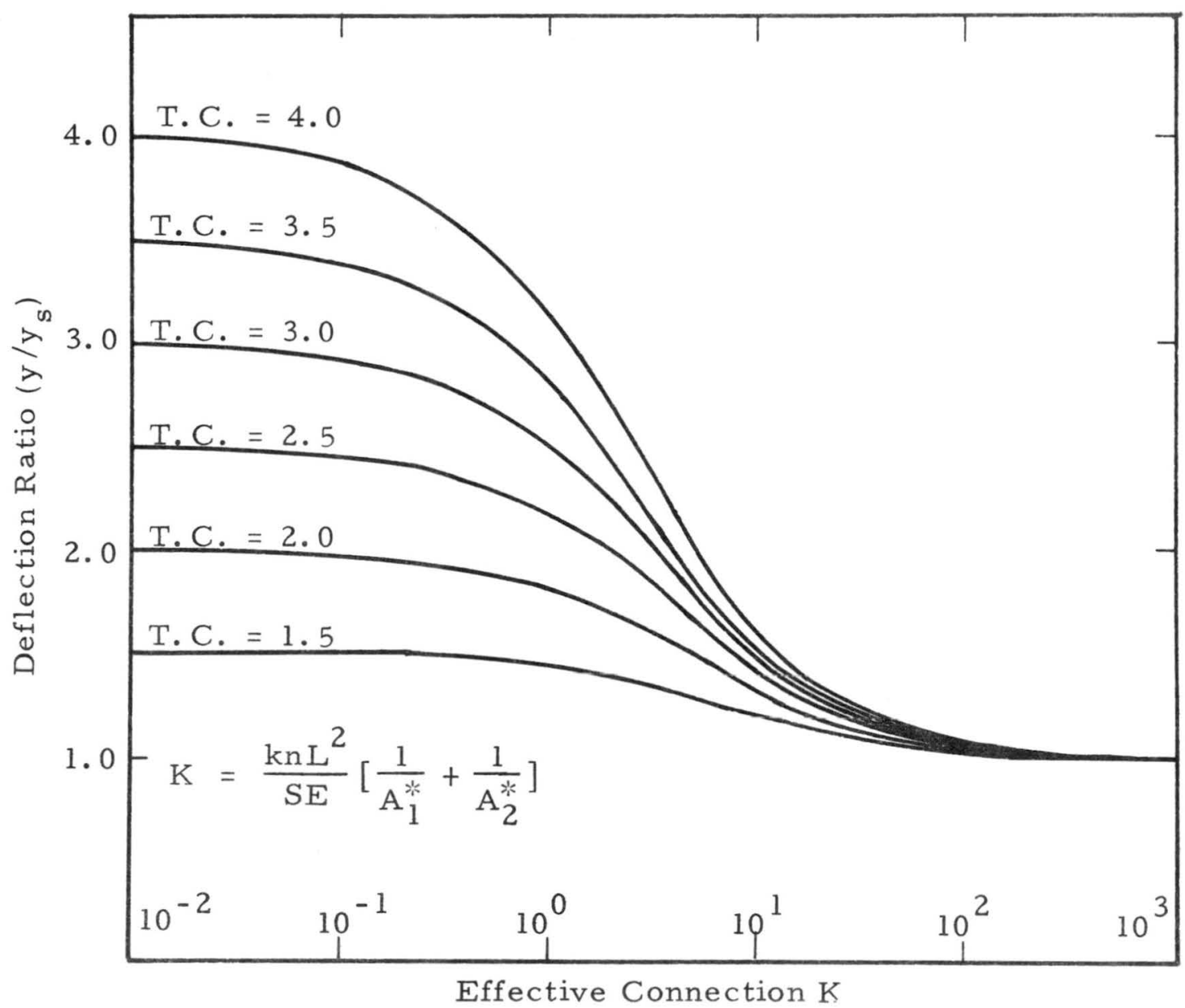

Figure 3.13. Deflection Ratio vs Effective Connection for Any Point Loaded Simply Supported Beam 


\section{CHAPTER 4}

\section{THREE LAYERED SYSTEMS}

\section{1 Introduction}

The development of the governing equations for general three layered systems directly parallels that for the two layered systems and also uses the same assumptions listed in Section 2.2. Again, transformed widths are used to compensate for modulus of elasticity differences. Figure 4.1 depicts the layered system and the associated beam forces and strain distribution.

\section{2 Closed Form Solution for Beam with Uniform Load} Referring to the beam element in Figure 4.1 (d), the equilibrium laws are applied to obtain the following three equations:

$$
\begin{array}{ll}
\text { from } \sum F_{x}=0 & \sum_{1}^{3} \frac{d F_{i}}{d x}=0 \\
\text { from } \sum F_{y}=0 & \frac{d V}{d x}=-q
\end{array}
$$

and

$$
\text { from } \sum M=0 \quad V=\sum_{1}^{3} \frac{d M_{i}}{d x}+\sum_{1}^{3} r_{i} \frac{d F_{i}}{d x}
$$




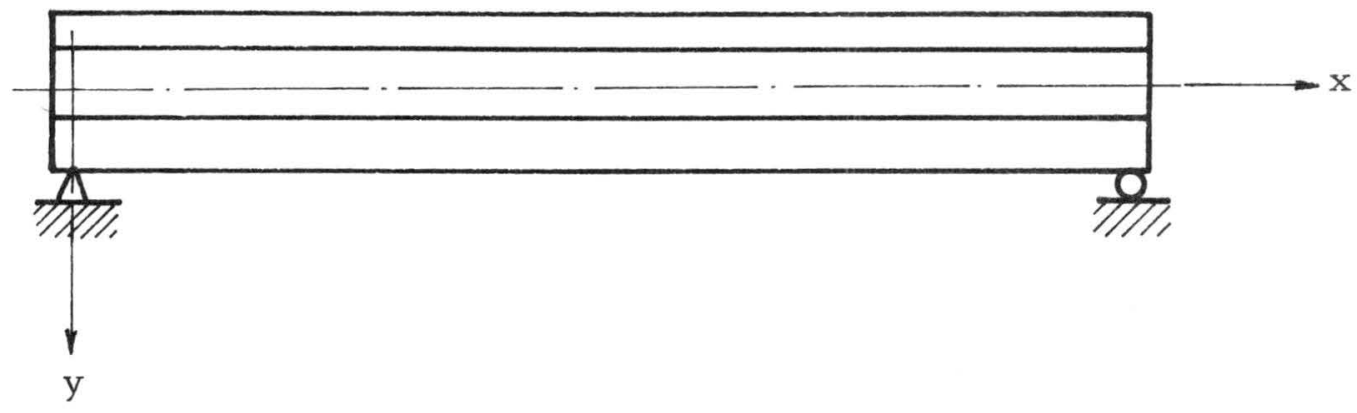

(a) Beam with sign convention

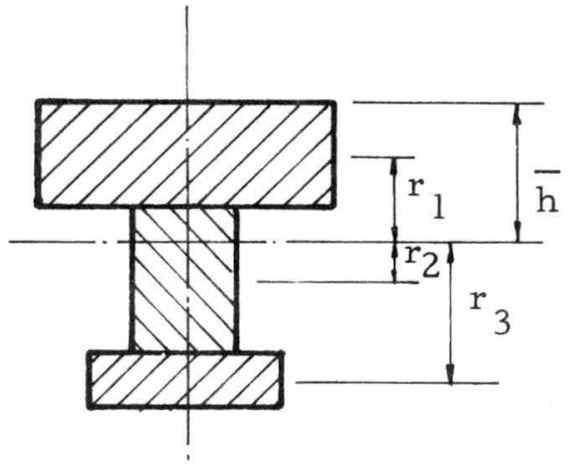

(b) Cross-section with one axis of symmetry

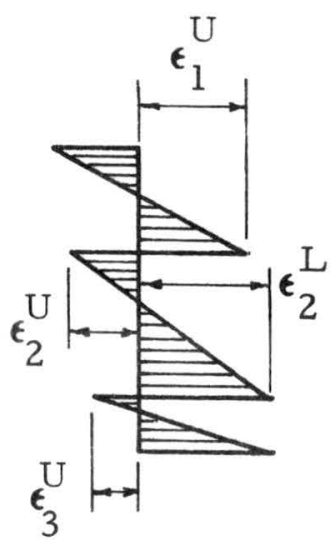

(c) Strain distribution

Figure 4. 1. Three Layered System 

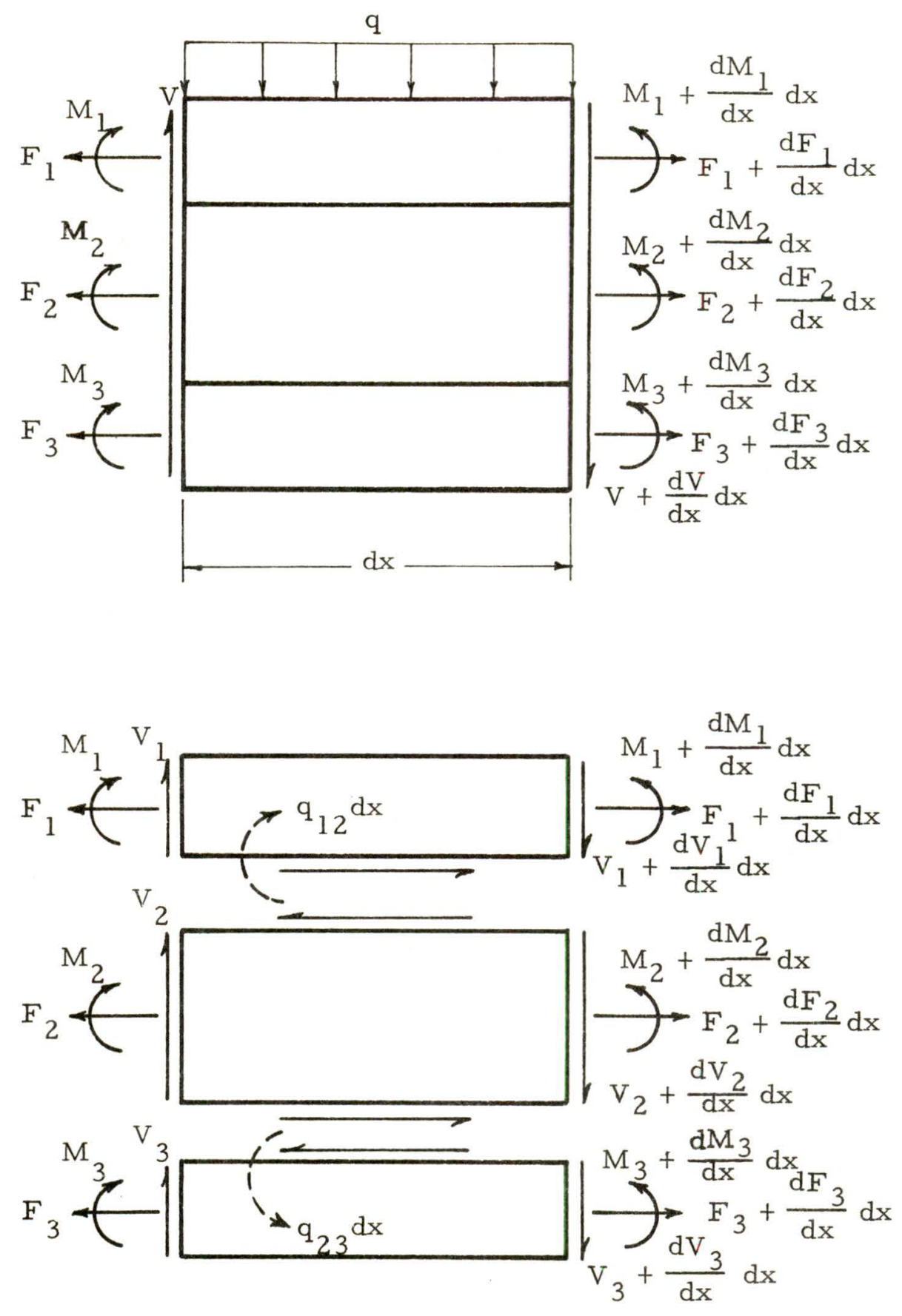

(e) Layer elements

Figure 4. 1.--Continued 
The assumption that the layers deflect the same amount requires that

$$
M_{i}=-E I_{i} \frac{d^{2} y}{d x^{2}}
$$

This can be substituted into (4.3) which, when combined with (4.2), gives

$$
\sum_{1}^{3} \operatorname{EI}_{i} \frac{\mathrm{d}^{4} y}{d x^{4}}-\sum_{1}^{3} r_{i} \frac{d^{2} F}{d x^{2}}=q
$$

The $F_{i}$ terms are now related to $y$ using the slip equations. Since the slip permitted by a connector is assumed to be proportional to the connector force and using the horizontal equilibrium of the layer elements as shown in Figure 4.1(e), the interlayer slip values may be written as

$$
\begin{aligned}
& \left.\Delta S_{12}=\left(\frac{S}{k n}\right)_{12} q_{12}=-\left(\frac{S}{k n}\right) \frac{d F}{12} \frac{1}{d x}+\int_{0}^{x} \epsilon_{2}^{U} d x-\int_{0}^{x} \epsilon_{1}^{L} d x\right) \\
& \text { and } \\
& \left.\Delta S_{23}=\left(\frac{S}{k n}\right)_{23} q_{23}=\left(\frac{S}{k n}\right){ }_{23} \frac{d F}{d x}=\int_{0}^{x} \epsilon_{3}^{U} d x-\int_{0}^{\mathrm{X}} \epsilon_{2}^{L} d x\right)
\end{aligned}
$$


The interlayer slip strain may also be written as

$$
\epsilon_{12}=\epsilon_{2}^{U}-\epsilon_{1}^{L}=\frac{d \Delta S_{12}}{d x}
$$

and

$$
\epsilon_{\mathrm{s}_{12}}=c_{3}^{U}-\epsilon_{2}^{L}=\frac{d \Delta S_{23}}{d x}
$$

Equations (4.5) and (4.6) are combined and differentiated once to yield

$$
-\left(\frac{S}{k n}\right)_{12} \frac{d^{2} F_{1}}{d x^{2}}=\frac{F_{2}}{E A_{2}^{*}}-\frac{F_{1}}{E A_{1}^{*}}+\left(\frac{h_{1}+h_{2}}{2}\right) \frac{d^{2} y}{d x^{2}}
$$

and

$$
\left(\frac{\mathrm{S}}{\mathrm{kn}}\right)_{23} \frac{\mathrm{d}^{2} \mathrm{~F}_{3}}{\mathrm{dx}^{2}}=\frac{\mathrm{F}_{3}}{\mathrm{EA}_{3}^{*}}-\frac{\mathrm{F}_{2}}{E A_{1}^{*}}+\left(\frac{\mathrm{h}_{2}+\mathrm{h}_{3}}{2}\right) \frac{\mathrm{d}^{2} \mathrm{y}}{\mathrm{dx}}
$$

Equations (4.1), (4.4), (4.7) and (4.8) form a set of four equations with four unknowns and are the governing equations of the general three layered system. The set may be reduced to three equations with three unknowns by using (4.1) to eliminate one of the $\mathrm{F}_{\mathrm{i}}$ terms. If $\mathrm{F}_{3}$ is eliminated the governing equations may be written as 


$$
\begin{aligned}
& \sum_{1}^{3} E_{i} \frac{d^{4} y}{d x^{4}}+\sum_{1}^{2}\left(r_{3}-r_{i}\right) \frac{d^{2} F_{i}}{d x^{2}}=q \\
& \left(\frac{S}{k n}\right) \frac{d^{2} F}{12} \frac{F_{1}}{d x^{2}}-\frac{1}{E A_{1}^{* *}}+\frac{F_{2}}{E A_{2}^{*}}+\left(\frac{h_{1}+h_{2}}{2}\right) \frac{d^{2} y}{d x^{2}}=0 \\
& \left(\frac{S}{k n}\right) \frac{d^{2} F}{d x^{2}}-\frac{F_{1}}{E A_{3}^{*}}+\left(\frac{S}{k n}\right) \frac{d^{2} F_{2}}{d^{2}}-\left(\frac{1}{E A_{2}^{*}}+\frac{1}{E A_{3}^{*}}\right) F_{2} \\
& \left.+\frac{h_{2}+h_{3}}{2}\right) \frac{d^{2} y}{d x^{2}}=0
\end{aligned}
$$

or in matrix form as

$$
\left[\begin{array}{ccc}
\sum_{1}^{3} \mathrm{EI}_{1} \mathrm{D}^{4} & \left(\mathrm{C}_{12}+\mathrm{C}_{23}\right) \mathrm{D}^{2} & \mathrm{C}_{23} \mathrm{D}^{2} \\
\mathrm{C}_{12} \mathrm{D}^{2} & \mathrm{G}_{12} \mathrm{D}^{2}-\mathrm{T}_{1} & \mathrm{~T}_{2} \\
\mathrm{C}_{23} \mathrm{D}^{2} & \mathrm{G}_{23} \mathrm{D}^{2}-\mathrm{T}_{3} & \mathrm{G}_{23} \mathrm{D}^{2}-\mathrm{T}_{1}-\mathrm{T}_{3}
\end{array}\right]\left\{\begin{array}{c}
\mathrm{y} \\
\mathrm{F}_{1} \\
\mathrm{~F}_{2}
\end{array}\right\}=\left\{\begin{array}{l}
\mathrm{q} \\
0 \\
0
\end{array}\right\}
$$

where

$$
\begin{aligned}
& D^{p}=\frac{d^{p}}{d x^{p}}, \\
& C_{i j}=\frac{h_{i}+h_{j}}{2},
\end{aligned}
$$




$$
\begin{aligned}
& G_{i j}=\left(\frac{S}{k n}\right)_{i j}, \\
& T_{i}=\frac{1}{E A_{i}^{*}} .
\end{aligned}
$$

Use the method stated in Section 2.3, and after some algebraic operations, the final governing equation for the deflection $y$ of general three layered systems is

$$
\begin{aligned}
& D^{8} y-\left[\frac{T_{1}}{G_{12}}\left(1+\frac{C_{12}^{2}}{T_{1} \sum_{1}^{3} E_{i} I_{i}}\right)+\frac{T_{3}}{G_{23}}\left(1+\frac{C_{23}^{2}}{T_{3} \sum_{1} E_{i}}\right)+T_{2}\left(\frac{G_{12}+G_{23}}{G_{12} G_{23}}\right)\right] D_{y}^{6} \\
& +\left[\frac{T_{1} T_{2}+T_{2} T_{3}+T_{3} T_{1}}{G_{12} G_{23}}+\frac{C_{23}^{2} T_{1}+\left(C_{12}+C_{23}\right)^{2} T_{2}+C_{12}^{2} T_{3}}{3}\right] D_{y}^{4} \\
& =\frac{1}{\sum E I_{i}} D^{4} q-\frac{1}{\sum E I_{i}}\left[\frac{1}{G_{12}}\left(T_{1}+T_{2}\right)+\frac{1}{G_{23}}\left(T_{2}+T_{3}\right)\right] D^{2} I_{i} \\
& +\left(T_{1} T_{2}+T_{2} T_{3}+T_{3} T_{1}\right) \frac{1}{\sum E I_{i} G_{12} G_{23}}
\end{aligned}
$$

The second and fourth order derivatives of the uniform load q are zero. Therefore (4.10) may be reduced to the form

$$
D^{8} y-C_{1} D^{6} y+C_{2} D^{4} y=C_{3} q
$$

where 


$$
\begin{aligned}
& C_{1}=\frac{T_{1}}{G_{12}}\left(1+\frac{C_{12}^{2}}{T_{1} \sum_{1}^{3} E_{i}}\right)+\frac{T_{3}}{G_{23}}\left(1+\frac{C_{23}^{2}}{T_{3} \sum_{1}^{3} E_{i}}\right)+T_{2}\left(\frac{G_{12}+G_{23}}{G_{12} G_{23}}\right), \\
& C_{2}=\frac{T_{1} T_{2}+T_{2} T_{3}+T_{3} T_{1}}{G_{12} G_{23}}+\frac{C_{23}^{2} T_{1}+\left(C_{12}+C_{23}\right)^{2} T_{2}+C_{12}^{2} T_{3}}{G_{12} G_{23} \sum_{1}^{3} E I_{i}}, \\
& C_{3}=\frac{T_{1} T_{2}+T_{2} T_{3}+T_{3} T_{1}}{\sum_{1}^{3} E_{1} G_{12} G_{23}} .
\end{aligned}
$$

To check the above general governing equation the system is reduced to three equal layers which results in the following values for the constants

$$
\begin{gathered}
T_{1}=T_{2}=T_{3}=T \\
G_{12}=G_{23}=G \\
\sum_{1}^{3} E_{i}=3 E I \\
A_{i}=A_{i}^{*}=A
\end{gathered}
$$

Equation (4.11) may now be factored into the form

$$
\left(D^{2}-3 \frac{T}{G}\right)\left(D^{6}-9 \frac{T}{G} D^{4}\right) y=\frac{1}{3 E I}\left(D^{2}-3 \frac{T}{G}\right)\left(D^{2}-\frac{T}{G}\right) q
$$

or

$$
\left(D^{6}-9 \frac{k n}{S} \frac{1}{E A} D^{4}\right) y=\frac{1}{3 E I}\left(D^{2}-\frac{k n}{S} \frac{1}{E A}\right) q .
$$


The governing equation of three equal layers derived by

Goodman (1), (2) is stated as below

$$
3 \operatorname{EID}^{4} \mathrm{y}-\frac{\mathrm{kn}}{\mathrm{S}} \frac{1}{\mathrm{EA}}\left(\mathrm{EI}_{\mathrm{S}} \mathrm{D}^{2} \mathrm{y}+\mathrm{M}\right)=-\mathrm{D}^{2} \mathrm{M}
$$

After differentiating (4.14) twice and using $q=-D^{2} M,(4.14)$ reduces to

$$
3 \mathrm{EID}^{6} \mathrm{y}-\frac{\mathrm{kn}}{\mathrm{S}} \frac{1}{\mathrm{EA}}(27 \mathrm{EI}) \mathrm{D}^{4} \mathrm{y}=\mathrm{D}^{2} \mathrm{q}-\frac{\mathrm{kn}}{\mathrm{S}} \frac{\mathrm{l}}{\mathrm{EA}} \mathrm{q}
$$

or

$$
\left(D^{6}-9 \frac{k n}{S} \frac{1}{E A} D^{4}\right) y=\frac{1}{3 E I}\left(D^{2}-\frac{k n}{S} \frac{1}{E A}\right) q
$$

A comparison of (4.13) with (4.15) shows that the results obtained when the general equation is reduced to a system with three equal layered system are the same as these previously reported by Goodman (1), (2).

For the general governing equation (4.12), the solution in exponential form is

$$
\begin{aligned}
y= & A_{1} e^{m_{1} x}+A_{2} e^{m_{2} x}+A_{3} e^{m_{3} x}+A_{4} e^{m_{4} x} \\
& +\frac{C_{3}}{C_{2}} \frac{q}{24} x^{4}+A_{5} x^{3}+A_{6} x^{2}+A_{7} x+A_{8}
\end{aligned}
$$

where 


$$
\begin{aligned}
& m_{1}=\left(\frac{C_{1}+\sqrt{C_{1}^{2}-4 C_{2}}}{2}\right)^{\frac{1}{2}}, \\
& m_{2}=\left(\frac{C_{1}-\sqrt{C_{1}^{2}-4 C_{2}}}{2}\right)^{\frac{1}{2}}, \\
& m_{3}=-\left(\frac{C_{1}+\sqrt{C_{1}^{2}-4 C_{2}}}{2}\right)^{\frac{1}{2}},
\end{aligned}
$$

and

$$
m_{4}=-\left(\frac{C_{1}-\sqrt{C_{1}^{2}-4 C_{2}}}{2}\right)^{\frac{1}{2}} .
$$

$A_{1}$ through $A_{8}$ are unknown constants and will be determined by eight boundary conditions. For a simply supported beam system four boundary conditions are

$$
\begin{aligned}
y(0) & =0 \\
y(L) & =0 \\
D^{2} y(0) & =0 \\
D^{2} y(L) & =0
\end{aligned}
$$

The other four boundary conditions are obtained as follows. The first of (4.9) includes the requirement that the second derivatives of $\mathrm{F}_{\mathrm{i}}$ terms are equal to zero at the supports, thus 


$$
\begin{aligned}
& D^{4} y(0)=\frac{q}{\sum_{1}^{3} E I_{i}} \\
& D^{4} y(L)=\frac{q}{\sum_{1}^{3} E I_{i}} .
\end{aligned}
$$

Differentiating the second and third of (4.9) twice and using (4.18) yields

$$
\left.\begin{array}{l}
\mathrm{D}^{4} \mathrm{~F}_{1}=-\frac{\mathrm{C}_{12}}{\mathrm{G}_{12}} \mathrm{D}^{4} \mathrm{y}=-\frac{\mathrm{C}_{12}}{\mathrm{G}_{12}} \frac{\mathrm{q}}{\sum_{1}^{3} \mathrm{EI}_{i}} \\
\mathrm{D}^{4} \mathrm{~F}_{2}=\frac{1}{\mathrm{G}_{23}} \frac{1}{\sum_{1}^{3} \mathrm{EI}_{i}}\left(-\mathrm{C}_{23}+\frac{\mathrm{G}_{23}}{\left.\mathrm{G}_{12} \mathrm{C}_{12}\right) \mathrm{q}}\right.
\end{array}\right\}
$$

Again, differentiating the first of (4.9) twice and with the substitutions of $D^{4} F_{1}$ and $D^{4} F_{2}$, the following requirement on $D^{6} y$ is obtained

$$
D^{6} y=\frac{q}{\left(\sum_{1}^{3} E I_{i}\right)^{2}}\left(\frac{C_{12}^{2}}{G_{12}}+\frac{C_{23}^{2}}{G_{23}}\right) \quad \text { at } x=0 \text { and } L
$$

Equations (4.17), (4.18) and (4.19) provide the eight boundary conditions which are needed. A matrix form for the closed form solution is given in (4.21). 


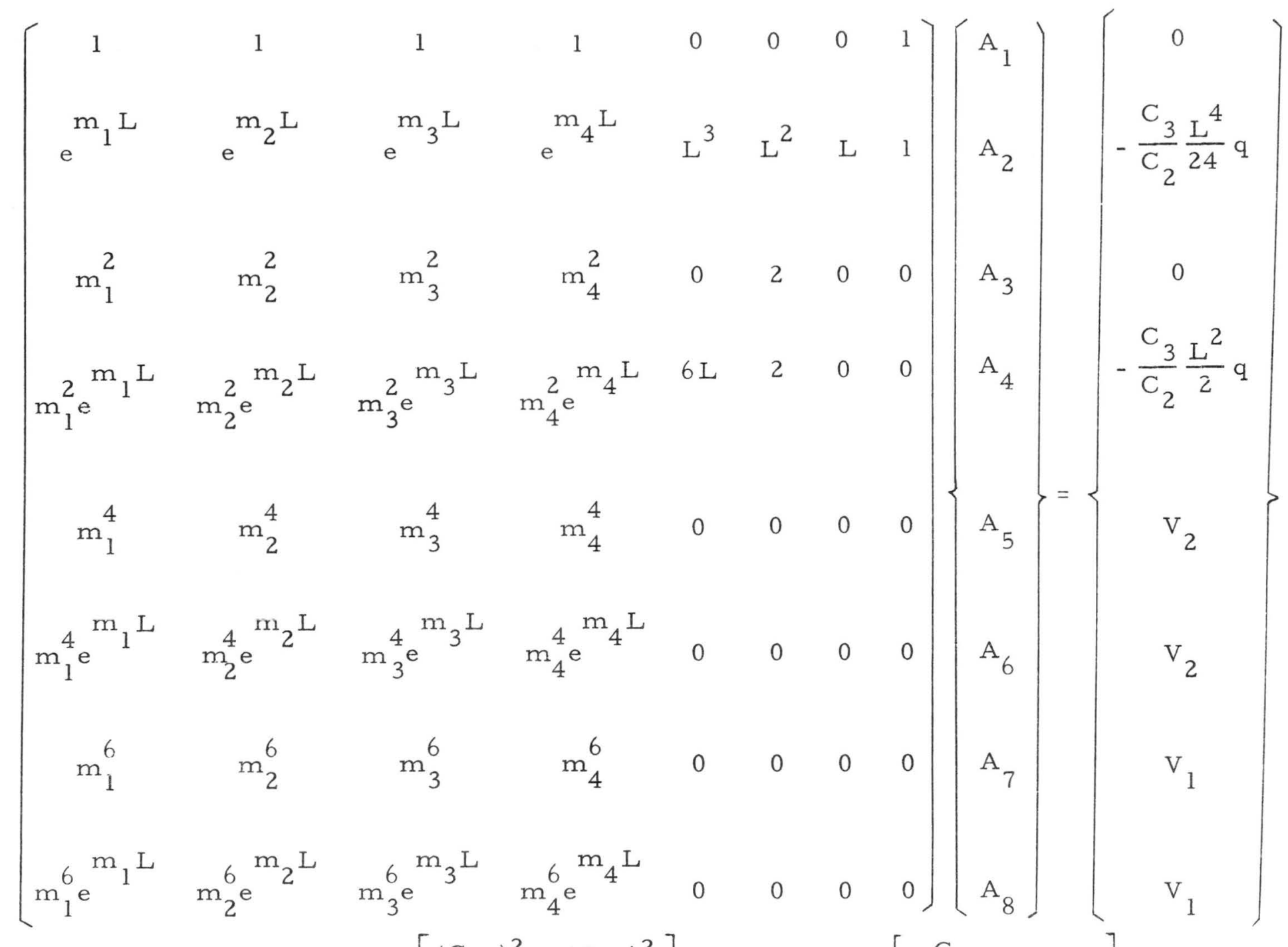

$\stackrel{\infty}{\sim}$ where $\quad \mathrm{V}_{1}=\frac{\mathrm{q}}{\left(\sum \mathrm{EI}_{\mathrm{i}}\right)^{2}}\left[\frac{\left(\mathrm{C}_{12}\right)^{2}}{\mathrm{G}_{12}}+\frac{\left(\mathrm{C}_{23}\right)^{2}}{\mathrm{G}_{23}}\right]$ and $\mathrm{v}_{2}=\left[-\frac{\mathrm{C}_{3}}{\mathrm{C}_{2}}+\frac{1}{\Sigma E I_{\mathrm{i}}}\right] \mathrm{q}$ 
Equation (4.21) provides the solution for eight constants, $A_{1}$ through $A_{8} \cdot$ By substituting these constants back into (4.16), the final deflection for various distance from support can be obtained.

4. 3 Finite Difference Approach for Beam with Uniform Load

The same procedures as developed in Section 3. 3 may be used to obtain the solution of (4.12) in numerical form. From Appendix III, the fourth, sixth and eighth order derivatives can be expressed as on the following page. Equation (4.12) becomes

$$
\frac{d^{8} y}{d z^{8}}-C_{1} L^{2} \frac{d^{6} y}{d z^{6}}+C_{2} L^{4} \frac{d^{4} y}{d z^{4}}=C_{3} q^{8}
$$

or written in operator form

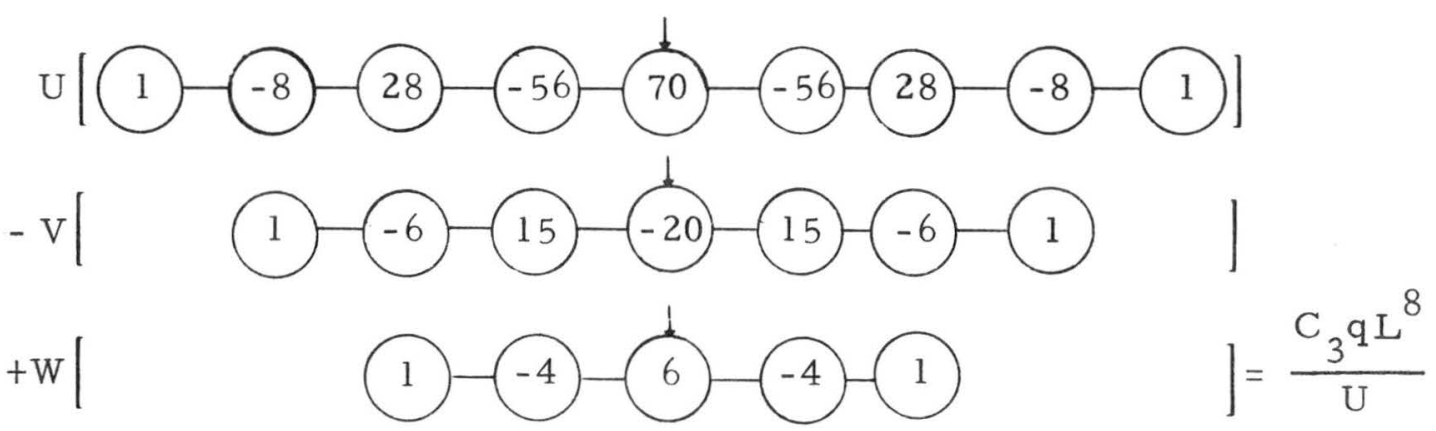

where

$$
\begin{aligned}
& \mathrm{U}=\mathrm{n}^{4}=(\mathrm{L} / \mathrm{h})^{4} \\
& \mathrm{~V}=\mathrm{n}^{2} \mathrm{C}_{1} \mathrm{~L}^{2} \\
& \mathrm{~W}=\mathrm{C}_{2} \mathrm{~L}^{4}
\end{aligned}
$$




$$
\begin{aligned}
& \frac{\mathrm{d}^{4}}{\mathrm{dx}}=\frac{1}{\mathrm{~L}^{4}} \frac{\mathrm{d}^{4}}{\mathrm{dz}^{4}}=\frac{1}{\mathrm{~h}^{4}}[1 \\
& \frac{\mathrm{d}^{6}}{\mathrm{dx}^{6}}=\frac{1}{\mathrm{~L}^{6}} \frac{\mathrm{d}^{6}}{\mathrm{dz}^{6}}=\frac{1}{\mathrm{~h}^{6}} \\
& \frac{\mathrm{d}^{8}}{\mathrm{dx}^{8}}=\frac{1}{\mathrm{~L}^{8}} \frac{\mathrm{d}^{8}}{\mathrm{dz}^{8}}=\frac{1}{\mathrm{~h}^{8}}[1
\end{aligned}
$$


The boundary conditions for the operator form are listed in Appendix III-2. A final matrix form of the governing equation is then written as

$$
[\mathrm{H}]\{\mathrm{y}\}=\left\{\mathrm{Q}^{\prime}\right\}
$$

where

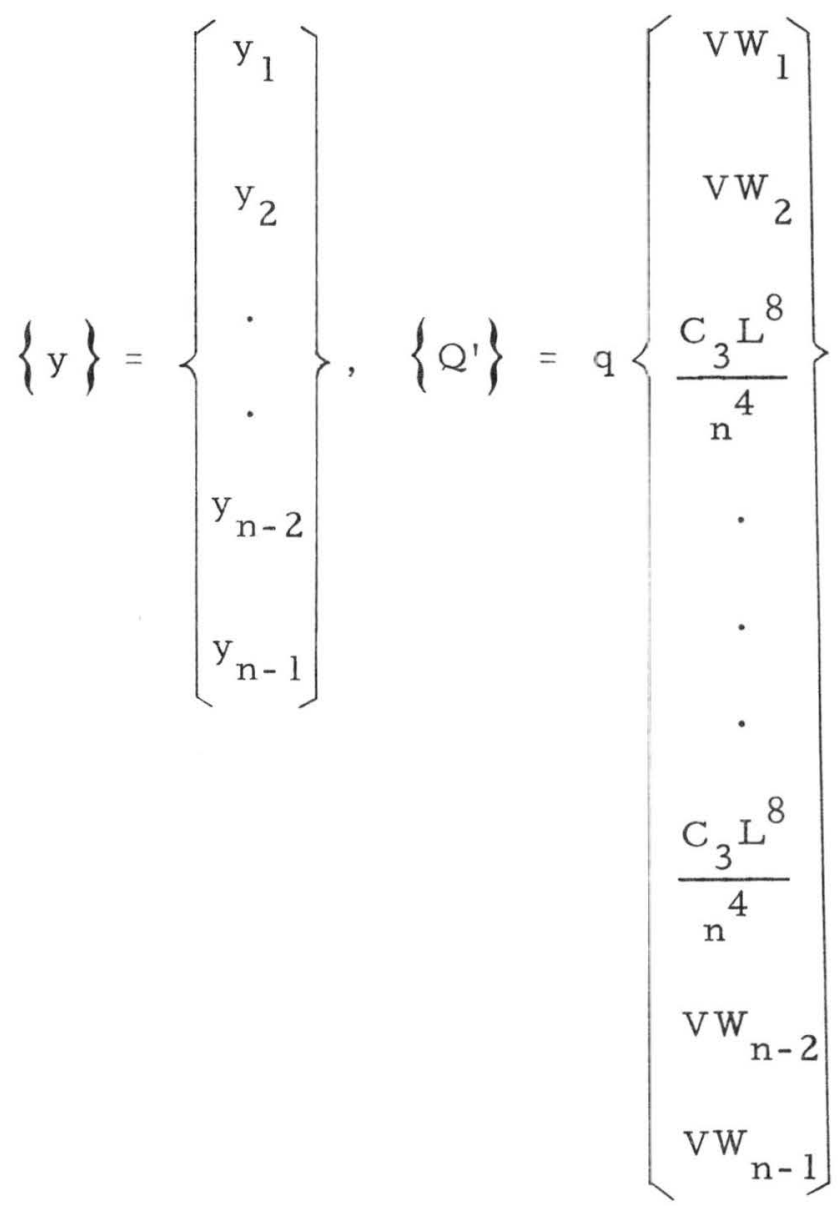

where 


$$
\begin{array}{rl}
V_{1}= & \frac{2 L^{4}}{\sum_{1}^{3} E_{i}}-\left(\frac{C_{12}^{2}}{G_{12}}+\frac{C_{23}^{2}}{G_{23}}\right) \frac{h^{2} L^{4}}{\left(\sum_{1}^{3} E I_{i}\right)^{2}}+C_{1} \frac{L^{4} h^{2}}{\sum_{1}^{3} E I_{i}} \\
& +C_{3} h^{4} L^{4} \\
V_{2}= & -\frac{L^{4}}{\sum_{1}^{3} E I_{i}}+C_{3} h^{4} L^{4} \\
V W_{n-2} & =W_{2} \\
V W_{n-1} & V W_{1}
\end{array}
$$

and $[\mathrm{H}]$ is shown in Figure 4.2. The symbols used in Figure 4.2 $\operatorname{are}$

$$
\begin{aligned}
& \mathrm{U}_{1}=70 \mathrm{U}+20 \mathrm{~V}+6 \mathrm{~W} \\
& \mathrm{U}_{2}=42 \mathrm{U}+14 \mathrm{~V}+5 \mathrm{~W} \\
& \mathrm{~V}_{1}=-56 \mathrm{U}-15 \mathrm{~V}-4 \mathrm{~W} \\
& \mathrm{~V}_{2}=-48 \mathrm{U}-14 \mathrm{~V}-4 \mathrm{~W} \\
& \mathrm{~W}_{1}=28 \mathrm{U}+6 \mathrm{~V}+\mathrm{W}
\end{aligned}
$$

and

$$
R=-8 U-V
$$




$$
\begin{aligned}
& {\left[\begin{array}{cccccccc}
\mathrm{U}_{2} & \mathrm{v}_{2} & \mathrm{w}_{1}-\mathrm{U} & \mathrm{R} & \mathrm{U} & & & \\
\mathrm{v}_{2} & \mathrm{U}_{1}-\mathrm{U} & \mathrm{v}_{1} & \mathrm{w}_{1} & \mathrm{R} & \mathrm{U} & & \\
\mathrm{w}_{1}-\mathrm{U} & \mathrm{v}_{1} & \mathrm{U}_{1} & \mathrm{v}_{1} & \mathrm{w}_{1} & \mathrm{R} & \mathrm{U} & \\
\mathrm{R} & \mathrm{w}_{1} & \mathrm{v}_{1} & \mathrm{U}_{1} & \mathrm{v}_{1} & \mathrm{w}_{1} & \mathrm{R} & \mathrm{U}
\end{array}\right.} \\
& \begin{array}{llllllll}
\mathrm{R} & \mathrm{W}_{1} & \mathrm{~V}_{1} & \mathrm{U}_{1} & \mathrm{~V}_{1} & \mathrm{w}_{1} & \mathrm{R} & \mathrm{U}
\end{array} \\
& \begin{array}{lllllllll}
\mathrm{u} & \mathrm{R} & \mathrm{w}_{1} & \mathrm{~V}_{1} & \mathrm{U}_{1} & \mathrm{v}_{1} & \mathrm{w}_{1} & \mathrm{R} & \mathrm{U}
\end{array} \\
& \begin{array}{llllllllll} 
& \mathrm{R} & \mathrm{W}_{1} & \mathrm{v}_{1} & \mathrm{U}_{1} & \mathrm{v}_{1} & \mathrm{~W}_{1} & \mathrm{R} & \mathrm{U}
\end{array} \\
& \begin{array}{llllllll}
\mathrm{U} & \mathrm{R} & \mathrm{W}_{1} & \mathrm{v}_{1} & \mathrm{U}_{1} & \mathrm{v}_{1} & \mathrm{w}_{1} & \mathrm{R}
\end{array} \\
& \begin{array}{lllllll}
\mathrm{U} & \mathrm{R} & \mathrm{W}_{1} & \mathrm{~V}_{1} & \mathrm{U}_{1} & \mathrm{~V}_{1} & \mathrm{~W}_{1}-\mathrm{U}
\end{array} \\
& \begin{array}{llllll}
\mathrm{U} & \mathrm{R} & \mathrm{W}_{1} & \mathrm{~V}_{1} & \mathrm{U}_{1}-\mathrm{U} & \mathrm{V}_{2}
\end{array} \\
& \mathrm{U} \quad \mathrm{R} \quad \mathrm{w}_{1}-\mathrm{U} \quad \mathrm{V}_{2} \quad \mathrm{U}_{2}
\end{aligned}
$$

Figure 4.2. H Matrix 
Equation (4.23) can be applied to any three layered beam system with various beam or connection properties between layers or along the beam length.

\subsection{Example Problem for Beam with Uniform Load}

Figure 4.3 shows a simply supported beam of 12 feet span loaded with a uniformly distributed load. If the layers of beam are rigidly connected, then the midspan deflection of 0.229456 inches will be the upper bound for the stiffness of the system. If no connection exists between layers, then the midspan deflection is 0.990924 inches and is the lower bound. Table 4.1 lists the deflection values obtained for a sequence of different connector moduli and Figure 4.4 is the plot of Table 4.1 . It is evident that every deflection value for various $k$ values, between zero and infinity, lies between these two limits. From Table 4.1, it is seen that the finite difference deflections are a little larger than the closed form deflections but the percentage difference is very small.

\section{5 Closed Form Solution for Beam with Concentrated Load}

The three layered system shown in Figure 4.1 but with a concentrated load $\mathrm{P}$ applied at any point along the beam length is discussed herein. The derivation is the same as that in Section 4.2 except that 


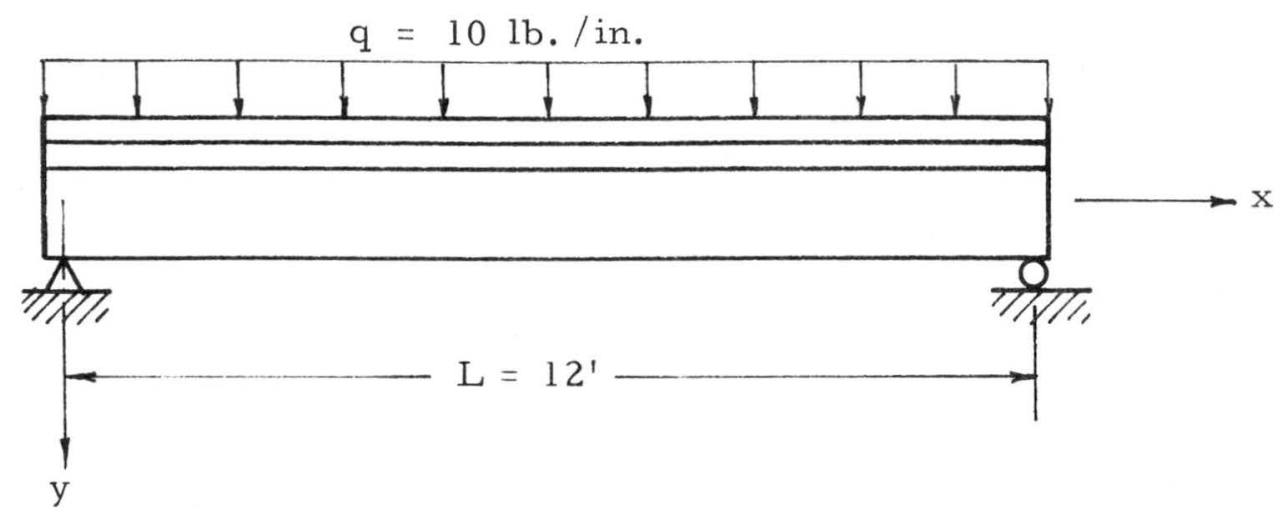

(a) Beam with sign convention and applied loading

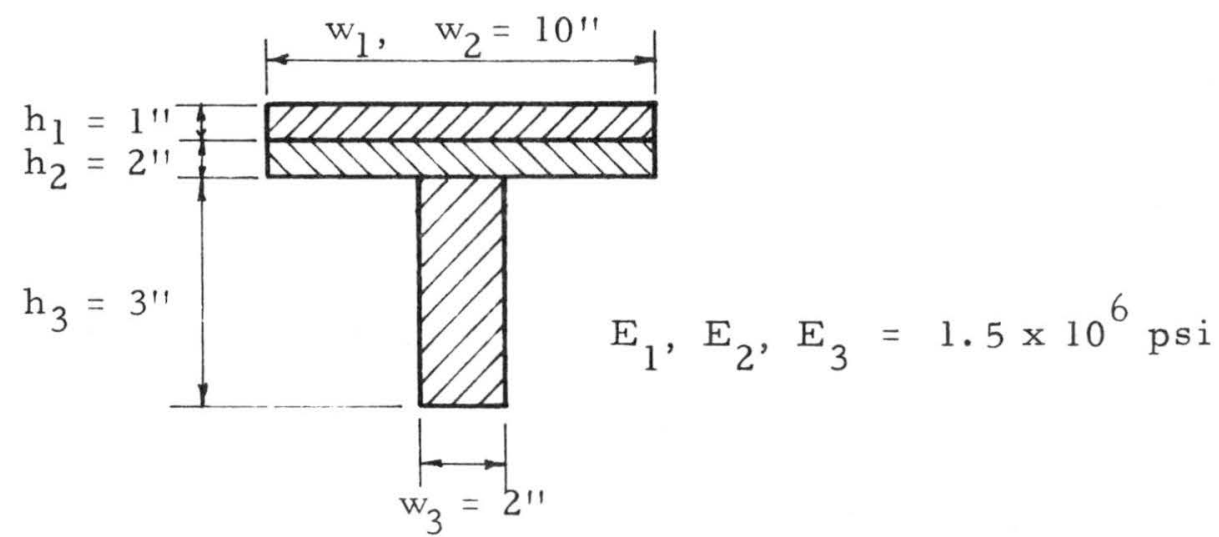

(b) Cross section with one axis of symmetry

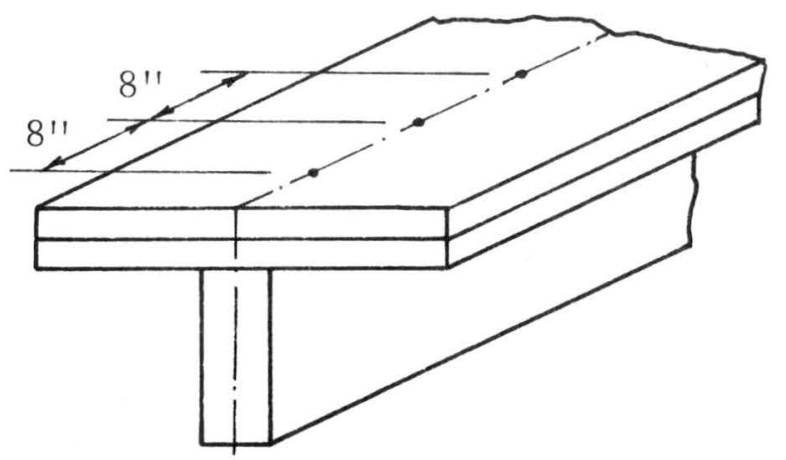

number of nails per

row, $\mathrm{n}=1$

connector spacing $\mathrm{s}=8 \mathrm{in}$.

(c) Connector spacing and number of nails

Figure 4. 3. Three Layered System with Uniform Load 
Table 4. 1. Deflections (in.) with Uniform Load vs Connector Modulus

\begin{tabular}{cccc} 
& closed & finite & \\
connector & form & difference & y/ys \\
modulus $k$ & solution & solution & by closed \\
(lb./in.) & $y$ (in.) & $y$ (in.) & form \\
\hline
\end{tabular}

(upper bound)

$\begin{array}{rlll}(\infty) & (0.229456) & & (1.00000) \\ 10,000,000 & 0.230473 & 0.231748 & 1.00443 \\ 1,000,000 & 0.239512 & 0.240787 & 1.04383 \\ 30,000 & 0.318950 & 0.320259 & 1.39003 \\ 10,000 & 0.460776 & 0.462397 & 2.00812 \\ 3,000 & 0.656899 & 0.659461 & 2.86286 \\ 1,000 & 0.844248 & 0.848247 & 3.67935 \\ 100 & 0.934457 & 0.939343 & 4.07250 \\ 10 & 0.984852 & 0.990288 & 4.29212 \\ 1 & 0.990312 & 0.995810 & 4.31592 \\ (0) & 0.990863 & 0.996367 & 4.31832 \\ 10.990924) & & (4.31858)\end{array}$

(lower bound) 


$$
\mathrm{V}=\frac{\mathrm{Pb}}{\mathrm{L}} \quad \text { for } \quad 0 \leq \mathrm{x} \leq \mathrm{a}
$$

and

$$
V=\frac{P a}{L} \quad \text { for } \quad a \leq x \leq L
$$

Finally, three governing equations for deflection and slip are obtained as

$$
\begin{aligned}
& \sum_{1}^{3} E I_{i} \frac{d^{2} y}{d x^{2}}+\sum_{1}^{2}\left(r_{3}-r_{i}\right) \frac{d^{2} F_{i}}{d x^{2}}=-M \\
& \left(\frac{h_{1}+h_{2}}{2}\right) \frac{d^{2} y}{d x^{2}}+\left(\frac{S}{k n}\right) \underset{12}{d^{2}}-\frac{d^{2} F_{1}}{E A_{1}^{* \frac{k}{2}}}+\frac{F_{2}}{E A_{2}^{*}}=0 \\
& \left(\frac{h_{2}+h_{3}}{2}\right) \frac{d^{2} y}{d x^{2}}+\left(\frac{S}{k n}\right) \frac{d^{2} F_{1}}{d x^{2}}-\frac{F_{1}}{E A_{3}^{*}}+\left(\frac{S}{k n}\right) \frac{d^{2} F_{2}}{d x^{2}} \\
& -\left(\frac{1}{\mathrm{EA}_{2}^{*}}+\frac{1}{\mathrm{EA}_{3}^{* *}}\right) \mathrm{F}_{2}=0
\end{aligned}
$$

where

$$
\begin{array}{ll}
M=\frac{P b}{L} x & \text { for } 0 \leq x \leq a \\
M=P a\left(1-\frac{x}{L}\right) & \text { for } a \leq x \leq L
\end{array}
$$

and 


$$
\sum_{1}^{2}\left(r_{3}-r_{i}\right) \frac{d^{2} F_{i}}{d x^{2}}=\left(\frac{h_{1}+h_{2}}{2}+\frac{h_{2}+h_{3}}{2}\right) \frac{d^{2} F_{1}}{d x^{2}}+\left(\frac{h_{2}+h_{3}}{2}\right) \frac{d^{2} F_{2}}{d x^{2}} .
$$

Equations (4.24) through (4.26) in matrix form are:

$$
\left[\begin{array}{ccc}
\mathrm{EI}_{\mathrm{i}} \mathrm{D}^{2} & \left(\mathrm{C}_{12}+\mathrm{C}_{12}\right) & \mathrm{C}_{23} \\
\mathrm{C}_{12} \mathrm{D}^{2} & \mathrm{G}_{12} \mathrm{D}^{2}-\mathrm{T}_{1} & \mathrm{~T}_{2} \\
\mathrm{C}_{23} \mathrm{D}^{2} & \mathrm{G}_{23} \mathrm{D}^{2}-\mathrm{T}_{3} & \mathrm{G}_{23} \mathrm{D}^{2}-\mathrm{T}_{2}-\mathrm{T}_{3}
\end{array}\right]\left\{\begin{array}{c}
\mathrm{y} \\
\mathrm{F}_{1} \\
\mathrm{~F}_{2}
\end{array}\right\}=\left\{\begin{array}{c}
-\mathrm{M} \\
0 \\
0
\end{array}\right\}
$$

where

$$
\begin{aligned}
& C_{i j}=\frac{h_{i}+h_{j}}{2}, \\
& G_{i j}=\left(\frac{S}{k n}\right)_{i j}, \\
& T_{i}=\frac{1}{E A_{i}^{*}} .
\end{aligned}
$$

Before solving these three simultaneous differential equations several separate functions for $y, F_{1}$ and $F_{2}$ in terms of $x$ only should be expressed. Applying Cramer's method to (4.27) gives 
( I)

$D^{6} y-C_{1} D^{4} y+C_{2} D^{2} y=-C_{3} M$

so, the solution to this equation will be

$$
\begin{aligned}
y_{L}= & A_{1} e^{m_{1} x}+A_{2} e^{m_{2} x}+A_{3} e^{m_{3} x}+A_{4} e^{m_{4} x} \\
& +A_{5} x+A_{6}-\frac{C_{3}}{C_{2}}\left(\frac{P b}{L}\right) \frac{x^{3}}{6} \\
y_{R}= & A_{7} e^{m_{1} x}+A_{8} e^{m_{2} x}+A_{9} e^{m_{3} x}+A_{10} e^{m_{4} x} \\
& +A_{11} x+A_{12}-\frac{C_{3}}{C_{2}} P a\left(\frac{x^{2}}{2}-\frac{x^{3}}{6 L}\right)
\end{aligned}
$$

(II)

$D^{4} F_{1}-C_{1} D^{2} F_{1}+C_{2} F_{1}=C_{4} M$

let the solution to this equation be

$$
\begin{aligned}
F_{1 L}= & A_{13} e^{m_{1} x}+A_{14} e^{m_{2} x}+A_{15} e^{m_{3} x}+A_{16} e^{m_{4} x} \\
& +\frac{C_{4}}{C_{2}} \frac{P b}{L} x \\
F_{1 R}= & A_{17} e^{m_{1} x}+A_{18} e^{m_{2} x}+A_{19} e^{m_{3} x}+A_{20} e^{m_{4} x} \\
& +\frac{C_{4}}{C_{2}} \mathrm{~Pa}\left(1-\frac{x}{L}\right)
\end{aligned}
$$


(III)

$\mathrm{D}^{4} \mathrm{~F}_{2}-\mathrm{C}_{1} \mathrm{D}^{2} \mathrm{~F}_{2}+\mathrm{C}_{2} \mathrm{~F}_{2}=\mathrm{C}_{5} \mathrm{M}$

let the solution to this equation be

$$
\begin{aligned}
F_{2 L}= & A_{21} e^{m_{1} x}+A_{22} e^{m_{2} x}+A_{23} e^{m_{3} x}+A_{24} e^{m} e^{m^{x}} \\
& +\frac{C_{5}}{C_{2}}\left(\frac{P b}{L}\right) x \\
F_{2 R}= & A_{25} e^{m_{1} x}+A_{26} e^{m_{2} x}+A_{27} e^{m_{3} x}+A_{28} e^{m_{4} x} \\
& +\frac{C_{5}}{C_{2}} \mathrm{~Pa}\left(1-\frac{x}{L}\right)
\end{aligned}
$$

where subscript $L$ and $R$ represent the left and right side of load point. $\mathrm{C}_{1}, \mathrm{C}_{2}, \mathrm{C}_{3}, \mathrm{~m}_{1}, \mathrm{~m}_{2}, \mathrm{~m}_{3}$, and $\mathrm{m}_{4}$ are the same as (4.12) and (4.16) and

$$
\begin{aligned}
C_{4} & =-\frac{\left(C_{12}+C_{23}\right) T_{2}+C_{12} T_{3}}{\left(G_{12} G_{23}\right) \sum_{1}^{3} E_{i}} \\
C_{5} & =\frac{-T_{1} C_{23}+T_{3} C_{12}}{\left(G_{12} G_{23}\right) \sum_{1}^{3} E_{i}}
\end{aligned}
$$

$A_{1}$ through $A_{28}$ are unknown and twenty-eight equations are required to determine these constants. Sixteen equations of them come from the relations between constants themselves and the remaining twelve come from boundary conditions of $y, F_{1}$ and $F_{2}$. 
To obtain the sixteen equations, it is necessary to substitute (4.28) through (4.33) into (4.27). After collecting terms each case has five terms that correspond to $e^{m_{1} x}, e^{m_{2} x}, e^{m_{3} x}, e^{m_{4} x}$ and $x$, respectively. For example, the first of (4.27) for the left side $\left(y_{L}, F_{1 L}, F_{2 L}\right)$ becomes

$$
\begin{aligned}
& {\left[\sum \mathrm{EI}_{i} \mathrm{~m}_{1}^{2} \mathrm{~A}_{1}+\left(\mathrm{C}_{12}+\mathrm{C}_{23}\right) \mathrm{A}_{13}+\mathrm{C}_{23} \mathrm{~A}_{21}\right] \mathrm{e}^{\mathrm{m} 1^{\mathrm{x}}}} \\
& +\left[\sum \mathrm{EI}_{\mathrm{i}} \mathrm{m}_{2}^{2} \mathrm{~A}_{2}+\left(\mathrm{C}_{12}+\mathrm{C}_{23}\right) \mathrm{A}_{14}+\mathrm{C}_{23} \mathrm{~A}_{22}\right] \mathrm{e}^{\mathrm{m} 2^{\mathrm{x}}} \\
& +\left[\sum \mathrm{EI}_{1} \mathrm{~m}_{3}^{2} \mathrm{~A}_{3}+\left(\mathrm{C}_{12}+\mathrm{C}_{23}\right) \mathrm{A}_{15}+\mathrm{C}_{23} \mathrm{~A}_{23}\right] \mathrm{e}^{\mathrm{m}_{3} \mathrm{x}} \\
& +\left[\sum \mathrm{EI}_{i} \mathrm{~m}_{4}^{2} \mathrm{~A}_{4}+\left(\mathrm{C}_{12}+\mathrm{C}_{23}\right) \mathrm{A}_{16}+\mathrm{C}_{23} \mathrm{~A}_{24}\right] \mathrm{e}^{\mathrm{m}_{4}^{\mathrm{x}}} \\
& +\left[-\sum \mathrm{EI}_{\mathrm{i}} \frac{\mathrm{C}_{3}}{\mathrm{C}_{2}}+\left(\mathrm{C}_{12}+\mathrm{C}_{23}\right) \frac{\mathrm{C}_{4}}{\mathrm{C}_{2}}+\mathrm{C}_{23} \frac{\mathrm{C}_{5}}{\mathrm{C}_{2}}+1\right] \frac{\mathrm{Pb}}{\mathrm{L}} \mathrm{x}=0
\end{aligned}
$$
zero which yields four equations,

$$
\begin{aligned}
& \sum \mathrm{EI}_{i} \mathrm{~m}_{1}^{2} \mathrm{~A}_{1}+\left(\mathrm{C}_{12}+\mathrm{C}_{23}\right) \mathrm{A}_{13}+\mathrm{C}_{23} \mathrm{~A}_{21}=0 \\
& \sum \mathrm{EI}_{i} \mathrm{~m}_{2}^{2} \mathrm{~A}_{2}+\left(\mathrm{C}_{12}+\mathrm{C}_{23}\right) \mathrm{A}_{14}+\mathrm{C}_{23} \mathrm{~A}_{22}=0 \\
& \sum \mathrm{EI}_{i} \mathrm{~m}_{3}^{2} \mathrm{~A}_{3}+\left(\mathrm{C}_{12}+\mathrm{C}_{23}\right) \mathrm{A}_{15}+\mathrm{C}_{23} \mathrm{~A}_{23}=0 \\
& \sum \mathrm{EI}_{i} \mathrm{~m}_{4}^{2} \mathrm{~A}_{4}+\left(\mathrm{C}_{12}+\mathrm{C}_{23}\right) \mathrm{A}_{16}+\mathrm{C}_{23} \mathrm{~A}_{24}=0 .
\end{aligned}
$$


The fifth equation

$$
-\sum E_{i} \frac{C_{3}}{C_{2}}+\left(C_{12}+C_{23}\right) \frac{C_{4}}{C_{2}}+C_{23} \frac{C_{5}}{C_{2}}+1=0
$$

will be satisfied automatically.

Similarly, the coefficients of the $x$ terms in the first of (4.27) for the right side section of load yields

$$
\begin{aligned}
& \sum \mathrm{EI}_{i} \mathrm{~m}_{1}^{2} \mathrm{~A}_{7}+\left(\mathrm{C}_{12}+\mathrm{C}_{23}\right) \mathrm{A}_{17}+\mathrm{C}_{23} \mathrm{~A}_{25}=0 \\
& \sum \mathrm{EI}_{i} \mathrm{~m}_{2}^{2} \mathrm{~A}_{8}+\left(\mathrm{C}_{12}+\mathrm{C}_{23}\right) \mathrm{A}_{18}+\mathrm{C}_{23} \mathrm{~A}_{26}=0 \\
& \sum \mathrm{EI}_{i} \mathrm{~m}_{3}^{2} \mathrm{~A}_{9}+\left(\mathrm{C}_{12}+\mathrm{C}_{23}\right) \mathrm{A}_{19}+\mathrm{C}_{23} \mathrm{~A}_{27}=0 \\
& \sum \mathrm{EI}_{\mathrm{i}} \mathrm{m}_{4}^{2} \mathrm{~A}_{10}+\left(\mathrm{C}_{12}+\mathrm{C}_{23}\right) \mathrm{A}_{20}+\mathrm{C}_{23} \mathrm{~A}_{28}=0 .
\end{aligned}
$$

The second of (4.27) for the left and right sides of the applied load point will also yield 


$$
\begin{aligned}
& \mathrm{C}_{12} \mathrm{~m}_{1}^{2} \mathrm{~A}_{1}+\left(\mathrm{G}_{12} \mathrm{~m}_{1}^{2}-\mathrm{T}_{1}\right) \mathrm{A}_{13}+\mathrm{T}_{2} \mathrm{~A}_{21}=0 \\
& \mathrm{C}_{12} \mathrm{~m}_{2}^{2} \mathrm{~A}_{2}+\left(\mathrm{G}_{12} \mathrm{~m}_{2}^{2}-\mathrm{T}_{1}\right) \mathrm{A}_{14}+\mathrm{T}_{2} \mathrm{~A}_{22}=0 \\
& \mathrm{C}_{12} \mathrm{~m}_{2}^{2} \mathrm{~A}_{3}+\left(\mathrm{G}_{12} \mathrm{~m}_{3}^{2}-\mathrm{T}_{1}\right) \mathrm{A}_{15}+\mathrm{T}_{2} \mathrm{~A}_{23}=0 \\
& \mathrm{C}_{12} \mathrm{~m}_{4}^{2} \mathrm{~A}_{4}+\left(\mathrm{G}_{12} \mathrm{~m}_{4}^{2}-\mathrm{T}_{1}\right) \mathrm{A}_{16}+\mathrm{T}_{2} \mathrm{~A}_{24}=0 \\
& \mathrm{C}_{12} \mathrm{~m}_{1}^{2} \mathrm{~A}_{7}+\left(\mathrm{G}_{12} \mathrm{~m}_{1}^{2}-\mathrm{T}_{1}\right) \mathrm{A}_{17}+\mathrm{T}_{2} \mathrm{~A}_{25}=0 \\
& \mathrm{C}_{12} \mathrm{~m}_{2}^{2} \mathrm{~A}_{8}+\left(\mathrm{G}_{12} \mathrm{~m}_{2}^{2}-\mathrm{T}_{1}\right) \mathrm{A}_{18}+\mathrm{T}_{2} \mathrm{~A}_{26}=0 \\
& \mathrm{C}_{12} \mathrm{~m}_{3}^{2} \mathrm{~A}_{12}+\left(\mathrm{G}_{12} \mathrm{~m}_{4}^{2} \mathrm{~A}_{10}+\left(\mathrm{G}_{12} \mathrm{~T}_{4} \mathrm{~A}_{19}+\mathrm{T}_{2} \mathrm{~A}_{27}=0\right.\right.
\end{aligned}
$$

In addition, the twelve required boundary conditions may be stated

as

$$
\left.\begin{array}{rlrl}
y_{L}(0) & =0 & y_{R}(L) & =0 \\
y_{L}(a) & =y_{R}(a) & D_{L}(a) & =D_{R}(a) \\
F_{1 L}(0) & =0 & F_{2 L}(0) & =0 \\
F_{1 R}(L) & =0 & F_{2 R}(L) & =0 \\
F_{1 L}(a) & =F_{1 R}(a) & F_{2} L(a) & =F_{2 R}(a) \\
D F_{1 L}(a) & =D_{1 R}(a) & D_{2 L}(a) & =D_{2 R}(a)
\end{array}\right\}
$$


Equations (4.34), (4.35), (4.36) and (4.37) provide the twentyeight independent equations that are required. Once $A_{1}$ through $A_{28}$ are obtained, then the final solutions of $y, F_{1}$ and $F_{2}$ can be easily obtained.

4.6 Example Problem for Beam with Concentrated Load

A beam with the same cross-section and properties as that examined in Section 4.4 and Figure 4.3 will be loaded with a concentrated load at any point along the beam length. The technique of solving the simultaneous ordinary differential equations is applied to solve this problem. The results for the special case, loading at midspan, for seven different slip moduli values are listed in Table 4.2. In three layered problem, the axial forces of top and bottom layers, $F_{1}$ and $F_{3}$, will always be compression and tension respectively. The sign of the force in the middle layer depends on the dimensions of each layer of the system. Figure 4.4 shows a deflection ratio curve of this example problem. 
Table 4.2. Deflections, Axial Forces and Deflection Ratio vs Connector Modulus for Load Applied at Midspan

\begin{tabular}{|c|c|c|c|c|}
\hline \multirow{2}{*}{$\begin{array}{l}\text { connector } \\
\text { modulus } \mathrm{k} \\
(1 \mathrm{~b} . / \mathrm{in} .)\end{array}$} & \multirow{2}{*}{$\begin{array}{c}\text { deflection } \\
y \\
\text { (in.) }\end{array}$} & \multicolumn{2}{|c|}{ axial force (lbs) } & \multirow[b]{2}{*}{$\mathrm{y} / \mathrm{y}_{\mathrm{s}}$} \\
\hline & & $\begin{array}{l}F_{1} \\
(-)^{*}\end{array}$ & $\begin{array}{l}\mathrm{F}_{2} \\
(-)\end{array}$ & \\
\hline
\end{tabular}

(upper bound)

\begin{tabular}{rrrrr}
\multicolumn{1}{c}{$(0)$} & $(0.254951)$ & & $(1.00000)$ \\
$1,000,000$ & 0.267988 & 3973.1300 & 2214.4800 & 1.05114 \\
100,000 & 0.361336 & 2999.0200 & 2212.1900 & 1.41728 \\
10,000 & 0.735503 & 1012.7500 & 1569.1700 & 2.88488 \\
1,000 & 1.039310 & 132.9670 & 310.0080 & 4.07650 \\
100 & 1.094390 & 13.7150 & 34.0370 & 4.29255 \\
10 & 1.100360 & 1.3758 & 3.4370 & 4.31596 \\
1 & 1.100960 & 0.1376 & 0.3440 & 4.31833 \\
$(0)$ & $(1.101100)$ & & & $(4.31887)$
\end{tabular}

(lower bound)

*Negative sign indicates compression force. 


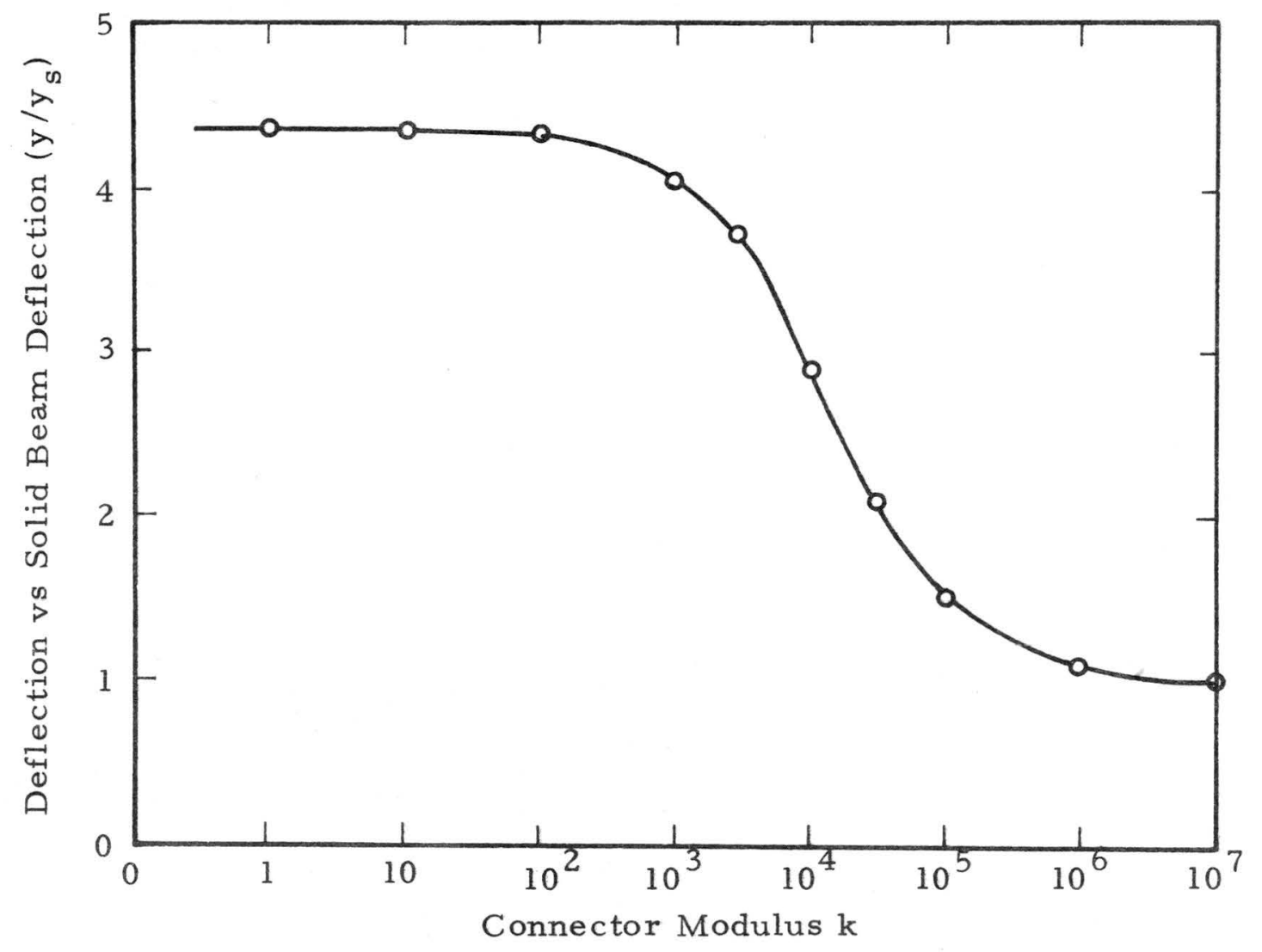

Figure 4.4. Deflection Ratio Curve for Varying $\mathbf{k}$ Values with Concentrated Load Applied at Midspan 


\section{CHAPTER 5}

\section{RESULTS OF BEAM TESTS}

\section{1 Introduction}

To provide an examination of the validity of the proposed theory, several tests were performed. The tests were limited to simply supported beam systems consisting of two layers. The test equipment and procedures used are detailed by Penner (20). In this chapter results obtained during testing are presented and compared with the developed theory. The variation in section properties along the beam length was considered by utilizing the finite difference method.

\section{2 Connector Modulus}

As mentioned before, an accurate determination of the connector modulus is necessary if a reasonable prediction of system behavior is to be made. Eight-penny cement coated nails and common nails were used as connectors in the experiments. Three slip tests for use of cement coated nails were made by using a double-shear test procedure as described by Patterson (21). A combined curve of applied nail force versus slip is shown in Figure 5.1(a). A linear approximation for the connector modulus, 


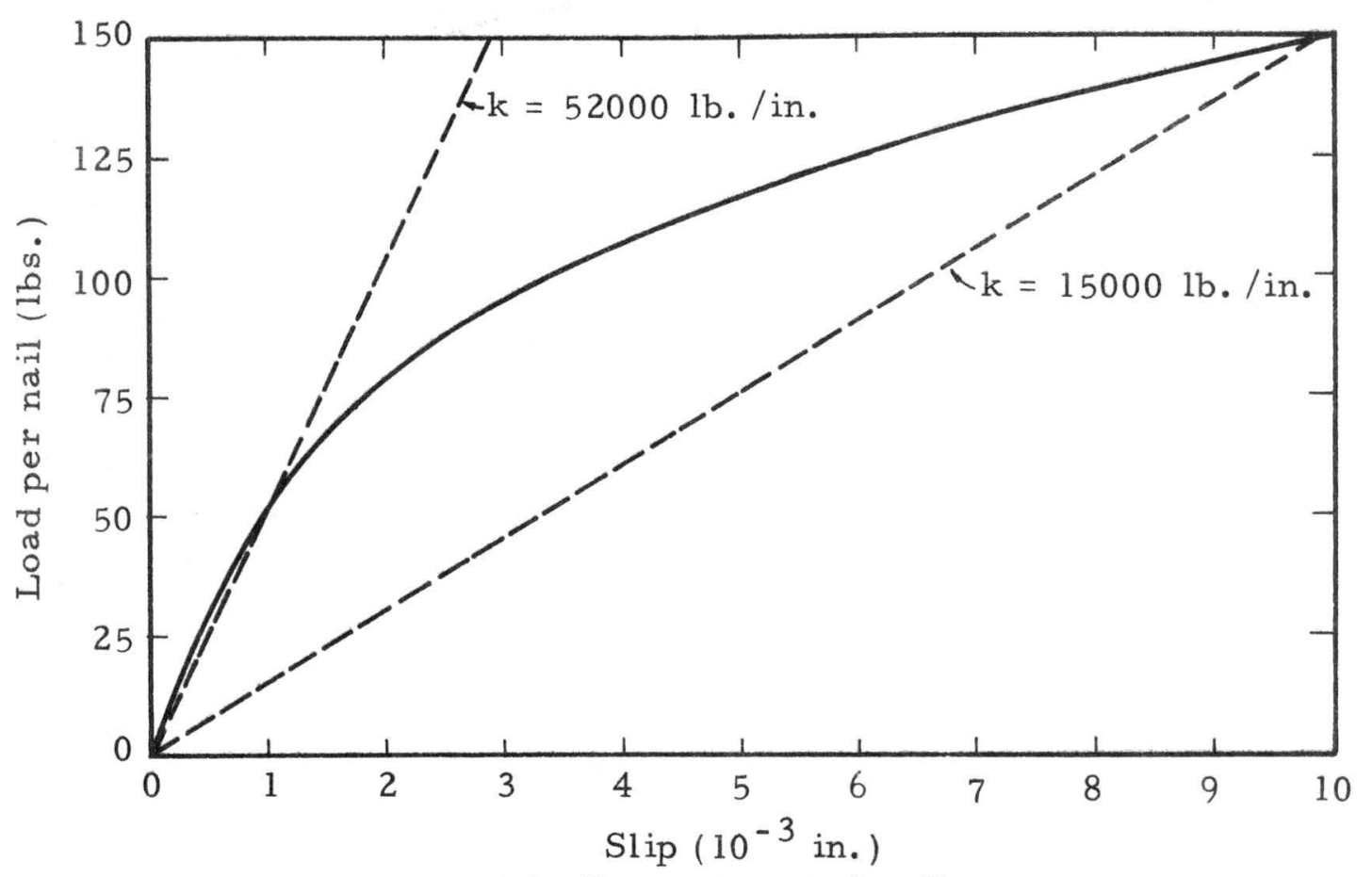

(a) Cement coated nails

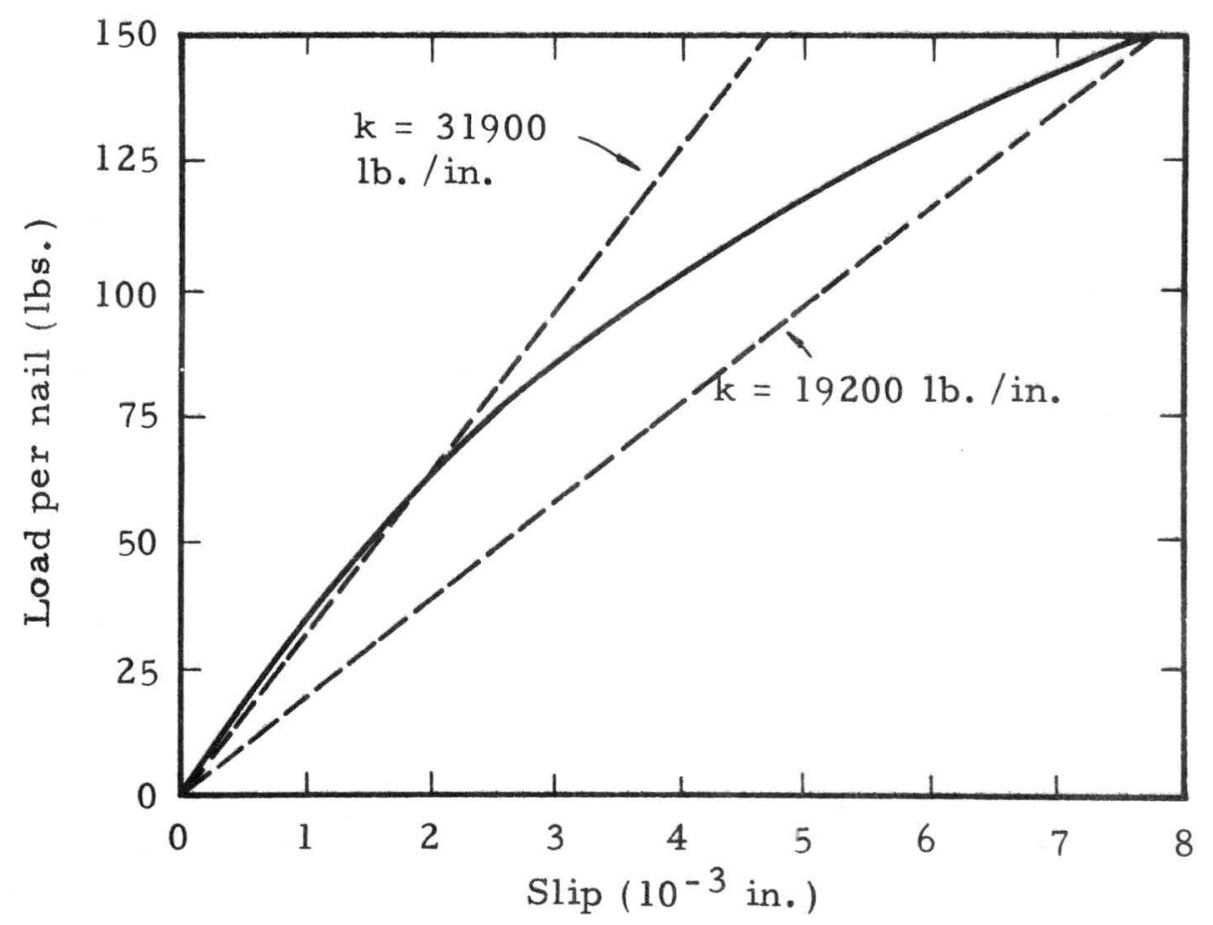

(b) Common nails

Figure 5.1. Force-Slip Curve for Connectors (Douglas Fir Specimen) 
$k$, can be obtained using a tangent or secant definition at any point along this curve. For the use of the theory, two approximations to the connector modulus are taken as shown in Figure 5.1 (a). These values are considered to be the upper and lower bounds, respectively. Twenty-one tests were conducted for common nails and a combined slip curve for these connectors is shown in Figure 5. 1 (b). Two selected bounds for the connector modulus are shown therein. In a later section, the theoretical deflection is assumed to be that obtained by averaging the deflection computed using both the upper and lower bounds of the connector modulus.

\section{3 Test Results}

a) Test Results T-Beam No. T1-8D16-1

The beam used in this test had a Douglas fir plywood top layer and Douglas fir joists as shown in Figure 5.2. The support system consisted of two sill plates spaced 12 feet apart. Joists had 2 in. wide by 8 in. deep nominal dimensions, however the average true dimensions were as shown in Figure 5.2(d). The plywood was $3 / 4 \mathrm{in}$. thick by $32 \mathrm{in.}$ wide. Three pieces of plywood with face grain parallel to the span of the beam, labeled as A, B and C, were used as the top layer of this two layered beam system. This beam was connected by eight-penny cement coated nails at 8 in. spacings along the beam length and one nail per row for each 


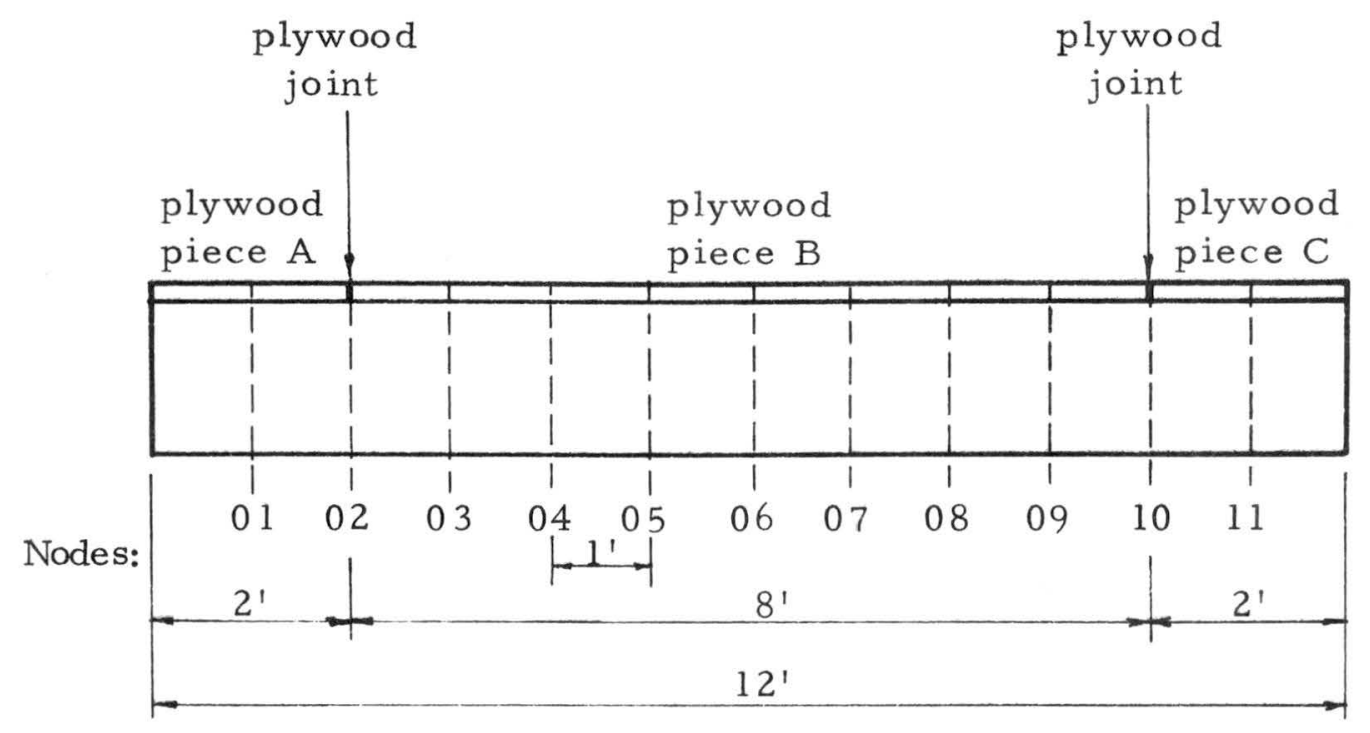

(a) Longitudinal view and nodal points

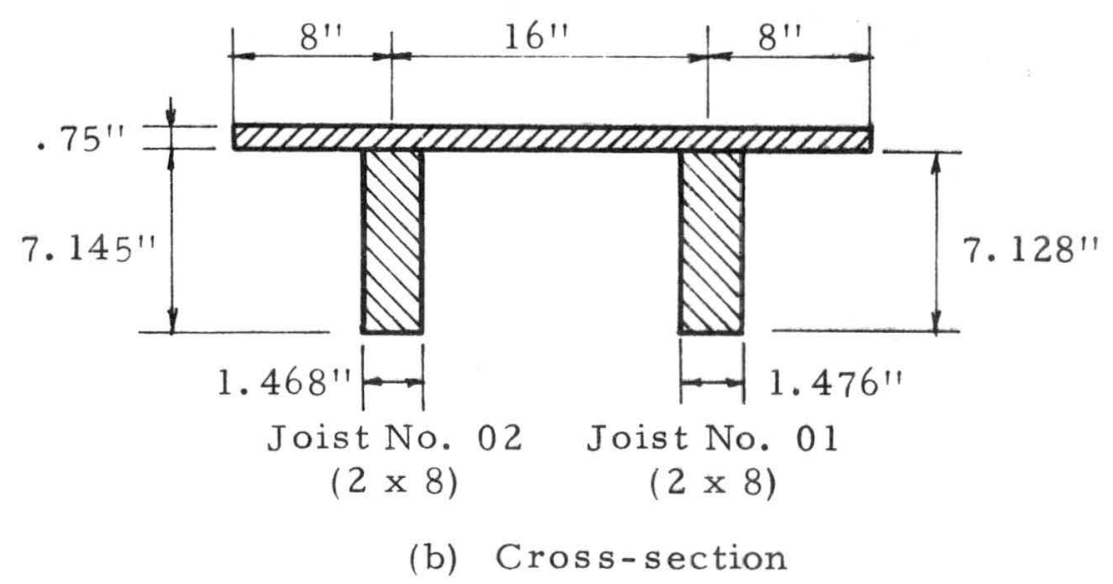

Figure 5.2. T-Beam Test T1-8D16-1 (Plywood Face Grain Parallel to Joists) 
joist. The beam was divided into 12 equal sections for analys is and for variation of properties.

Two joists were used in this test to insure beam stability. The moduli of elasticity values along the length are listed in Table 1, Appendix IV. A sequence of vertical point loads were applied at different locations of the beam. It was assumed that each single joist was loaded with one-half the applied load. The plots comparing the test and theoretical values are shown in Figure 5. 3.

b) Test Results T-Beam No. T2-8D48-1

In this test, T-beam containing a single joist with a $48 \mathrm{in.}$ wide flange and shown in Figure 5.4 was used. The moduli of elasticity along the length of the joist are listed in Table 2, Appendix IV. In this test, eight-penny cement coated nails with 8 in. spacing along the beam length and one nail per row were used. Figure 5.5 shows the results the measured and theoretical values of deflection.

c) Test Results T-Beam No. T4-8D16-1

The beam used in this test is shown in Figure 5.6. Three sheathing pieces were cut from the same Douglas fir plywood sheet and their face grain directions were placed perpendicular to the joist direction. The moduli of elasticity of this beam are listed in Table 3, Appendix IV. Eight-penny common nails with 


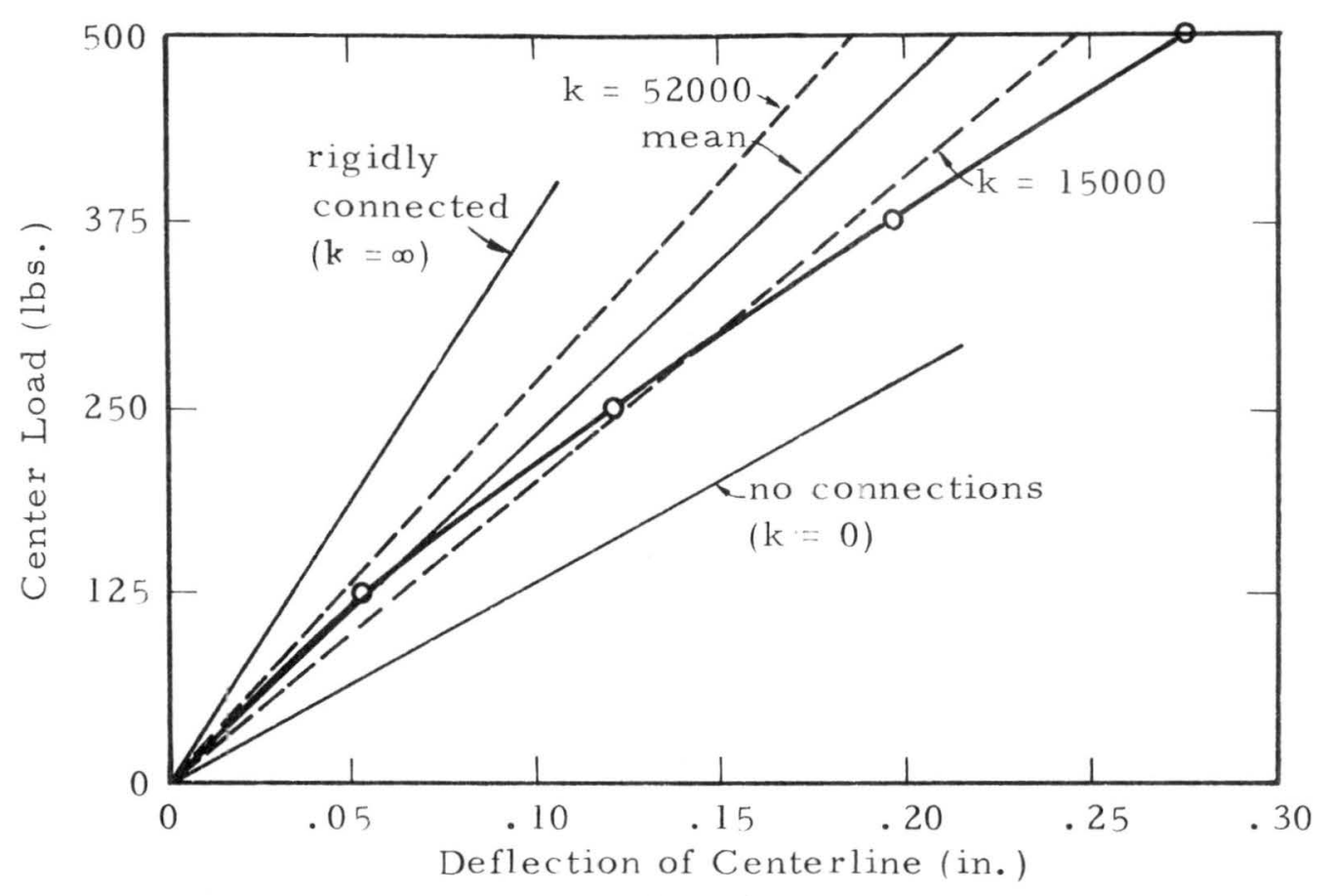

(a) Joist 01

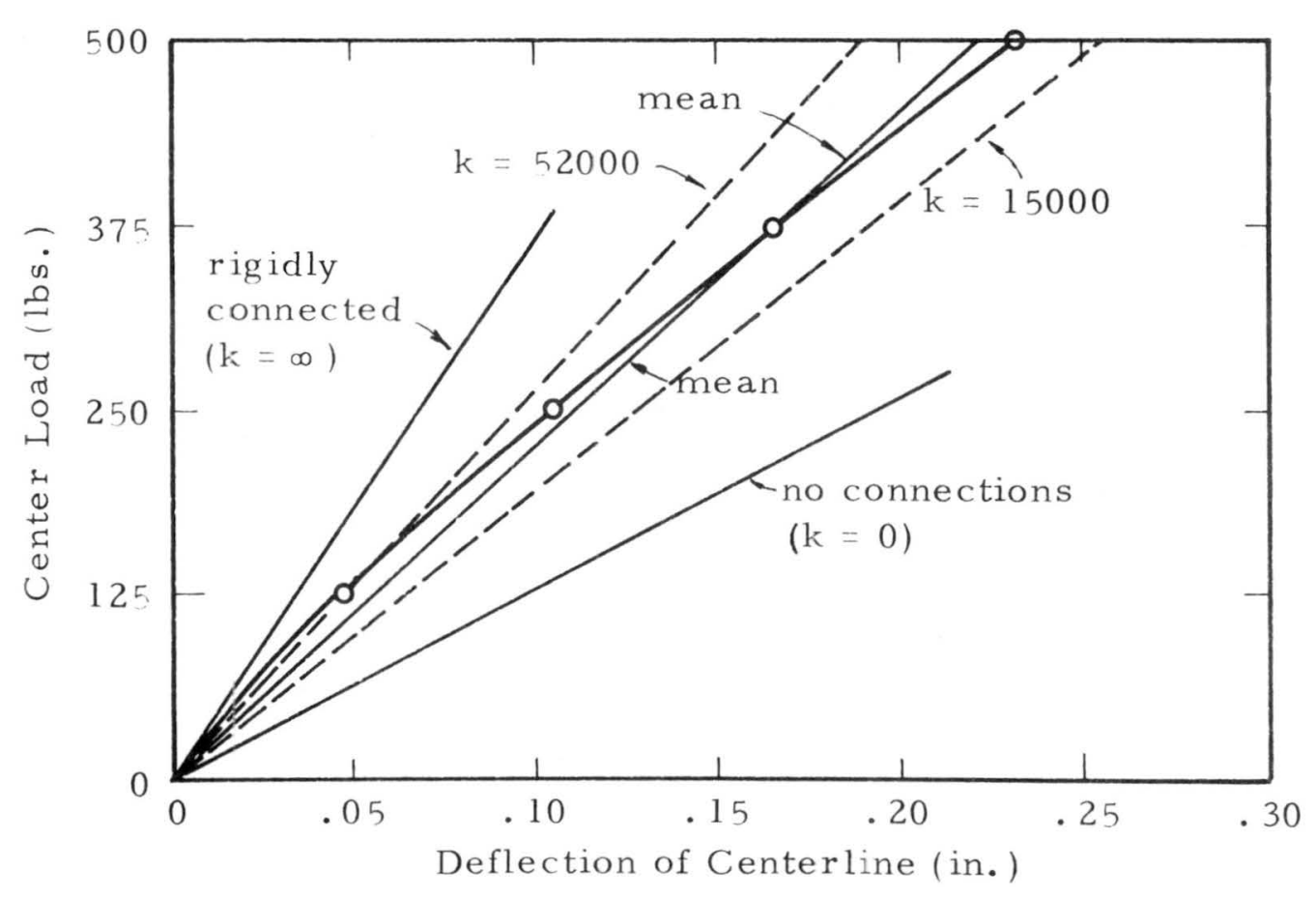

(b) Joist 02

- Measured values

-- Upper and lower bounds by theory

Figure 5.3. Test Results of T1-8Dl6-1 


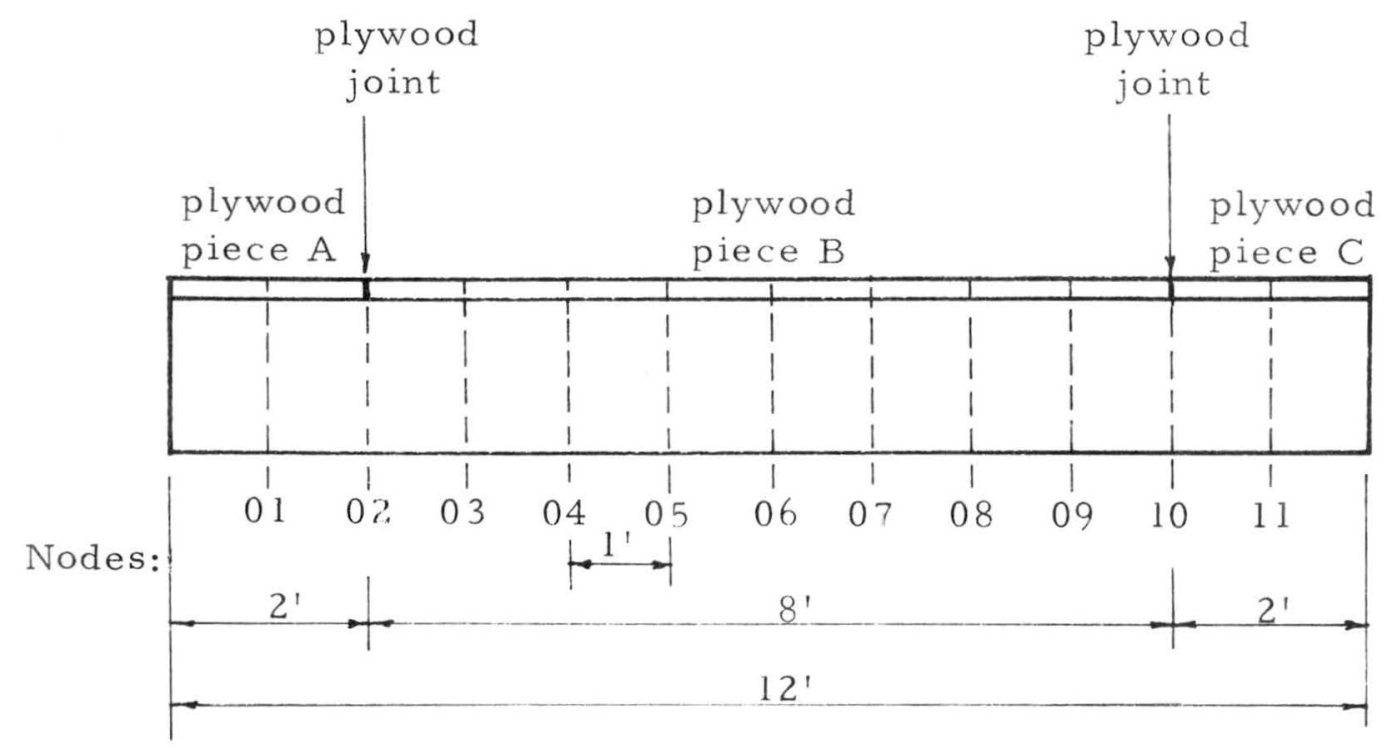

(a) Longitudinal view and nodal points

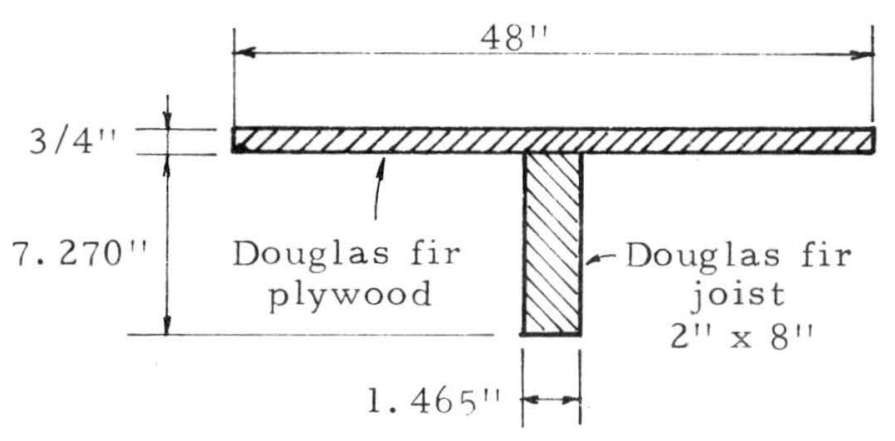

(b) Cross-section

Figure 5.4. T-Beam Test T2-8D48-1 (Plywood Face Grain Direction Parallel to Joist) 


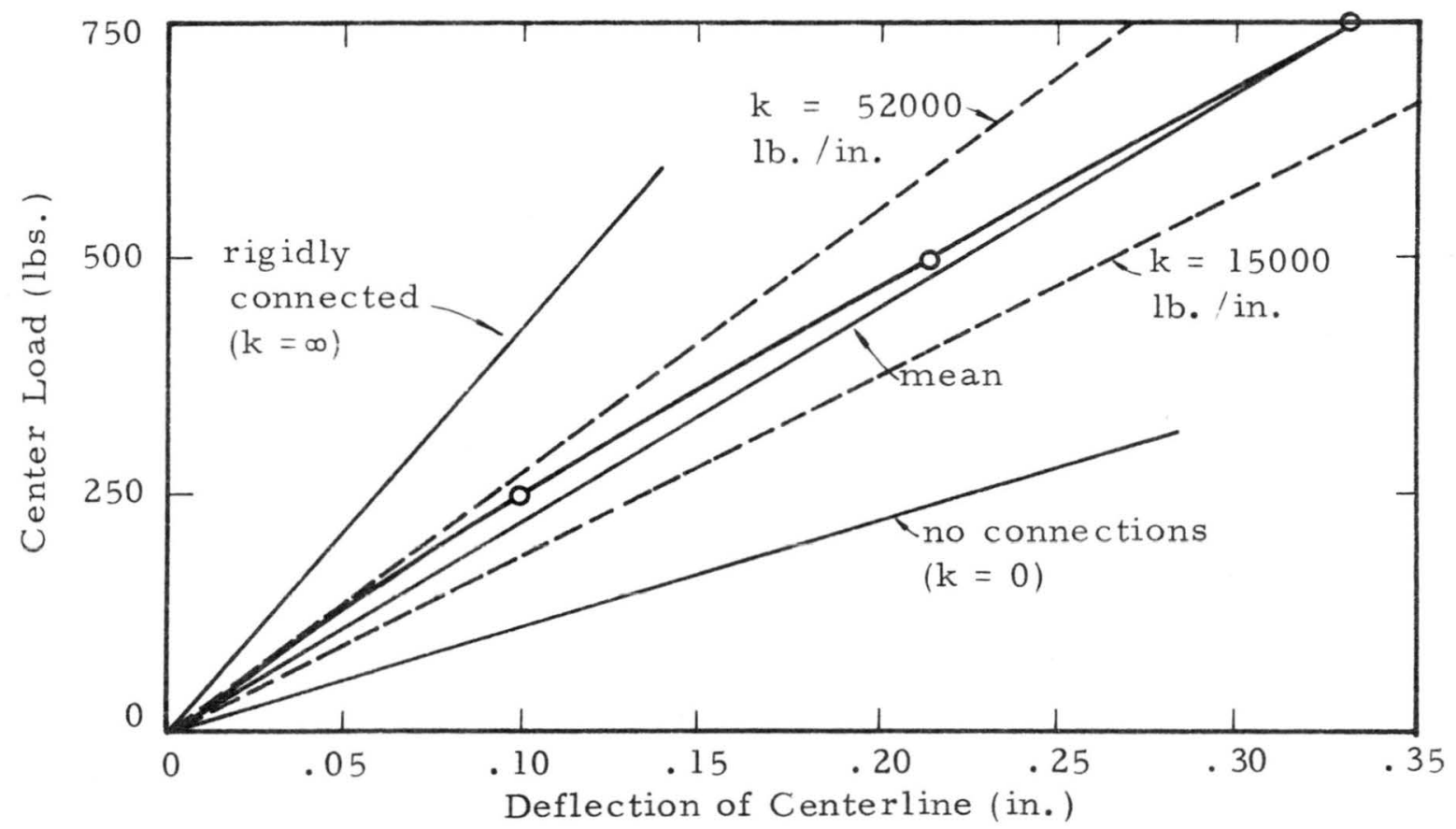

- Measured values

-- Upper and lower bounds by theory

Figure 5.5. Test Results of T2-8D48-1 


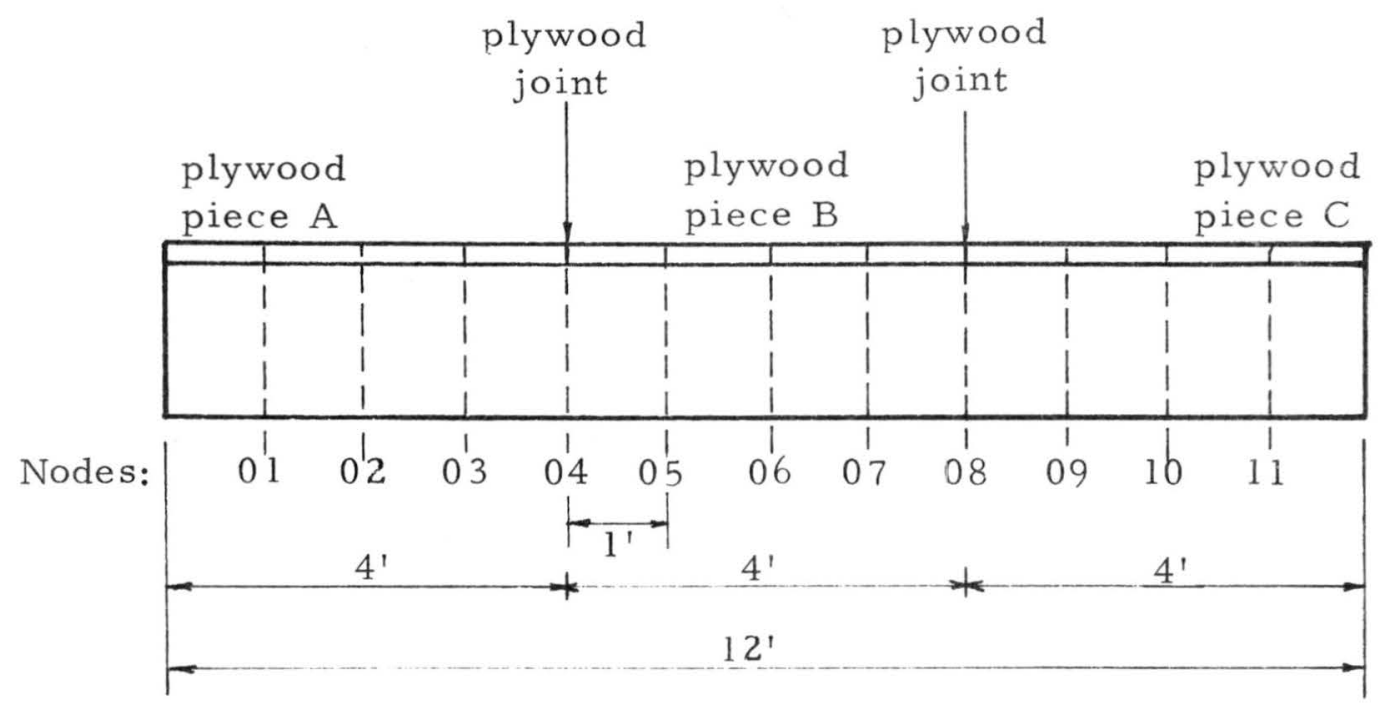

(a) Longitudinal view and nodal points

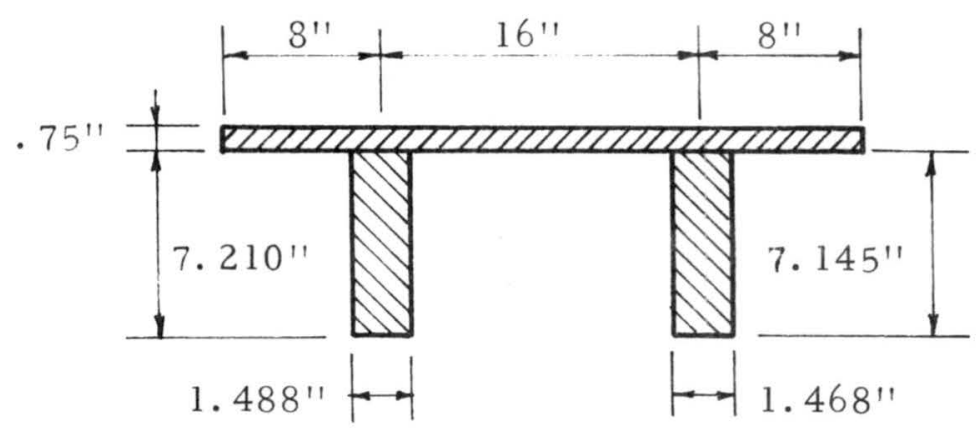

Joist No. 02 Joist No. 01

(b) Cross-section

Figure 5.6. T-Beam Test T4-8Dl6-1 (Plywood Face Grain Direction Perpendicular to Joists) 
8 in. spacing along the beam length and one nail per row for each joist were used as connectors. Thus the connector properties were used as shown in Figure 5.1(b). Figure 5.7 shows the results of measured and theoretical values of deflection.

d) Test Results T-Beam No. T5-8D16-1

A double-joist T-beam used in this test is shown in Figure 5. 8. The moduli of elasticity were listed in Table 4, Appendix IV. The connector condition was the same as that of $\mathrm{T}$-beam test T4-8D16-1. Plywood face grain direction was perpendicular to the joist direction. Figure 5.9 shows the results of measured and theoretical values of deflection. 


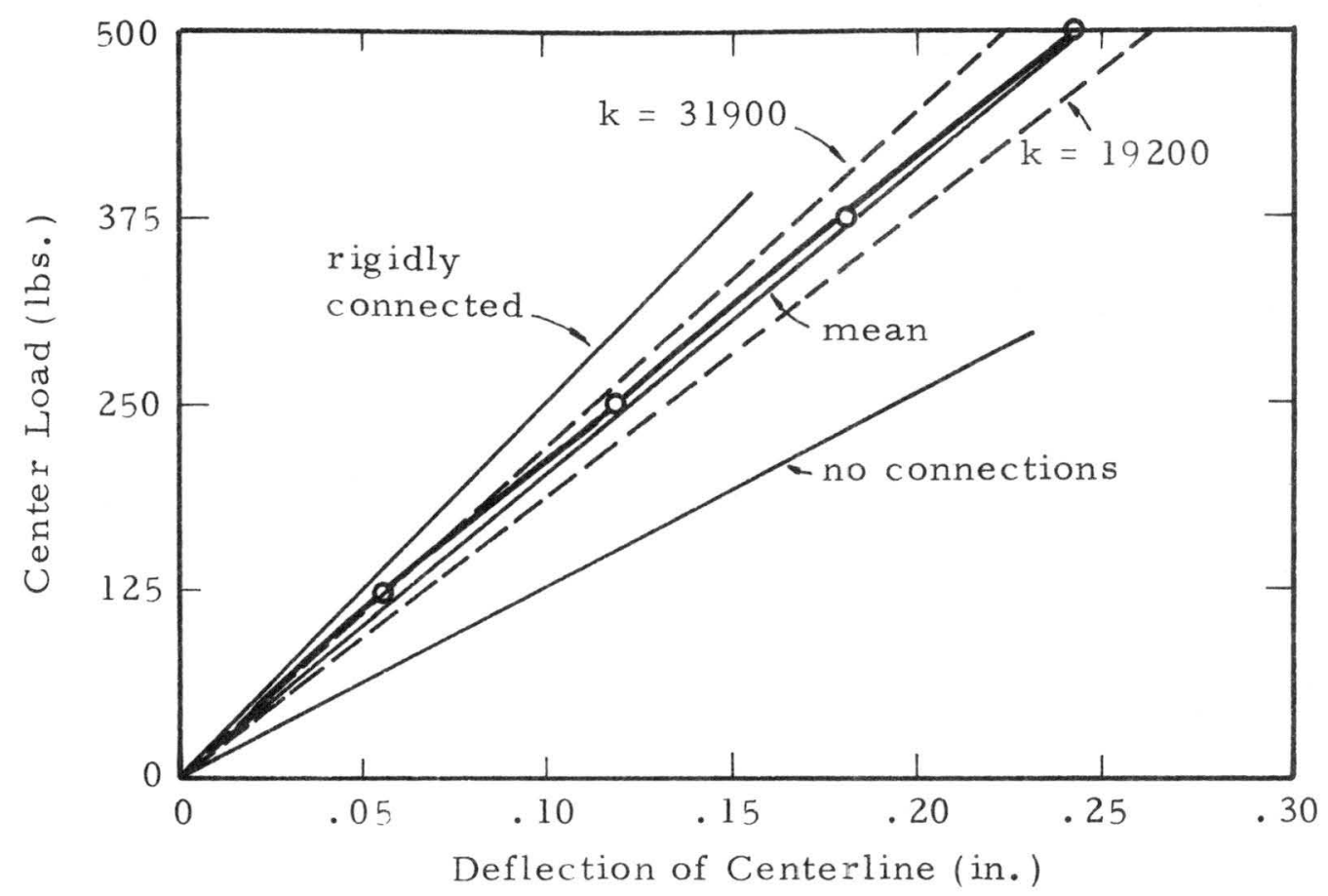

(a) Joist 01

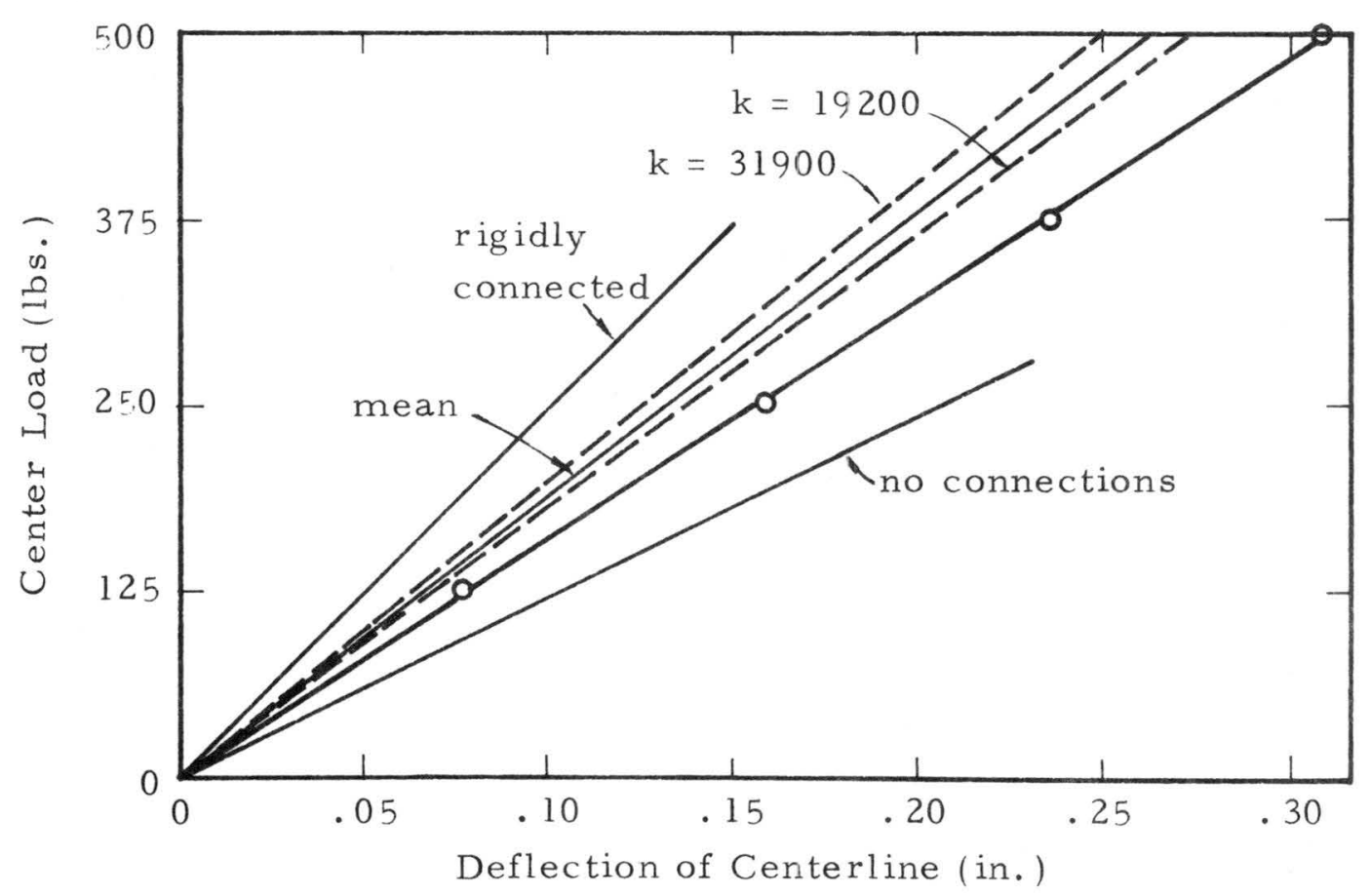

(b) Joist 02

- Measured values

-- Upper and lower bounds by theory

Figure 5.7. Test Results of T4-8D15-1 


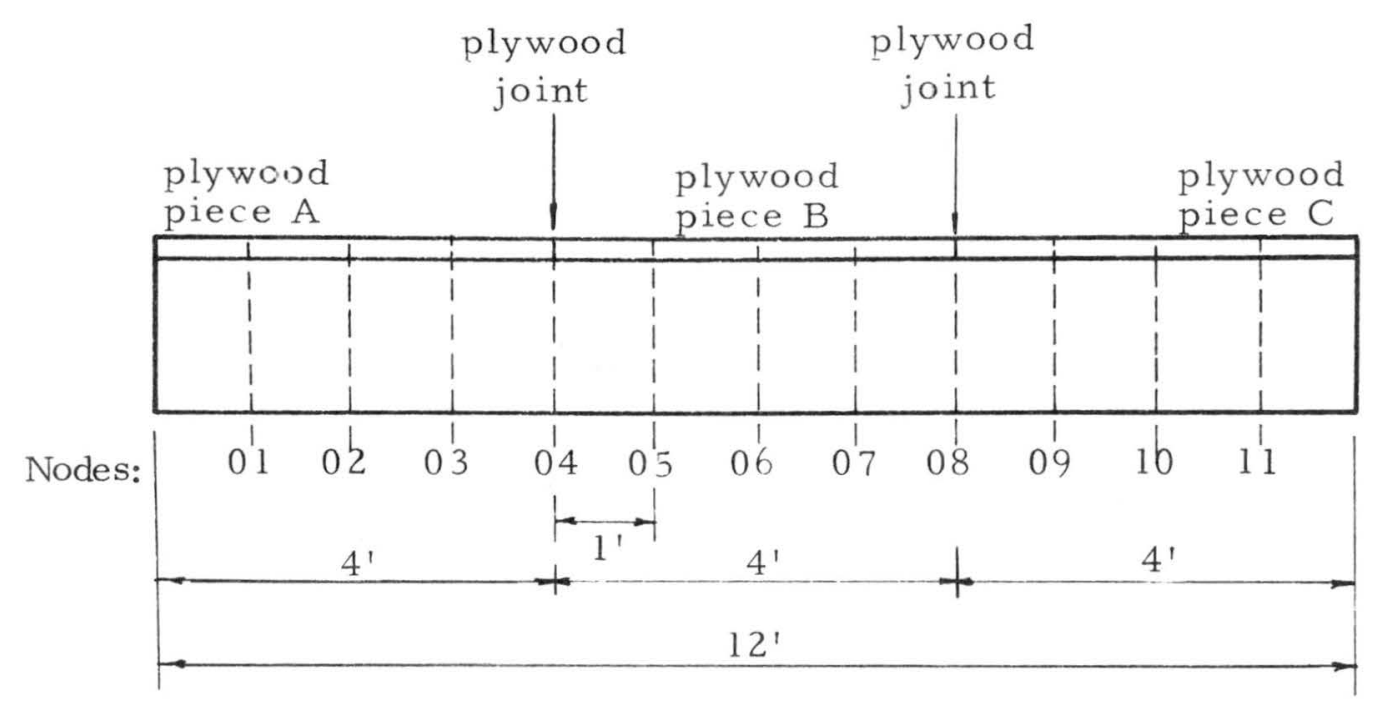

(a) Longitudinal view and nodal points

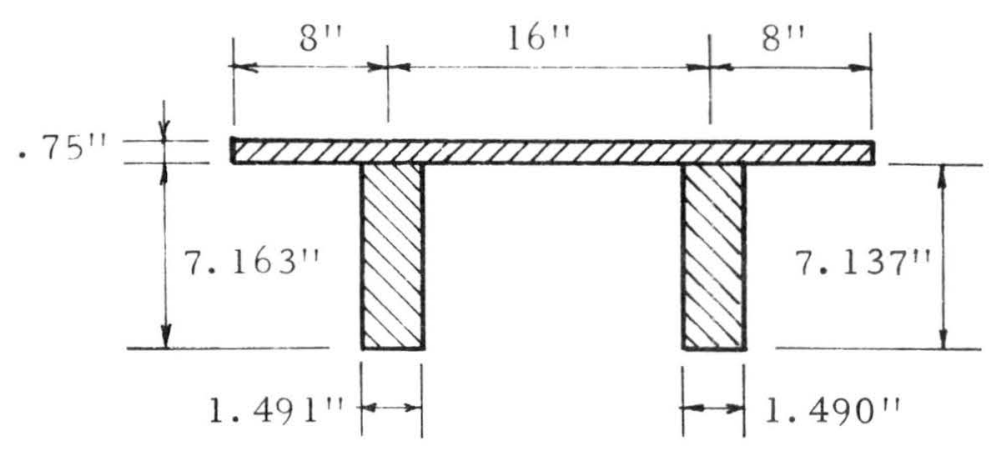

Joist No. 02 Joist No. 01

(b) Cross-section

Figure 5.8. T-Beam Test T5-816-1 (Plywood Face Grain Direction Perpendicular to Joists) 


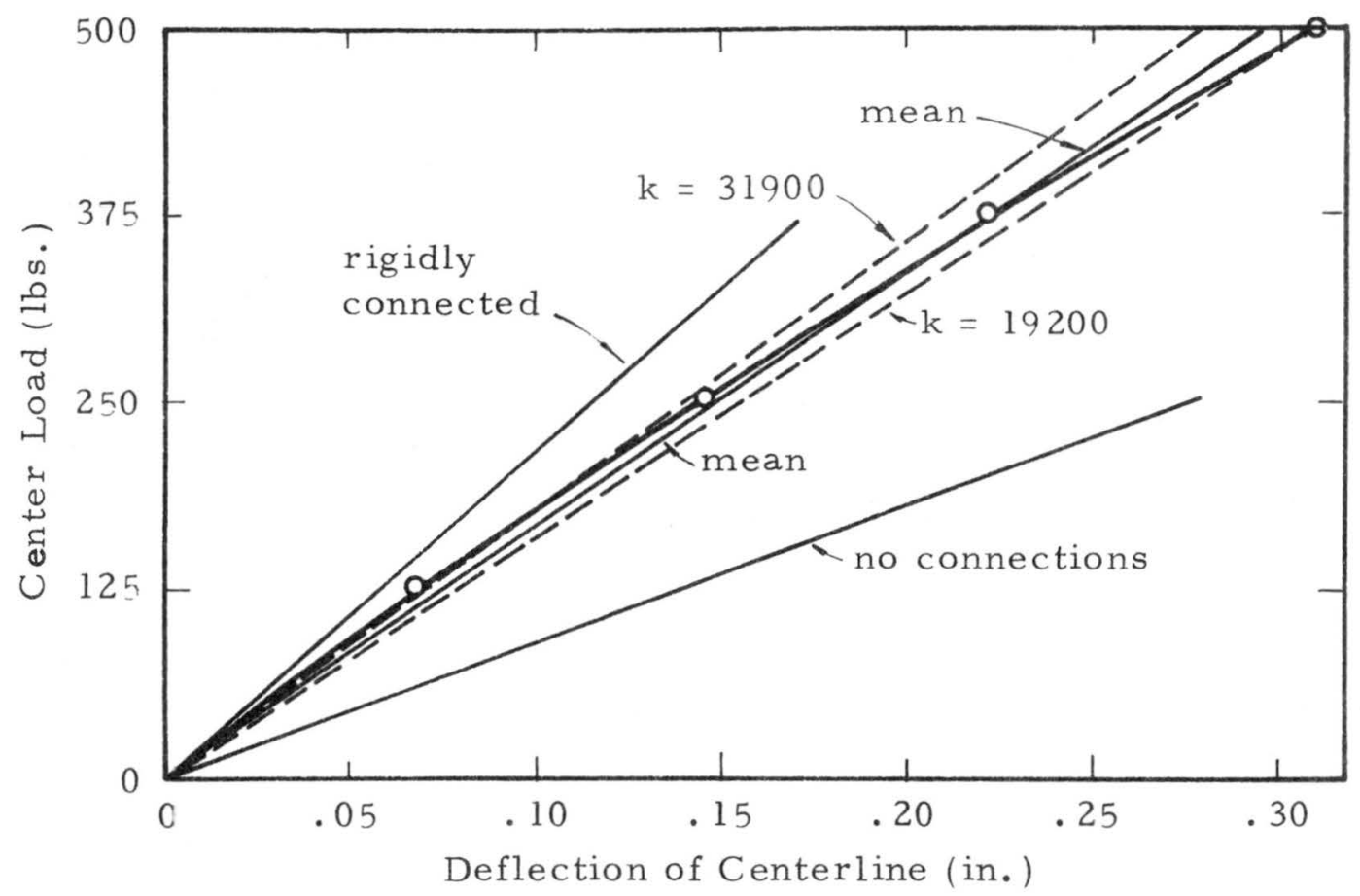

(a) Joist 01

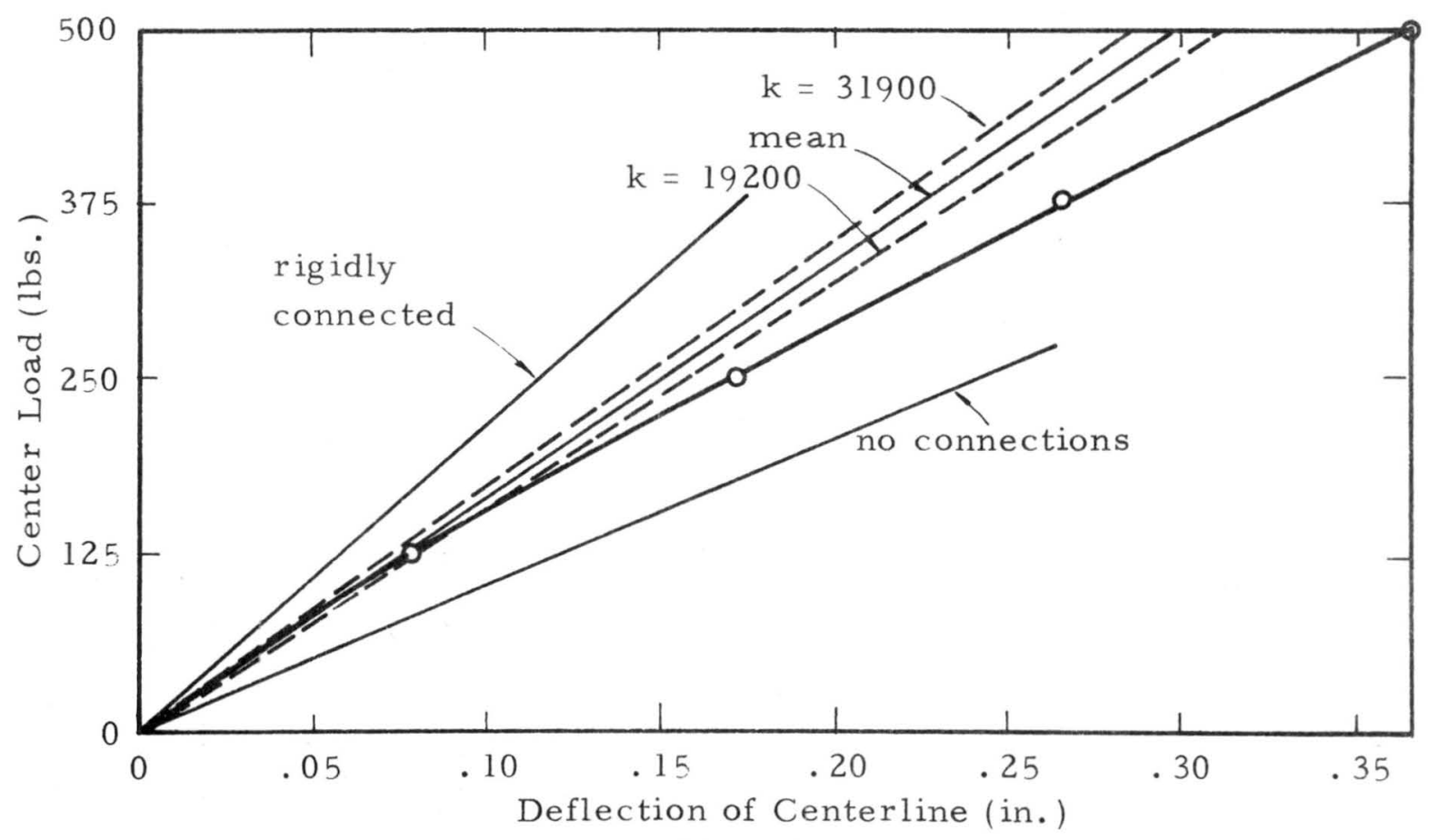

(b) Joist 02

- Measured values

-- Upper and lower bounds by theory

Figure 5.9. Test Results T5-8D16-1 
CHAPTER 6

CONCLUSIONS

In this study, a small deflection theory was developed for the transverse loading of layered beams with the effects of interlayer slip and variable material properties along the leng th of the beam included. The basic theory was developed for the deflection of an $m$ layered system, then specialized to two and three layered systems with one axis of symmetry in the cross section. It was shown that the $m$ layered system with uniform load yields a single differential equation but for a concentrated load the results are a set of simultaneous differential equations in $m$ unknowns, $y, F_{1}, F_{2} \cdot$. and $\mathrm{F}_{\mathrm{m}-1}$. The boundary conditions necessary to solve each problem were presented.

The governing equations of two and three layered systems were reduced to the equal layered beam system and showed agreement with those previously developed by Goodman (1), (2). In all cases the limiting solutions were shown to give bounds for the expected results, that is, beams with very stiff connectors behaved as the equivalent rigidly connected beam and those with no connectors cause the system to act as separate beams. 
In the tests, all readings were taken immediately after applying a given load. In general, good theoretical agreement with experimental results was achieved except at higher loads. It is felt that there are two main effects that could cause this deviation. The theory presented shows that the system behavior is greatly dependent upon the moduli of elasticity of the layers and the stiffness of the interlayer connectors. The moduli of elasticity of the joists used in theory were measured flatwise whereas the joists were loaded edgewise in the tests. This variation should produce primarily a random effect. The presence of a local defect in the joist such as an edge knot under the load could cause a significant effect in the actual joist behavior.

Results obtained show that a proper knowledge of connector modulus is of prime importance. The connector modulus, k, varies in a non-linear manner as shown by the force-slip curves. In the $\mathrm{T}$-beam tests, the $\mathrm{k}$ value is smaller for higher applied loads than that at lower loads. If the exact connector modulus for each connector would be used then the theoretical values should approximate the measured values with very little deviation.

In $\mathrm{T}$-beams with double joists, a mismatch in the stiffness of the joists may cause a larger deflection in one joist than the other. This difference in deflection introduces some torsional and other interaction effects. No simple method of evaluating these 
effects are available, but it is not expected that this behavior introduces large errors in the prediction of deflection values.

Some other secondary effects, such as transverse joists and gaps of sheathing, restraints of end supports, effective flange width, cycling of applied loads and time dependency of slip tests, also exist and may affect the theoretical and test results somewhat.

Although the theory developed in this study is applicable only to static bending problems, it is evident that problems of vibration and buckling may also be considered by similar methods. While the procedures developed were applied to layered systems of wood, any glued or mechanically-connected layered beam system can be analyzed in the same manner.

Results of this study can be used for more efficient designs of structural components, resulting in a reduction in the amount of materials needed. 
APPENDICES 


\section{APPENDIX I}

\section{REFERENCES}

1. Goodman, J. R., "Layered Wood Systems with Interlayer Slip," Ph. D. Dissertation, University of California, Berkeley, 1967.

2. Goodman, J. R. and Popov, E. P., "Layered Beam Systems with Interlayer Slip, " Journal of Structural Division, American Society of Civil Engineering, Vol. 94, No. ST11, Nov. 1968, pp. 2535-2547.

3. Calcote, L. R., The Analys is of Laminated Composite Structures, Van Norstrand Reinhold Company, New York, 1969.

4. Abel, J. F., "Static and Dynamic Analysis of Sandwich Shells with Viscoelastic Damping, Ph. D. Dissertation, University of California, Berkeley, 1968.

5. Hoff, N. J. and Mautner, S. E., "Bending and Buckling of Sandwich Beams, " J. Aero Sci., Vol. 15, No. 12, Dec. 1948, pp. 707-720.

6. Raville, M. E., Ueng, E. S. and Lei, M. M., "Natural Frequencies of Vibration of Fixed-Fixed Sandwich Beams, " Journal of Applied Mechanics, Vol. 28, No. 3, Sept. 1961 , pp. $367-372$.

7. Ross, D., Ungar, E. E. and Kerwin, E. M., "Damping of Plate Flexural Vibrations by Means of Viscoelastic Laminae, "Structural Damping, American Society of Mechanical Engineers, Dec. 1959., J. E. Ruzicka ed., pp. $49-87$.

8. Granholm, H., "Om Sammansatta Balkar Och Pelare Med Sarkilo Hansyn Till Spikade Trakonstruktioner" ("On Composite Beams and Columns with Particular Regard to Nailed Timber Structures"), Chalmers Tekniska Hogskoas Handlingar, No. 88, 1949. 
9. Pleshkov, P. F., Teoriia Rashceta Depeviannykh (Theoretical Studies of Composite Wood Structures), Moscow, 1952.

10. Newmark, N. M., Seiss, C. P. and Viest, I. M., "Tests and Analysis of Composite Beams with Incomplete Interaction, " Proceedings, Society for Experimental Stress Analys is, Vol. 19, No. 1, 1951.

11. Seiss, C. P., Viest, I. M. and Newmark, N. M. "Small Scale Tests of Shear Connectors of Composite T-Beams," Bulletin 396, University of Illinois Experiment Station, Vol. 49, No. 45, Feb. 1952.

12. Clark, L. G., "Deflections of Laminated Beams," Transactions, American Society of Civil Engineers, Vol. 119 , 1954, pp. $721-736$.

13. Henghold, W. M., "Layered Beam Vibrations Including Slip," Ph. D. Dissertation, Colorado State University, Fort Collins, Colorado, June, 1972.

14. Rassam, H. Y., "Layered Columns with Interlayer Slip," Ph. D. Dissertation, Colorado State University, Fort Collins, Colorado, March, 1969.

15. Rassam, H. Y. and J. R. Goodman, "Design of Layered Wood Columns with Interlayer Slip," Wood Science, Vol. 3, No. 3, 149-155 pp., Jan. 1971.

16. Henghold, W. M. and J. R. Goodman, "Static and Dynamic Behavior of Layered Beams Including Slip," Presented and published, Sixth St. Louis Symposium on Composite Materials in Engineering Design, May 1972.

17. Rassam, H. Y. and J. R. Goodman, "Buckling Behavior of Layered Wood Columns, "Wood Science, 2(4)238-246.

18. Norris, Charles B., Ericksen, Wilhelm S., and Kommers, Wm. J. "Flexural Rigidity of A Rectangular Strip of Sandwich Construction--Comparison Between Mathematical Analysis and Results of Tests," Forest Prod. Lab. Rep. 1505A. May 1952. 
19. Kuenzi, E. W. and Wilkinson, T. L., "Composite Beams-Effect of Adhesive or Fastener Rigidity." 1971.

20. Penner, B. G., "Experimental Behavior of Wood Flooring Systems, "M.S. thesis, Colorado State University, Fort Collins, Colorado, December, 1972.

21. Patterson, D. W., "Nailed Wood Joist Under Lateral Loads," M.S. thesis, Colorado State University, Fort Collins, Colorado, 1973. 


\section{LIST OF SYMBOLS}

$A_{i}=$ Area of the $i^{\text {th }}$ layer

$\mathrm{A}_{i}^{*}=$ Transformed area of the $i^{\text {th }}$ layer

$\mathrm{C}_{\mathrm{i}} \quad=$ Constant relating $\mathrm{y}$ and $\mathrm{F}$ solutions

$\mathrm{C}_{\mathrm{ij}}=$ Centroidal distance between $i^{\text {th }}$ and $\mathrm{j}^{\text {th }}$ layers

$\mathrm{D}^{\mathrm{p}}=$ Operator indicating the $\mathrm{p}^{\text {th }}$ derivative with respect to the space variable

$\mathrm{E}=$ Modulus of elasticity

$\mathrm{F}_{\mathrm{i}}=$ Axial force in the $\mathrm{i}^{\text {th }}$ layer

$\mathrm{G}=$ Average connector modulus

$G_{i j}=$ Flexibility per unit length between $i^{\text {th }}$ and $j^{\text {th }}$ layers

h $=$ Height in equal layer system

$h_{i}=$ Height of the $i^{\text {th }}$ layer

$\overline{\mathrm{h}}=$ Height from top of beam to centroid of cross-section

$I_{i}=$ Moment of inertia of the $i^{\text {th }}$ layer

$\mathrm{I}_{\mathrm{S}} \quad=$ Moment of inertia of equivalent rigidly connected beam

$\mathrm{k}=$ Connector modulus

$\mathrm{L}=$ Beam length

$\mathrm{M}_{\mathrm{i}}=$ Bending moment in the $i^{\text {th }}$ layer

$\mathrm{M}_{\mathrm{T}}=$ Total moment on a cross-section 


$$
\begin{aligned}
& \mathrm{n} \quad=\text { Integer number } \\
& \mathrm{P} \quad=\text { Point load (positive while downward) } \\
& \text { Q = Load transmitted by a connector } \\
& \mathrm{q}=\text { Uniformly distributed load (positive while downward) } \\
& \mathrm{q}_{\mathrm{c}}=\mathrm{L}_{\text {beam }} \text { Load transmitted between two layers per unit length of a } \\
& q_{i j}=\text { Load transmitted between the } i^{\text {th }} \text { and } j^{\text {th }} \text { layers } \\
& \begin{aligned}
r_{i}= & \text { Distance from centroid of beam to centroid of } i^{\text {th }} \text { layer } \\
& \text { (negative while above centroid line) }
\end{aligned} \\
& \Delta S_{i}=\text { Slip of } i^{\text {th }} \text { layer } \\
& \mathrm{S}=\text { Connector spacing } \\
& \mathrm{T}_{\mathrm{i}}=1 /\left(\mathrm{EA}_{\mathrm{i}}^{*}\right) \\
& =\text { Axial stiffness per unit length for the } i^{\text {th }} \text { layer } \\
& \text { T. C. = A transfer constant relating } I_{S} \text { and the summation of } I \\
& \mathrm{~V} \quad=\text { Shear force on beam element } \\
& \mathrm{V}_{\mathrm{i}}=\text { Shear force on the } i^{\text {th }} \text { layer element } \\
& \mathrm{V}_{\mathrm{T}}=\text { Total shear } \\
& \mathrm{x} \quad=\text { Space variable } \\
& \mathrm{y} \quad=\text { Beam deflection } \\
& y_{\mathrm{s}} \quad=\text { Solid beam deflection } \\
& \text { z } \quad=\text { Dimensionless space variable } \\
& \Delta S_{i j}=\text { Interlayer slip between } i^{\text {th }} \text { and } j^{\text {th }} \text { layers } \\
& \epsilon_{i}^{L}=\text { Strain in the } i^{\text {th }} \text { layer at the lower edge } \\
& \epsilon_{i}^{U}=\text { Strain in the } i^{\text {th }} \text { layer at the upper edge }
\end{aligned}
$$




\section{APPENDIX III- 1}

EXPRESSION OF HIGH ORDER DIFFERENTIAL TERM DERIVED FROM TAYLOR SERIES EXPANSION

Taylor Series Expansion:

This method allows judgement of order of error involved in various approximations.

Taylor Series

$$
\begin{aligned}
y\left(x_{i}+m h\right)= & \sum_{p=0}^{n} \frac{m^{p} h^{p}}{p !} y^{(p)}+\text { error term } \\
= & y_{0}+\frac{m h}{1 !} y_{i}^{\prime}+\frac{m^{2} h^{2}}{2 !} y_{i}^{\prime \prime}+\frac{m^{3} h^{3}}{3 !} y_{i}^{\prime \prime \prime} \\
& +\cdots+\frac{m^{p h}}{p !} y_{i}^{(p)}+\text { error term }
\end{aligned}
$$

where $\mathrm{m}=1,2,3$ etc.

For a five-term expansion:

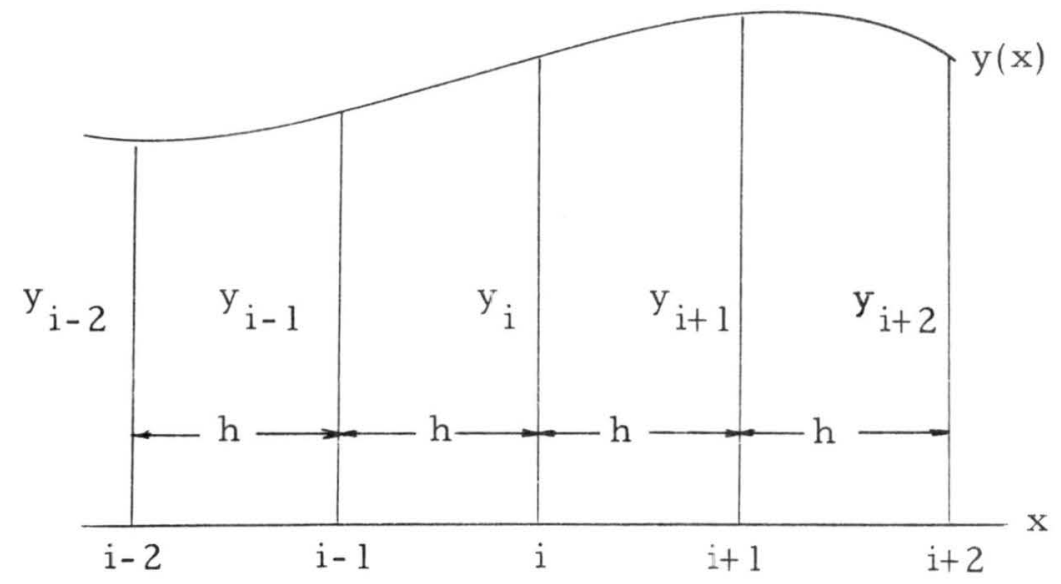


then

$$
\begin{aligned}
& y_{i-2}=y\left(x_{i}-2 h\right)=y_{0}-2 h y_{i}^{\prime}+\frac{4 h^{2}}{2 !} y_{i}^{\prime \prime}-\frac{8 h^{3}}{3 !} y_{i}^{\prime \prime \prime} \\
& +\frac{16 h^{4}}{4 !} y_{i}^{(4)}-\ldots+. . . \\
& y_{i-1}=y\left(x_{i}-h\right)=y_{i}-h y_{i}^{\prime}+\frac{h^{2}}{2 !} y_{i}^{\prime \prime}-\frac{h^{3}}{3 !} y_{i}^{\prime \prime \prime} \\
& +\frac{h^{4}}{4 !} y_{i}^{(4)}-\ldots .+. . \\
& y_{i}=y\left(x_{i}\right)=y_{i} \\
& y_{i+1}=y\left(x_{i}+h\right)=y_{i}+h y_{i}^{\prime}+\frac{h^{2}}{2 !} y_{i}^{\prime \prime}+\frac{8 h^{3}}{3 !} y_{i}^{\prime \prime \prime} \\
& +\frac{h^{4}}{4 !} y_{i}^{(4)}+\ldots+\ldots \\
& y_{i+2}=y\left(x_{0}+2 h\right)=y_{i}+2 h y_{i}^{\prime}+\frac{4 h^{2}}{2 !} y_{i}^{\prime \prime}+\frac{8 h^{3}}{3 !} y_{i}^{\prime \prime \prime} \\
& +\frac{16 h^{4}}{4 !} y_{i}^{(4)}+\ldots .+\ldots
\end{aligned}
$$

4.

5.

Eq. 2 plus Eq. 4 implies

$$
y_{i-1}+y_{i+1}=2\left(y_{i}+\frac{h^{2}}{2 !} y_{i}^{\prime \prime}+\frac{h^{4}}{4 !} y_{i}^{(4)}\right)
$$

6.

Eq. 1 plus Eq. 5 implies 


$$
y_{i-2}+y_{i+2}=2\left(y_{i}+\frac{4 h^{2}}{2 !} y_{i}^{\prime \prime}+\frac{16 h^{4}}{4 !} y_{i}^{(4)}\right)
$$

Eq. 7 - 16 times Eq. 6, yields

$$
\begin{aligned}
& y_{i}^{\prime \prime}=\frac{1}{12 h^{2}}\left(-y_{i-2}+16 y_{i-1}-30 y_{i}+16 y_{i+1}-y_{i+2}\right) \\
& \text { error order } e=\frac{h^{6}}{h^{2}}=h^{4}
\end{aligned}
$$

Eq. 7 - 4 times Eq. 6, yields

$$
\begin{aligned}
& y_{i}^{(4)}=\frac{1}{h^{4}}\left(y_{i-2}-4 y_{i-1}+6 y_{i}-4 y_{i+1}+y_{i+2}\right) \\
& \text { error order } e=\frac{h^{6}}{h^{4}}=h^{2}
\end{aligned}
$$

By the similar method, for a seven-term expansion

$$
y_{i}^{(6)}=\frac{1}{h^{6}}\left(y_{i-3}-6 y_{i-2}+15 y_{i-1}-20 y_{i}+15 y_{i+1}-6 y_{i+2}+y_{i+3}\right)
$$

For a nine-term expansion

$$
\begin{aligned}
y_{i}^{(8)}= & \frac{1}{h^{8}}\left(y_{i-4}-8 y_{i-3}+28 y_{i-2}-56 y_{i-1}+70 y_{i}\right. \\
& \left.-56 y_{i+1}+28 y_{i+2}-8 y_{i+3}+y_{i+4}\right)
\end{aligned}
$$




\section{BOUNDARY CONDITIONS FOR THREE LAYERED BEAM WITH UNIFORM LOAD}

From the closed form equation of Chapter 4 ,

$$
\begin{gathered}
D^{4} F_{1}=-\frac{C_{12}}{G_{12} \frac{q}{\sum_{1}^{3} E I}} \\
D^{4} F_{2}=\frac{1}{G_{23}} \frac{1}{\sum_{1}^{3} E I}\left(-C_{23}+\frac{G_{23}}{G_{12}} C_{12}\right) q \\
D^{4}=\frac{q}{\sum_{1}^{3} E I} \\
D^{6} y=\frac{1}{\left(\sum_{1}^{3} E I\right)^{2}}\left(\frac{C_{12}^{2}}{G_{12}}+\frac{C_{23}^{2}}{G_{23}}\right) q
\end{gathered}
$$

From Eq. 3

$$
\frac{1}{h^{4}}\left(y_{-2}-4 y_{-1}+6 y_{0}-4 y_{1}+y_{2}\right)=\frac{q}{\sum_{1}^{3} E I}
$$

because

$$
\begin{aligned}
& y_{0}=0 \\
& y_{-1}=y_{1}
\end{aligned}
$$

thus 


$$
y_{-2}=-y_{2}+\frac{q h^{4}}{\sum_{1}^{3} E I}
$$

From Eq. 4

$$
\begin{gathered}
\frac{1}{h^{6}\left(y_{-3}-6 y_{-2}+15 y_{-1}-20 y_{0}+15 y_{1}-6 y_{2}+y_{3}\right)} \\
=\frac{q}{\left(\sum_{1}^{3} E I\right)^{2}}\left(\frac{C_{12}^{2}}{G_{12}}+\frac{C_{23}^{2}}{G_{23}}\right)
\end{gathered}
$$

this implies

$$
y_{-3}=-y_{3}+\frac{6 q h^{4}}{\sum_{1}^{3} E I}+\frac{q h^{6}}{\left(\sum_{1}^{3} E I\right)^{2}}\left(\frac{C_{12}^{2}}{G_{12}}+\frac{C_{23}^{2}}{G_{23}}\right)
$$


APPENDIX IV

MODULI OF ELASTICITY OF T-BEAM TESTS

Table 1. T-Beam Test No. T1-8Dl6-1

\begin{tabular}{|c|c|c|c|c|c|}
\hline \multirow{2}{*}{$\begin{array}{c}\text { Node } \\
01\end{array}$} & \multirow{2}{*}{$\begin{array}{l}\text { Joist } 01 \\
\qquad E_{2}(10 \\
2.295\end{array}$} & \multirow{2}{*}{$\begin{array}{l}\text { Joist } 02 \\
\text { i) } \\
1.509\end{array}$} & \multicolumn{3}{|c|}{$\begin{array}{l}\text { plywood } \\
E_{1}\left(10^{6} \mathrm{psi}\right)\end{array}$} \\
\hline & & & 1.330 & - & piece A \\
\hline 02 & 2. 345 & 1.473 & 1.393 & - & $\begin{array}{l}\text { transverse } \\
\text { joint }\end{array}$ \\
\hline 03 & 1.743 & 1.946 & 1.456 & & \\
\hline 04 & 1.672 & 2.119 & 1.456 & & \\
\hline 05 & 1.837 & 1.950 & 1.456 & & \\
\hline 06 & 1.881 & 1.774 & 1.456 & \} & piece B \\
\hline 07 & 1.908 & 1.755 & 1.456 & & \\
\hline 08 & 2.024 & 1.866 & 1.456 & & \\
\hline 09 & 2.377 & 1.703 & 1.456 & & \\
\hline 10 & 2. 345 & 1.580 & 1.393 & - & $\begin{array}{l}\text { transverse } \\
\text { joint }\end{array}$ \\
\hline 11 & 1.848 & 1.732 & 1. 330 & - & piece C \\
\hline
\end{tabular}


Table 2. T-Beam Test No. T2-8D48-1

\begin{tabular}{|c|c|c|c|c|}
\hline Node & $\begin{array}{c}\text { Joist } \\
E_{2}\left(10^{6} \mathrm{psi}\right)\end{array}$ & \multicolumn{3}{|c|}{$\begin{array}{c}\text { plywood } \\
E_{1}\left(10^{6} \mathrm{psi}\right)\end{array}$} \\
\hline 01 & 1.295 & 1.505 & - & piece A \\
\hline 02 & 1.473 & 1. 506 & - & $\begin{array}{l}\text { transverse } \\
\text { joint }\end{array}$ \\
\hline 03 & 1.521 & 1.507 & & \\
\hline 04 & 1.487 & 1. 507 & & \\
\hline 05 & 1. 534 & 1. 507 & & \\
\hline 06 & 1.485 & 1. 507 & & piece $B$ \\
\hline 07 & 1. 424 & 1.507 & & \\
\hline 08 & 1. 448 & 1. 507 & & \\
\hline 09 & 1. 362 & 1.507 & & \\
\hline 10 & 1.459 & 1.506 & - & $\begin{array}{l}\text { transverse } \\
\text { joint }\end{array}$ \\
\hline 11 & 1.410 & 1. 505 & - & piece C \\
\hline
\end{tabular}


Table 3. T-Beam Test No. T4-8D16-1

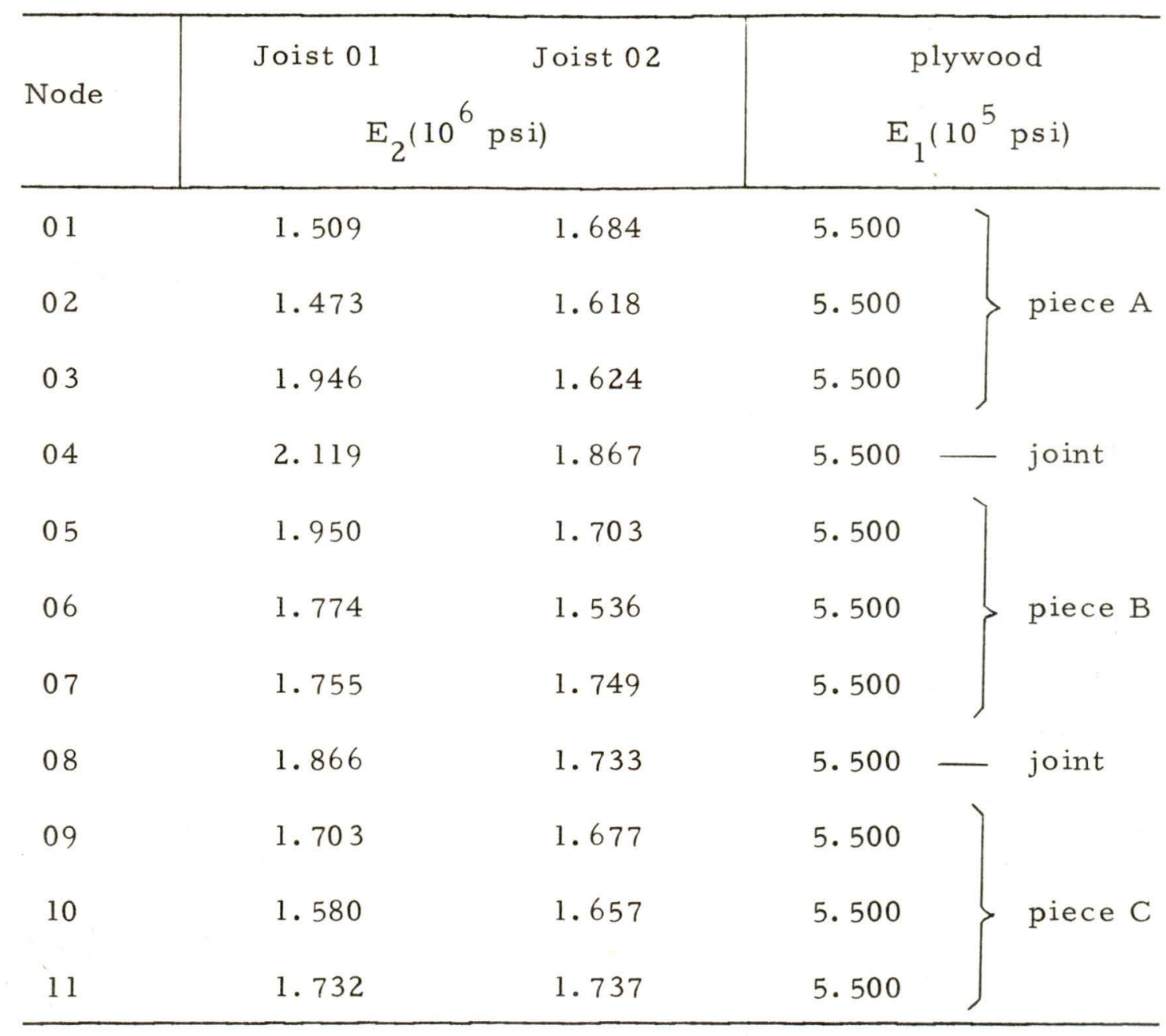


Table 4. T-Beam Test No. T5-8D16-1

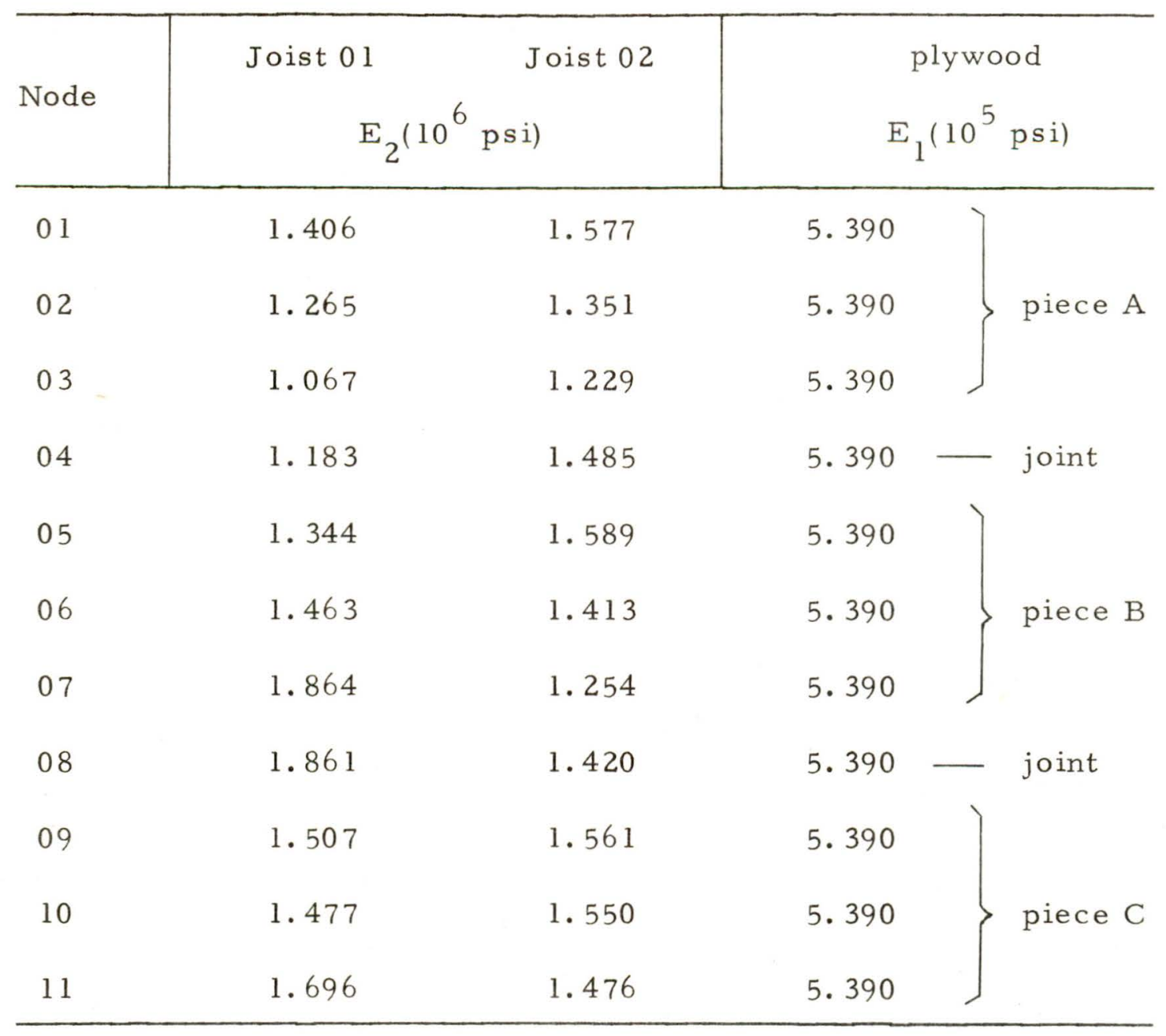


Typed by:

Mary K. Guin

500 Cornell

Ft. Collins, Colorado

484-6211 